\title{
CULTURAL AND LINGUISTIC DIVERSITY IN EARLY CHILDHOOD TEACHER PREPARATION: THE IMPACT OF CONTEXTUAL CHARACTERISTICS ON COURSEWORK AND PRACTICA
}

\author{
Chih-Ing Lim
}

A dissertation submitted to the faculty of the University of North Carolina at Chapel Hill in partial fulfillment of the requirements for the degree of Doctor of Philosophy in the School of Education

Chapel Hill

2007
Approved by:

Chair: Harriet Able-Boone

Advisor: Kelly Maxwell

Reader: Virginia Buysse

Reader: Xue Lan Rong

Reader: Pamela Winton

Reader: Catherine Zimmer 
(C) 2006

Chih-Ing Lim

ALL RIGHTS RESERVED 


\begin{abstract}
CHIH-ING LIM: Cultural and Linguistic Diversity in Early Childhood Teacher Preparation: The Impact of Contextual Characteristics on Coursework and Practica

(Under the direction of Kelly Maxwell)
\end{abstract}

The population of children in early childhood settings is becoming increasingly culturally and linguistically diverse, and these changes in demographics have warranted teachers becoming more culturally responsive and better prepared to work with diverse young children and families. Teacher preparation programs across the nation have responded differently to this critical issue because of the different contexts in which they are in. Some promising strategies are including cultural and linguistic diversity in both course content and clinical experiences into early childhood teacher preparation programs. Using data from the National Prekindergarten Center’s (NPC) National Study of Early Childhood Teacher Preparation Programs and the National Center for Educational Statistics (NCES) Integrated Post-Secondary Education Dataset (IPEDS), this research study examined the variables that contributed to how much cultural and linguistic diversity content and experiences were required of Bachelor's degree students in their coursework and practica in early childhood teacher preparation programs. Specifically, geographical contexts, program and institutional characteristics were analyzed from a sample of 417 Bachelor's degree programs to determine how these variables predicted the amount of diversity content and experience required in teacher preparation programs. Results indicated that percentage of non-Hispanic White in a state, geographic region, degree of urbanization, governance of institutions, NCATE 
accreditation, and the presence of non-White full-time faculty in early childhood programs were predictors of coursework or practica requirements. Implications and recommendations for policy, future research, and early childhood teacher preparation are discussed. 


\section{ACKNOWLEDGEMENTS}

This study would not have been possible without Kelly Maxwell and Richard Clifford of the National Prekindergarten Center (NPC) who generously gave me access to the NPC dataset on early childhood teacher preparation programs. Kelly Maxwell who was also my advisor and Harriet who chaired my dissertation committee were both instrumental in providing guidance and development of the study. Many thanks to Catherine Zimmer for serving on my dissertation committee and for working very patiently with me through numerous statistical issues and throughout the analyses process. A special thanks also to Virginia Buysse, Xue-Lan Rong, and Pamela Winton for serving on my committee and for their valuable and constructive feedback. Last but not least, thanks to my husband, HsienYao and my family for their constant support and encouragement. 


\section{TABLE OF CONTENTS}

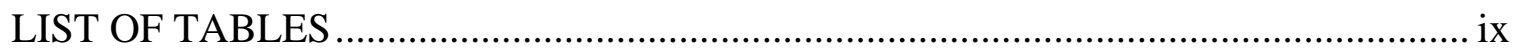

TABLE OF FIGURES .............................................................................................

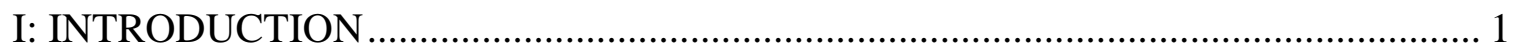

The Need for a Focus on Cultural and Linguistic Diversity ........................................... 1

Role of the Early Childhood Professional in Facilitating Child Development................ 3

Indicators of Effective Personnel Preparation Programs Focusing on Diversity ........... 4

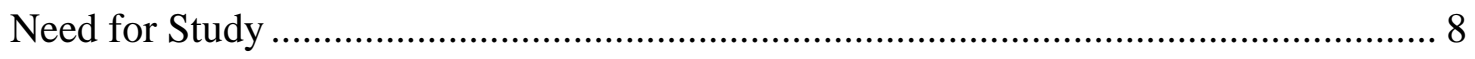

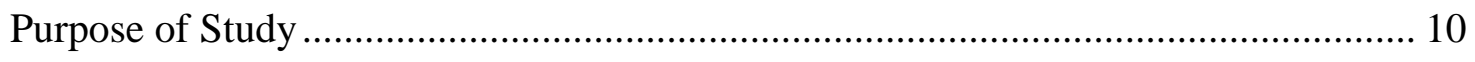

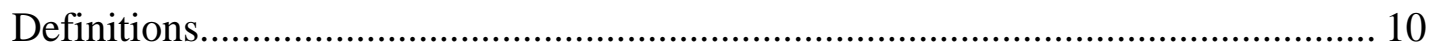

Predictors of Cultural and Linguistic Diversity Coursework and Practica.................... 11

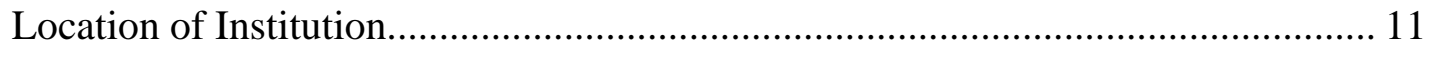

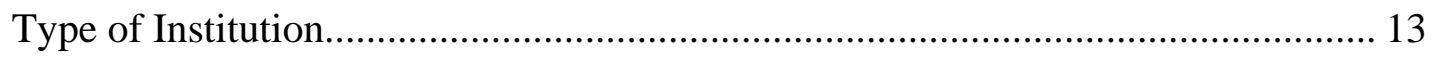

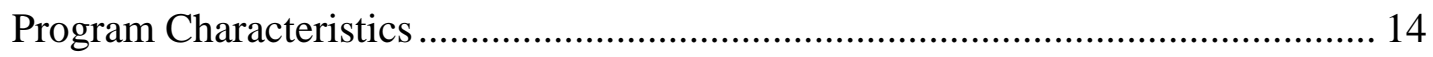

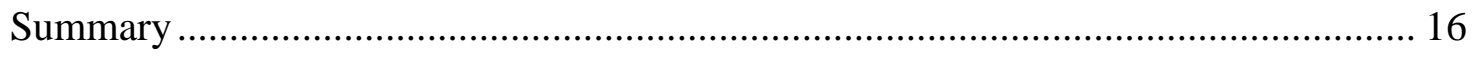

II. RESEARCH QUESTIONS AND CONCEPTUAL FRAMEWORK........................... 19

Research Questions ......................................................................................... 19

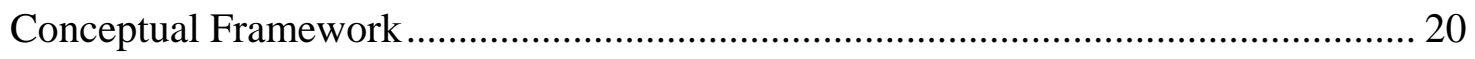

Hypotheses and Assumptions ................................................................................ 22 
National Survey of Early Childhood Teacher Preparation Programs .......................... 26

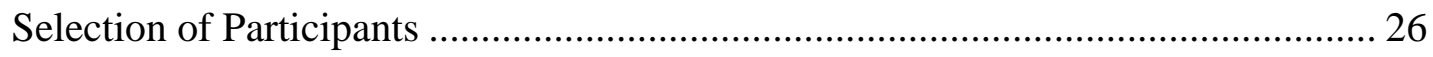

Data Collection Procedures............................................................................... 28

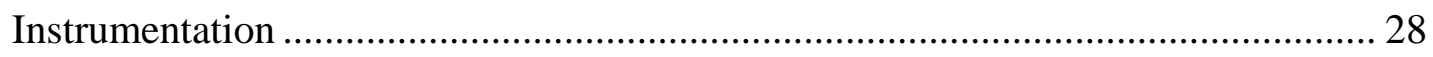

Response Rate and final sample characteristics.............................................. 29

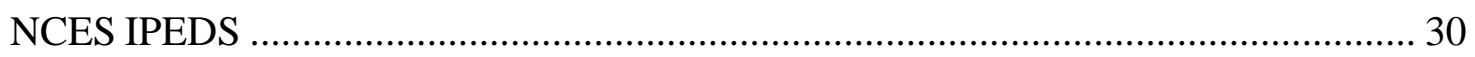

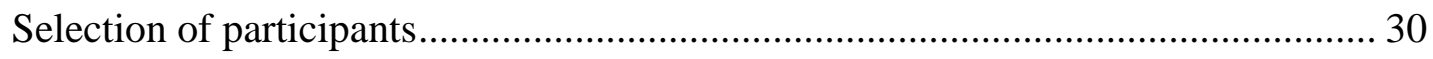

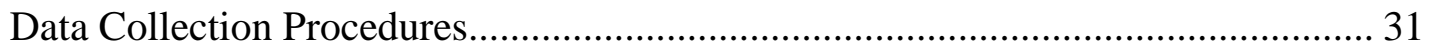

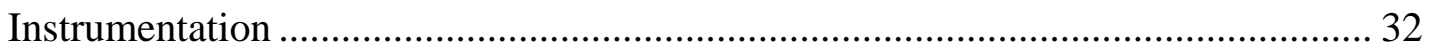

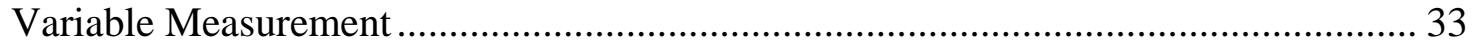

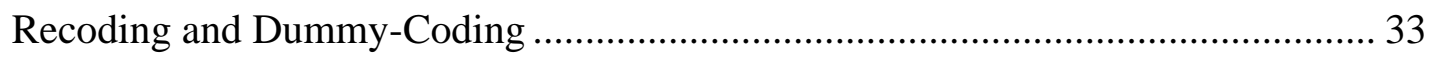

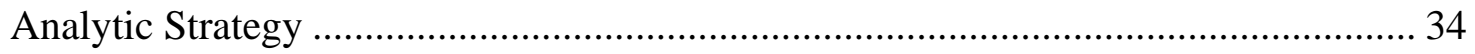

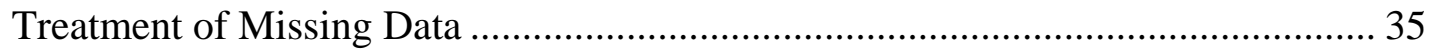

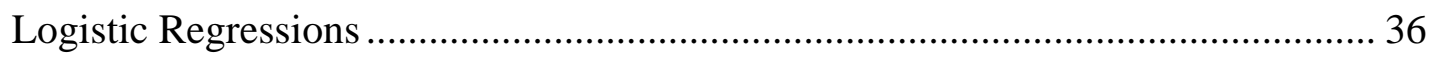

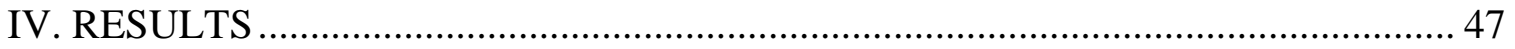

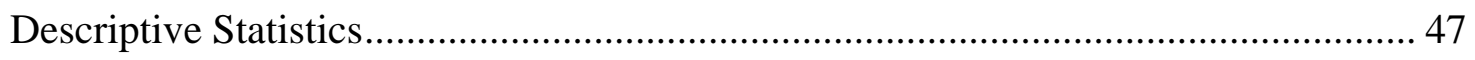

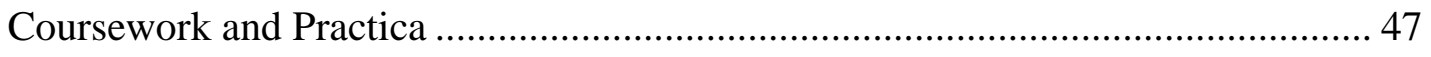

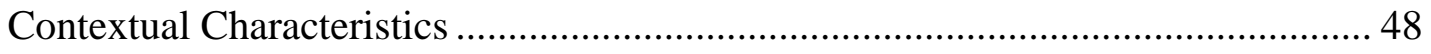

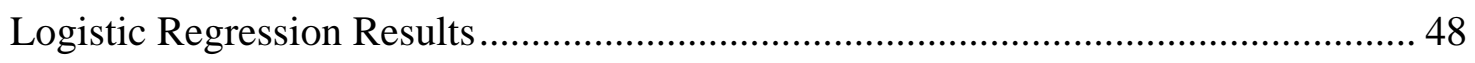

Bivariate and within context models.......................................................... 50

Models with geographical context, institutional, and program characteristics

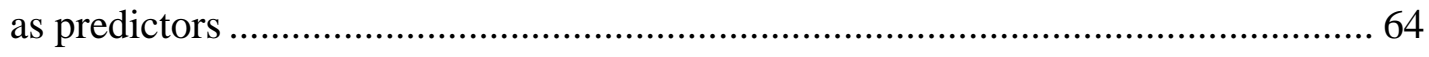


Summary

Required course coverage on working with children and families from diverse ethnic and cultural backgrounds .................................................................. 67

Required course coverage on working with bilingual children or children learning English as a second language.

Required practicum coverage on working with bilingual children or children learning English as a second language.

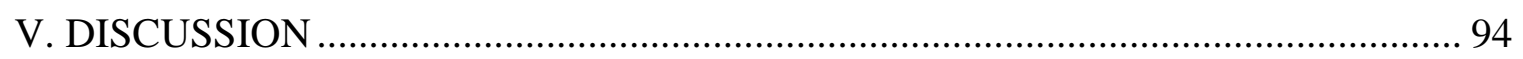

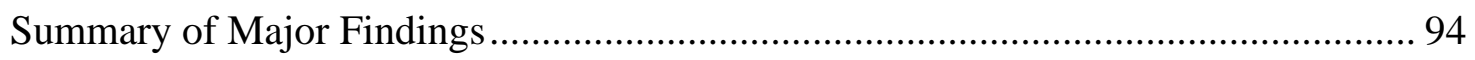

Geographical characteristics ............................................................................... 94

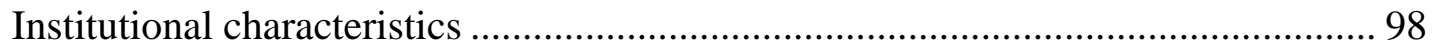

Program characteristics ...................................................................................... 98

The need for equal emphasis on linguistic and cultural diversity............................ 101

Recommendations............................................................................................. 102

Align standards, policies, curriculum, and professional development efforts........ 103

Create opportunities for teachers to develop cultural competence .......................... 105

Recruit and retain more non-White faculty .......................................................... 106

Professional development opportunities for existing faculty.................................... 107

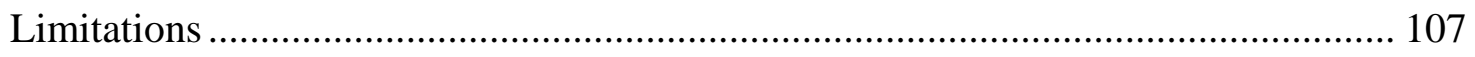

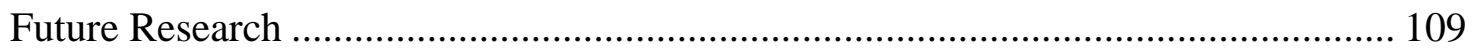

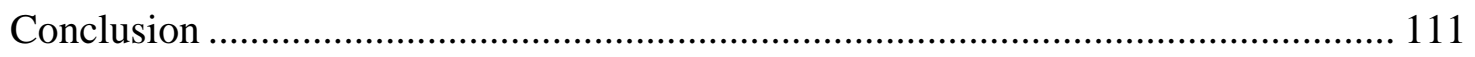

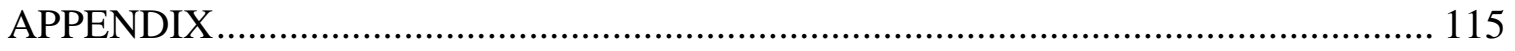

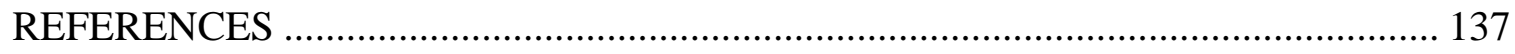




\section{LIST OF TABLES}

Table 2.1: Research Questions and Hypotheses

Table 3.1: Summary of the National Survey of Early Childhood Teacher Preparation

Programs and Integrated Postsecondary Education Data System (IPEDS).... 39

Table 3.2: Dependent Variables in this study and how they were measured

Table 3.3: Independent Variables (from IPEDS and U.S.Census) used in this study and how they were measured.

Table 3.4: Independent Variables (from NCATE and NPC) used in this study and how they were measured

Table 4.1: Coverage and Presence of Cultural and Linguistic Diversity Coursework and Practica for Bachelor's Programs (Frequencies with percentages in parentheses)

Table 4.2: Contextual Characteristics of Early Childhood Teacher Preparation Programs (Frequencies with percentages in parentheses) $(n=416)$

Table 4.3: Mean Percentages of White, non-Hispanic Population and Non-White Faculty in Early Childhood Teacher Preparation Programs (standard deviations in parentheses) $(n=416)$

Table 4.4: Bivariate Multinomial Logistic Regression Examining Geographical Context and Course Requirements Focused on Cultural Diversity (Odds Ratios)

Table 4.5: Multivariate Multinomial Logistic Regression Examining Geographical Context and Course Requirements Focused on Cultural Diversity (Odds Ratios)

Table 4.6: Bivariate Multinomial Logistic Regression Examining Geographical Context and Course Requirements Focused on Linguistic Diversity (Odds Ratios)

Table 4.7: Multivariate Multinomial Logistic Regression Examining Geographical Context and Course Requirements Focused on Linguistic Diversity (Odds Ratios)

Table 4.8: Bivariate Binary Logistic Regression Examining Geographical Context and Practicum Requirements Focused on Linguistic Diversity (Odds Ratios) 
Table 4.9: Multivariate Binary Logistic Regression Examining Geographical Context and Practicum Requirements Focused on Linguistic Diversity (Odds Ratios)

Table 4.10: Bivariate Multinomial Logistic Regression Examining Institutional Characteristics and Course Requirements Focused on Cultural Diversity (Odds Ratios)

Table 4.11: Multinomial Logistic Regression Examining Institutional Characteristics and Course Requirements Focused on Linguistic Diversity in Bachelor's Degree Programs (Odds Ratios)

Table 4.12: Binary Logistic Regression Examining Institutional Characteristics and Practicum Requirements Focused on Linguistic Diversity (Odds Ratios) .. 83

Table 4.13: Bivariate Multinomial Logistic Regression Examining Program Characteristics and Course Requirements Focused on Cultural Diversity (Odds Ratios).

Table 4.14: Multivariate Multinomial Logistic Regression Examining Program Characteristics and Course Requirements Focused on Cultural Diversity (Odds Ratios).

Table 4.15: Bivariate Multinomial Logistic Regression Examining Program Characteristics and Course Requirements Focused on Linguistic Diversity (Odds Ratios) 86

Table 4.16: Multivariate Multinomial Logistic Regression Examining Program Characteristics and Course Requirements Focused on Linguistic Diversity (Odds Ratios) 87

Table 4:17: Bivariate Binary Logistic Regression Examining Program Characteristics and Practicum Requirements Focused on Linguistic Diversity (Odds Ratios)

Table 4:18: Multivariate Binary Logistic Regression Examining Program Characteristics and Practicum Requirements Focused on Linguistic Diversity (Odds Ratios)

Table 4:19: Multivariate Multinomial Logistic Regression Examining All Contextual Characteristics and Course Requirements Focused on Cultural Diversity (Odds Ratios)

Table 4:20: Multivariate Multinomial Logistic Regression Examining All Contextual Characteristics and Course Requirements Focused on Linguistic Diversity (Odds Ratios) 91 
Table 4:21: Multivariate Binary Logistic Regression Examining All Contextual Characteristics and Practicum Requirements Focused on Linguistic Diversity (Odds Ratios) ........................................................................ 92

Table 4.22: Predictors of Coursework and Practica Focused on Cultural and Linguistic Diversity $(\mathrm{p}<.05)$...................................................................... 93

Table 5.1: Results of Hypotheses................................................................................ 113 


\section{LIST OF FIGURES}

Figure 2.1: Conceptual Framework ......................................................................... 22

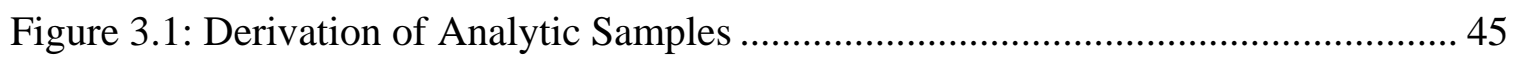

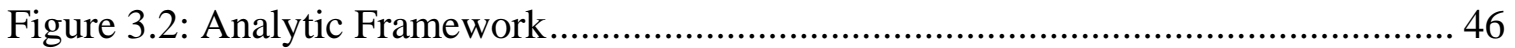




\section{I: INTRODUCTION}

\section{The Need for a Focus on Cultural and Linguistic Diversity}

In the United States, 74\% of children below the age of 18 were White, non-Hispanic in 1980 . This dropped to just over $60 \%$ in 1990 and is projected to be just slightly over 50\% by the year 2020 (U.S. Census 2004b). Currently, approximately 45\% of children under 5 are children of color. Hispanics and Asians are among the fastest growing populations in the United States, and it is projected that by 2020, the number of Hispanic children below the age of 18 will have increased by over 70\% (U.S. Census). If this trend continues, by 2020 early childhood classrooms will have at least 50\% non-White children or a majority of Hispanic children. The two fastest growing populations are also diverse in culture, religion, socioeconomic status, and language (Jo \& Rong, 2003; Rong \& Priessle, 1998). Within the Asian population, over 50 languages are spoken, and numerous dialects may be spoken as well. For example, Chinese alone has eight dialect groups (Rong \& Priessle). Linguistic diversity in the early childhood classroom is expected to continue increasing as most of the recent immigrants come from non-English speaking countries (Han, Baker, \& Rodriguez, 1997), and fertility rates are much higher for ethnic-minority women than for White women (Villarruel, Imig, \& Kostelnik, 1995). Increasingly, these children are spending a larger proportion of their day in early childhood settings than in their own homes (NAEYC, 2001). For example, in 1990, only $20 \%$ of the children enrolled in preschool programs were of a race or ethnicity other than White, non-Hispanic. However, in 2000 this figure doubled to close to 40\% (U.S. Census, 1990; 2000). 
More than ever, the diversity of languages and culture in the early childhood classroom pose a critical challenge for the early childhood professional. Research has shown that children's ethnicity and language predict how children spend their time over and above variations in quality (Kontos, Burchinal, Howes, Wisseh, \& Galinsky, 2002; Tonya, 2003). For example, Kontos and colleagues found that children who spoke English at home had more complex interactions with objects than those who spoke other languages. From an ecocultural perspective, social contexts play an important role in a child's development (Bowman, 1994; Bronfenbrenner, 1979, 2005; Rogoff, 1990), and it is important that teachers acknowledge how these contexts influence a child's learning and socialization. In understanding ethnic minority children's learning and socialization in schools, the most critical factors are 1) family background (including prior exposure to Western culture, education, immigration status, socioeconomic status, languages spoken), 2) length of stay in the country, 3) age on arrival, and 4) how their families deal with prejudice (Gibson, 1995; Jo \& Rong, 2003). For example, if the family had prior exposure to Western culture, children may learn to socialize faster as they may have already been familiar with the 'norms' of this new culture. The family's status as a voluntary or involuntary immigrant may also affect children’s learning and socialization (Ogbu \& Simons, 1998). Voluntary immigrants may tell their children about how life is better in the United States as compared to their home country, and may therefore motivate and encourage the children to learn the language and culture of the host country. Together with these cultural differences that affect a child's development, a child's aptitude, social, and psychological differences may affect his or her learning (Bowman, 1994; Tabors, 1997). For example, a child may be more motivated to learn English if he or she has a sibling or siblings who also speak English. On the other hand, a 
child also may be withdrawn and frustrated if there is social isolation and linguistic constraints.

\section{Role of the Early Childhood Professional in Facilitating Child Development}

With these multiple and complex differences among children, early childhood professionals need to know how to best respond and meet the individual learning and socialization needs of each child. The Division for Early Childhood (DEC) and the National Association for Education of Young Children (NAEYC) suggested that effective personnel preparation programs focusing on diversity provide opportunities for professionals to 1) develop an awareness and knowledge of one’s own heritage and culture, 2) develop an understanding and knowledge of others (in a non-stereotypical way), 3) understand the influence of culture, ethnicity, and socioeconomic status, 4) balance children’s specific cultural and linguistic needs with preparing them to meet broader societal needs, 5) recognize power differences between themselves and families and children, and 6) develop a variety of alternative strategies to meet the diverse needs of children (see NAEYC, 2001; Stayton, Miller, \& Dinnebeil, 2003). It has been asserted that teachers have the power to transform societies by empowering ethnic-minority students (Cummins, 2001). Wishard and colleagues (2003) found that teacher and program practices influenced children’s experiences beyond variations in quality. For example, in programs where home language and home culture were supported, children had more competent peer behavior. On the other hand, children in programs that focused on assimilation into the American society and learning English had negative peer behavior. They were more involved in routine activities, and had fewer opportunities for creative and language arts activities. 
It is clear that the role of a teacher is crucial, yet it is disturbing to know that teachers do not feel prepared to serve children and families from culturally diverse backgrounds (Gay \& Howard, 2000; U.S. Department of Education, 1997) and may also be uncomfortable talking about race and racism (Gay \& Howard). In addition, few early childhood education programs foster cultural and linguistic diversity, and many programs also hold the view that “English is best” (Kagan \& Garcia, 1995, as cited in Kushner \& Ortiz, 2001).

The lack of knowledge and understanding of culturally and linguistically diverse children may in part be due to the fact that the majority of the professionals who are providing care and education are Euro-Americans. In a study conducted in six states by the NCEDL, it was found that $68 \%$ of the teachers were White as opposed to $42 \%$ of the children (Clifford et al., 2005). Findings from another study conducted by the National Center for Early Development and Learning (NCEDL) showed 71\% of preschool classrooms with at least 75\% of African American children had African American teachers, but only 46\% of classrooms with at least 75\% of Latino children had Latino teachers (Saluja, Early, \& Clifford, 2001). Harry (2002) suggests White professionals may be inclined to turn to the dominant culture and values to guide their practices, and perceive these values as universal because of a lack of knowledge and exposure to cultures other than their own.

\section{Indicators of Effective Personnel Preparation Programs Focusing on Diversity}

Given the important role of an early childhood professional in helping children negotiate between different cultures and develop their sense of identity (NAEYC, 2001), it is essential that teacher preparation programs focus on preparing teachers who are responsive to diverse needs of children and families. Despite increasing attention being paid to teacher preparation (Early \& Winton, 2001; Horm, 2003), there is still a lack of research on 
indicators of effective teacher preparation programs for diversity (Bredekamp, 1996;

Isenberg, 2001; Lim \& Able-Boone, 2005; Sleeter, 2001). In a literature review of innovative efforts focusing on diversity, Lim and Able-Boone found current research was 1) lacking in generalizability because of small sample sizes, 2) relying mainly on self-reports, and 3) lacking in longitudinal research designs. Nevertheless, the authors suggest that infusing components of diversity into all courses, and including field experiences to work with diverse families and children may be promising strategies. Similarly, in a review of research on K-12 teacher preparation programs focusing on diversity, a paucity of research was reported (Hollins \& Guzman, 2005). Infusion of diversity components and field experiences were also noted as strategies that could address the challenges of preparing teachers to work in diverse classrooms (Hollins \& Guzman), although this has not yet been tested through scientific research.

The DEC and NAEYC have both delineated recommended practices for personnel preparation programs based on empirical research on practices that best predict positive outcomes for children and families (NAEYC, 2001; Stayton, Miller, \& Dinnebeil, 2003). In their position statement on linguistic and cultural diversity, NAEYC suggests that training institutions and programs "consider providing specific courses in the following topic areas or include these issues in current courses: language acquisition; second-language learning; use of translators; working with diverse families; sociolinguistics; cross-cultural communication; issues pertaining to the politics of race, language, and culture; and community involvement” (NAEYC, 1995, p.6). Similarly, DEC’s quality indicators of personnel preparation (see Stayton, Miller, \& Dinnebeil) include course content focusing on cultural diversity throughout the program. In K-12 education, multicultural education scholars (e.g. Banks and 
Banks, 2004; Cochran-Smith, 2004; Irvine, 2003) argue that “race and culture count in significant ways in the teaching-learning process; they should play a central role in the professional preparation and performance assessment of teachers” (Gay, 2005, p.222).

There is no agreement in the field about how much coursework is necessary to ensure teachers develop cultural competence. Some studies in early childhood and K-12 education have shown that a single course may have positive effects on students (e.g. Correa, Hudson, \& Hayes, 2004; Marshall, 1998, Obidah, 2000). However, these studies need to be interpreted with caution as they have very small sample sizes, and are evaluated internally by course instructors, using student self-report measures. On the other hand, many in the field have voiced their concern that a single course may not be enough, and suggest cultural competencies cannot be developed unless components of diversity are infused into the entire teacher preparation program (Chisholm, 1994; Horm, 2003; Isenberg, 2001). In one of the few studies on the effects of an infused curriculum in early childhood teacher preparation programs, a high percentage of employer satisfaction and graduates’ perception of competence and confidence in working with children and families from diverse backgrounds were reported (Stayton, Smith-Bonahue, Strangis, Conroy, Derer, DeLeon, et. al., 2003). In K-12 teacher preparation program research, Grottkau and Nickolai-Mays (1989) found White students' level of bias toward specific groups decreased after they went through a broad based multicultural program. Currently, studies comparing the effects of a single course focused on cultural and linguistic diversity and the infusion of cultural and linguistic diversity content into the entire teacher preparation program are absent.

Another indicator of quality in personnel preparation laid out by the DEC is having field experiences where students work with children and families who are culturally and 
linguistically diverse. Being placed in different internship sites reflecting the range of early childhood services in their community and the diversity of families and children, or in settings that are "out of their comfort zone" into neighborhoods that are unfamiliar to them (Miller, Ostrosky, Laumann, Thorpe, Sanchez, \& Fader-Dunne, 2003) have been found to be effective in helping students come to terms with their own biases and values, and attaining a better understanding of children and families from diverse backgrounds. In a review of literature on K-12 teacher preparation programs, Hollins and Guzman (2005) suggested that field experiences with diverse children help students "acquire more complex understandings and awareness of cultural and experiential differences than do their peers placed in suburban settings” (p.512).

Despite recommendations being laid out by national early childhood professional organizations such as NAEYC and DEC, results from a national study conducted by the NCDEL on the state of early childhood teacher preparation programs indicated that few programs had a focus on cultural and linguistic diversity (Early \& Winton, 2001). Only 11\% of Bachelor's degree programs and 8\% of Associate's degree programs offered one or more classes in working with children whose home language was not English or who were bilingual, and less than $50 \%$ of the programs required a course in working with racially and ethnically diverse children (Early \& Winton). Similarly, Walton and colleagues (2001) conducted a national survey examining teacher preparation programs in bilingual education, English as a second language, and multicultural education, and found that the pressure to produce more teachers in a shorter time often conflicts with program goals to increase emphasis on critical cultural and linguistic diversity issues. Current child development courses and texts may also be monocultural, and may lead students to see development as 
universal and lacking in context (Phillips, 1998). The lack of emphasis on cultural and linguistic diversity in early childhood teacher preparation programs is further exacerbated by the fact that over $80 \%$ of higher education faculty in early childhood programs are White (Early \& Winton, 2001), and may also be in need of professional development related to diversity issues (Early \& Winton; Horm, 2003). Thus, current teacher preparation programs may indeed be inadequate in preparing students to work with diverse children and families.

\section{Need for Study}

The above information outlines the need for a focus on cultural and linguistic diversity in the field of early childhood teacher education. The gap between the number of children who are culturally and linguistically diverse and their teachers who are mainly White, non-Hispanic is further exacerbated by the lack of preparation, knowledge and skills in working with diverse populations. Although NAEYC and DEC have delineated explicit guidelines on preparing early childhood professionals to work with diverse children and families, the field has been slow in responding to these recommendations (Horm, 2003). Thus far, two strategies have been highlighted in both early childhood and K-12 teacher preparation programs to help teachers serve children and families from diverse backgrounds effectively. Although research is still in its infancy, there are some indications that 1) infusing components of cultural diversity into all courses, as well as 2) providing field experiences that include opportunities to work with children, and families who are from diverse backgrounds may be two important efforts that provide teachers with a good understanding and knowledge of the diverse needs and characteristics of families, children and their communities. Since these two strategies have been identified as promising 
indicators of effective teacher preparation to meet the challenges of diversity, their predictors merit study.

Research examining why some early childhood teacher preparation programs are requiring more coursework and practica focused on diversity than others is lacking in the field of early childhood education. In stating the assumptions of the American Educational Research Association (AERA) panel on research and teacher education, Cochran-Smith and Fries (2005) acknowledge conditions and contexts as very important determinants of program outcomes, yet the contexts of programs are still relatively unknown (Cochran-Smith \& Zeichner, 2005; Hollins \& Guzman, 2005; Winton, 2006). This study aimed to identify supports and barriers that may be in place at the various systemic levels in order for the field to work towards better preparation of teachers.

The absence of teacher education research using large-scale datasets, as observed by the AERA panel on research in teacher education (Cochran-Smith \& Fries, 2005; Hollins \& Guzman, 2005), also warrants a study using large scale datasets to be conducted in order to generate more power in the interpretation of results, and to offer more generalizability of results. In seeking to understand the relationship between contextual predictors and indicators of quality preparation focusing on diversity, this study will inform policymakers, teacher educators and researchers of the complexity and variation between and among programs, and provide knowledge on the different conditions and contexts of early childhood teacher preparation programs specifically related to diversity practices. Most importantly, this study will guide both future research and practice in teacher preparation programs focusing on cultural and linguistic diversity. 


\section{Purpose of Study}

The purpose of this study was to examine program and institutional characteristics that contribute to how much cultural and linguistic diversity content and experiences are offered as part of core course and practica requirements in early childhood teacher preparation programs. Specifically a) geographical contexts (i.e., percentage of non-Hispanic White in a state, geographic region, degree of urbanization), b) institutional characteristic (public versus private, Historically Black Colleges and Universities (HBCUs) versus nonHBCUs), c) program characteristics (presence of non-White full-time and part-time faculty, NCATE accreditation status were analyzed to inform how these may account for the variance in the diversity content offered by teacher preparation programs. At this point of time, it is useful to note that existing datasets were used for the purpose of this study, and therefore not all possible contexts that may predict the two quality indicators of diversity practices in teacher preparation programs were examined.

\section{Definitions}

Diversity. Diversity components include individual differences in culture (e.g. race / ethnicity, religion, socioeconomic status, and language), gender, ability, and learning stylesall of which are critically important for preparing culturally competent early childhood professionals (Lim \& Able-Boone, 2005). However, for this study, only components related to cultural and linguistic diversity were examined as these are some of the most pressing and critical issues in the field, thus they warrant full attention. 
Early childhood teacher preparation. In this study, early childhood teacher preparation refers specifically to the preservice preparation of professionals working with children ages 0-5.

\section{Predictors of Cultural and Linguistic Diversity Coursework and Practica}

As summarized earlier, there are gaps in the research on contexts of early childhood teacher preparation programs. Thus, literature from K-12 teacher education is also included in the following review to help shed light on contextual characteristics and teacher preparation programs. From the review, it is clear that there is not a strong research base regarding characteristics that influence cultural and linguistic diversity practices in teacher preparation programs, but it is evident that characteristics at 1) the broader context of the community that institutions are in, 2) the institutional level, and 3) the program level (including faculty characteristics), play crucial roles in explaining variation in teacher preparation programs' response to cultural and linguistic diversity.

Teacher preparation programs are value-laden, and politically driven. For example, states which value teacher preparation tend to have policies that support meaningful professional development, accreditation and licensing, while institutions that value teacher preparation may seek accreditation and create programs that are tied to teacher competencies laid out by professional organizations (Sleeter, 2001; Wise and Leibrrand, 2000).

\section{Location of Institution}

The state and degree of urbanization may predict coursework and practica requirements because needs, values, and priorities may vary accordingly. The educational experience of a teacher candidate is driven mostly by state licensing standards and mandates

and other nonprofessional political channels (Bredekamp, 1996; Isenberg, 2001; Welch-Ross, 
Wolf, Moorehouse, \& Rathgeb, 2005). Thus, the state in which a teacher preparation program is located may determine what is included in its course content and offering. For example, Heston, Raschke, \& Kliewer (1998) cited state policies as the driving force and support behind the development of an early childhood unified teacher preparation program. In a qualitative study examining the impact of state policies on an urban teacher preparation program, Weiner, Rand, \& Pagano (2001) found that state policies influenced the core curriculum standards, a field experience requirement, and an early childhood education requirement. As of 2002, 47 states certify or license teachers based on state-approved standards and competencies (Council of Chief State School Officers (CCSSO), 2002). Within these 47 states, required competencies and age ranges covered varied. While some states like Alaska and Arkansas use NCATE standards to license their teachers, others like Maine, Minnesota, and Nebraska do not have specific state requirements (CCSSO). Only some states require teachers to have a practicum in order for them to become certified, while few states stipulate that diversity content is mandated for accreditation standards in early childhood teacher preparation programs, and has to be a competency required for teachers to be licensed (Morgan, 2002). It is also observed that regions with the most diverse populations such as California, Texas, New York and Florida were at the forefront in terms of diversity training (Morgan). The state of New Mexico for example, has a teacher licensure model which requires a multicultural course for all preservice teachers (Stayton, Jones, SmithBonahue, et. al, 2003).

Teachers in urban schools tend to work with more culturally and linguistically diverse students than do teachers in suburban or rural communities (Duarte \& Reed, 2004). However, it has been asserted that teachers in urban schools lack the knowledge and understanding of 
students’ diverse cultures (Gay, 2005; Sleeter, 2001). There are no studies examining if the degree of urbanization has an impact on teacher preparation programs.

In sum, there is still a lack of research base 1) to determine if the percentage of nonHispanic Whites in a state has an impact on cultural and linguistic diversity requirements in teacher preparation programs, 2) to establish if the geographic region that a program is situated in affects course and practica requirements on diversity, and 3) to understand if diversity content and practica requirements differ based on an institution’s degree of urbanization.

\section{Type of Institution}

Different institutions may have different priorities and historical backgrounds which may affect course and practica requirements. There have been mixed findings in whether Historically Black Colleges and Universities (HBCUs) and non-HBCUs differed in their coursework and practica requirements. Data from the large scale NCEDL study on early childhood teacher preparation programs indicated that HBCUs were more likely than nonHBCUs to require one course or more and practica in ethnic and linguistic diversity content areas (Early, Winton, \& Day, 2000). However, in a study of 58 undergraduate seniors enrolled in 8 early childhood teacher preparation programs in North Carolina, White-Moore (2003) found significant differences between reported number of classes taken on multicultural education in HBCUs and non-HBCUs. Specifically, students from HBCUs reported they took significantly less courses on multicultural education, as compared to students from non-HBCUs. However, given the small sample size, the results should be interpreted with caution. In a case study to understand the trends in curriculum in HBCUs, Berg-Cross, Craig \& Wessel (1998) found that HBCUs had proportionately equal number of 
courses on cultural diversity as non-HBCUs. There is still an absence of research examining if there will be variation in coursework and practica in public or private institutions of higher education.

\section{Program Characteristics}

Accreditation Status. The variability in the quality of early childhood teacher preparation programs is perhaps one of the most pressing issues in the field, and has been noted to be a barrier to education reform (U.S. Department of Education, 2001). Accreditation has been noted as a promising approach to ensure that early childhood teacher preparation programs meet minimum standards, and that there is a congruence of knowledge and skills that all early childhood teacher candidates will acquire (Darling-Hammond, 1997; Kagan \& Cohen, 1997; Isenberg, 2001).

The National Council for the Accreditation of Teacher Education (NCATE) is a national accreditation organization, and the accreditation ${ }^{1}$ process involves a rigorous selfstudy and an extensive review by external evaluators. In 2000, it began a system of performance-based standards where teacher candidates’ performance is also evaluated in order for a program to be accredited (NCATE, 2000). In terms of responding to cultural and linguistic diversity issues, NCATE strongly encourages institutions to explicitly define and institutionalize supports and policies for enrollment and retention of culturally and linguistically diverse faculty and students (Isenberg, 2001; Wise, Leibbrand, \& Williams, 1997). In addition, for a program to be accredited, it has to fulfill the diversity standard, which measures if 1) the curriculum and experiences include opportunities to work with diverse faculty, teacher candidates, and children, and 2) teacher candidates acquire and apply

\footnotetext{
${ }^{1}$ Currently, only Baccalaureate programs are accredited, with accreditation of Associate's programs currently being piloted in several states.
} 
knowledge, skills and dispositions that can help all students learn (NCATE, n.d.). NCATEaccredited institutions are also expected to incorporate diversity issues throughout the entire program, rather than having a single course (Wise \& Leibbrand, 2000).

Although many educational researchers in the field of early childhood education, as well as K-12 education have suggested that accreditation is tied to higher quality teacher preparation programs and better prepared teacher candidates (e.g. U.S. Department of Education, 2001), few have examined if accreditation does indeed make a difference, and there are mixed findings. A study of 270,000 teacher candidates by the Educational Testing Service (ETS) showed that graduates of NCATE-accredited programs passed the PRAXIS II examinations for teacher licensing at a higher rate than did those from unaccredited programs (ETS, 2001). This finding suggests that NCATE-accredited programs produce higher quality teachers.

In 2004, an anonymous online survey was conducted by NCATE to evaluate the appropriateness and effectiveness of standards from the perspectives of institutional representatives (Mitchell \& Yamagishi, n.d.). Respondents were asked to rate their level of agreement using a 4-point Likert-type scale to statements regarding 1) the structure and organization of the unit standards, 2) the appropriateness of the unit standards, 3) the effectiveness of the unit standards, and 4) the worth of the accreditation process. In addition, open-ended questions regarding respondents' concerns were also posed. Over 760 deans and NCATE coordinators at accredited institutions that represented wide ranges in size, control, and type (e.g. HBCU) responded, and approximately $90 \%$ of them agreed that their programs were better able to align standards, curriculum, instruction, and assessment, and provided more purposeful and directed field experiences for their teacher candidates. In regard to 
diversity, over $77 \%$ agreed that their programs had a stronger commitment to diversity in their coursework and practica experiences as a result of going through the accreditation process (Mitchell \& Yamagishi). However, given that this study is conducted by NCATE itself, there may be a need for external evaluations of NCATE’s impact on diversity.

Only one study found that NCATE accreditation did not make an impact on diversity practices in teacher preparation programs. A study conducted by Erikson Institute on the contribution of four-year undergraduate teacher preparation programs to the preparation of teachers to educate all children (Ray, Bowman, \& Robbins, 2006) found that NCATE and non-NCATE accredited early childhood teacher preparation programs did not differ in the semester hours of courses that referenced diversity categories, requirement of a practicum in a diverse setting, and the frequency of use of diversity content in course descriptions and program reviews. One limitation of the findings was that the authors drew conclusions about the differences based on descriptive statistics and did not conduct further statistical tests to examine if there was indeed a statistical difference between NCATE and non-NCATE accredited programs.

In sum, there is a need for external research and the use of a more sophisticated method to examine if NCATE accreditation predicts coursework and practica requirements focused on diversity in early childhood teacher preparation programs, and there is also an absence of evidence of the relationship between the presence of ethnically diverse faculty on coursework and practica requirements.

\section{Summary}

There is a paucity of research on the characteristics that contribute to how much cultural and linguistic diversity content and experiences are offered as part of core course and 
practica requirements in early childhood teacher preparation programs. The fact that teachers enter the field with varying experiences, skills and knowledge about working with children and families who are diverse has implications for teacher preparation programs and early childhood education policies. We know that teacher characteristics, together with other contextual characteristics influence child outcomes, yet we have little information on the contextual variables that predict quality in teacher preparation programs. In order to identify barriers or supports that contribute to how programs address the challenges of diversity, we need to understand the types of characteristics that predict diversity content and experiences, and the effect that these characteristics have on the enrollment of culturally diverse students.

Teacher preparation programs do not exist in a vacuum but they are embedded within a social context. An ecological approach is necessary for improving our understanding of how we may enhance the cultural and linguistic diversity climate in higher education (Hurtado, Milem, Clayton-Pedersen, \& Allen, 1999). As outlined earlier, examining the contexts of teacher preparation programs will add to our understanding of programmatic or institutional variation in programs. From the review, there is some evidence that contextual characteristics such as 1) location of institutions, 2) institutional characteristics, and 3) program characteristics (including faculty characteristics) do affect teacher preparation programs. However, most of this evidence is from K-12 teacher preparation programs, which may have different needs, foci, and systems than early childhood education. Thus, there is still scant evidence regarding characteristics at all 3 levels and their impact on cultural and linguistic diversity practices in early childhood teacher education programs. For example, accreditation was found to be a promising strategy for improving teacher preparation, but 
there is still a lack of research to validate that accreditation does indeed add value and enhance the diversity climate in these programs.

To reiterate, there is still a lack of research base 1) to determine the percentage of non-Hispanic Whites in a state has an impact on cultural and linguistic requirements in teacher preparation programs, 2) to understand if diversity content and practica requirements differ based on an institution's degree of urbanization or geographic region, 3) to examine if there will be variation in coursework and practica in public or private schools, 4) to examine if NCATE accreditation predicts coursework and practica requirements, and 5) to understand the effect of the presence of ethnically diverse faculty on coursework and practica requirements.

This study seeks to understand the above influences on how much cultural and linguistic diversity content and clinical experiences are offered as part of core course and practica requirements in early childhood teacher preparation programs. 


\section{RESEARCH QUESTIONS AND CONCEPTUAL FRAMEWORK Research Questions}

Based on the literature reviewed, two aspects of personnel preparation programs' degree of diversity focus were identified: 1) coursework, and 2) field experiences that include opportunities to work with children, and families who are from diverse backgrounds. In this study, 3 research questions examining predictors of these two outcome variables were addressed:

Research Question 1 (RQ1): To what extent does the location of institution (i.e., percentage of White, non-Hispanic population in a state, geographic region, and degree of urbanization) predict cultural and linguistic diversity course and practica requirements in early childhood teacher preparation programs?

Research Question 2 (RQ2): To what extent do institutional characteristics (i.e., governance and type of institution) predict cultural and linguistic diversity course and practica requirements in early childhood teacher preparation programs?

Research Question 3 (RQ3): To what extent do program characteristics (i.e., NCATE accreditation status and the presence of non-White full-time and part-time faculty) predict cultural and linguistic diversity course and practica requirements in early childhood teacher preparation programs? 


\section{Conceptual Framework}

The ecological systems model articulated by Bronfenbrenner $(1979,2005)$ provides

the guiding framework for this study. The main thesis of the ecological theory is:

The ecology of human development is the scientific study of the progressive, mutual accommodation, throughout the life course, between an active, growing human being and the changing properties of the immediate settings in which the developing person lives, as this process is affected by the relations between these settings, and by the larger contexts in which the settings are embedded.

- $\quad$ Bronfenbrenner, 2005, p.107

Human beings create multiple physical and cultural levels of environments that in turn shape their own development (Bronfenbrenner, 2005). Specifically, human beings are influenced by the multi-levels of contexts and environments in which they reside. For example, the goals and priorities of teacher preparation programs may be determined by the geographical region, degree of urbanization, the types of institutions in which they are housed, and the characteristics of the faculty in the programs. In a similar vein, Harry (2002) suggests there are three planes that influence one’s development: Personal (i.e., cognitive and psychological), interpersonal (communication and dialogue), and community (values, culture, and history).

It is also suggested that the most distal and expansive environment - the macrosystem - is one that has a major impact on children within their homes and in the classrooms (microsystem), family-early childhood professional relationships and relationships among early childhood professionals (mesosystem), and the practices of early childhood teacher preparation programs (exosystem) (Bronfenbrenner, 2005). Similarly, Cummins (1993, 2000) posits that macro-interactions such as policies affect what goes on in the classroom and how the education system is structured. Indeed, the systems that we work in should not be 
disconnected from the systems that we hope to help improve (Isenberg, 2001; Kennedy, 1997).

Consistent with Bronfenbrenner's thesis on the significance of macrosystems, the focus of this study is to identify characteristics in the macrosystems that predict cultural and linguistic diversity course and practica requirements, as well as the enrollment of early childhood teacher candidates. A macrosystem is defined as one that "consists of the overarching pattern of micro-, meso-, and exosystems characteristics of a given culture, subculture, or other broader social context, with particular reference to the developmentally instigative belief systems, resources, hazards, lifestyles, opportunity structures, life course options, and patterns of social interchange that are embedded in each of these systems” (Bronfenbrenner, 2005, p.150). In other words, a teacher's development is significantly dependent on the options that may be available at a certain time and place. These options may be generated either consciously or unconsciously by institutions, governments, and faculty based on a cultural repertoire of belief systems that permeates all levels of the ecological system.

The conceptual framework (Figure 2.1) lays out how institutional, faculty and program characteristics may predict the extent to which programs decide how much cultural and linguistic content and experiences are included in early childhood teacher preparation programs. The broader contexts (i.e., the geographical region of the country, state, and degree of urbanization) in which these educational institutions are nested are also crucial in affecting practices in teacher preparation programs. 
Figure 2.1: Conceptual Framework

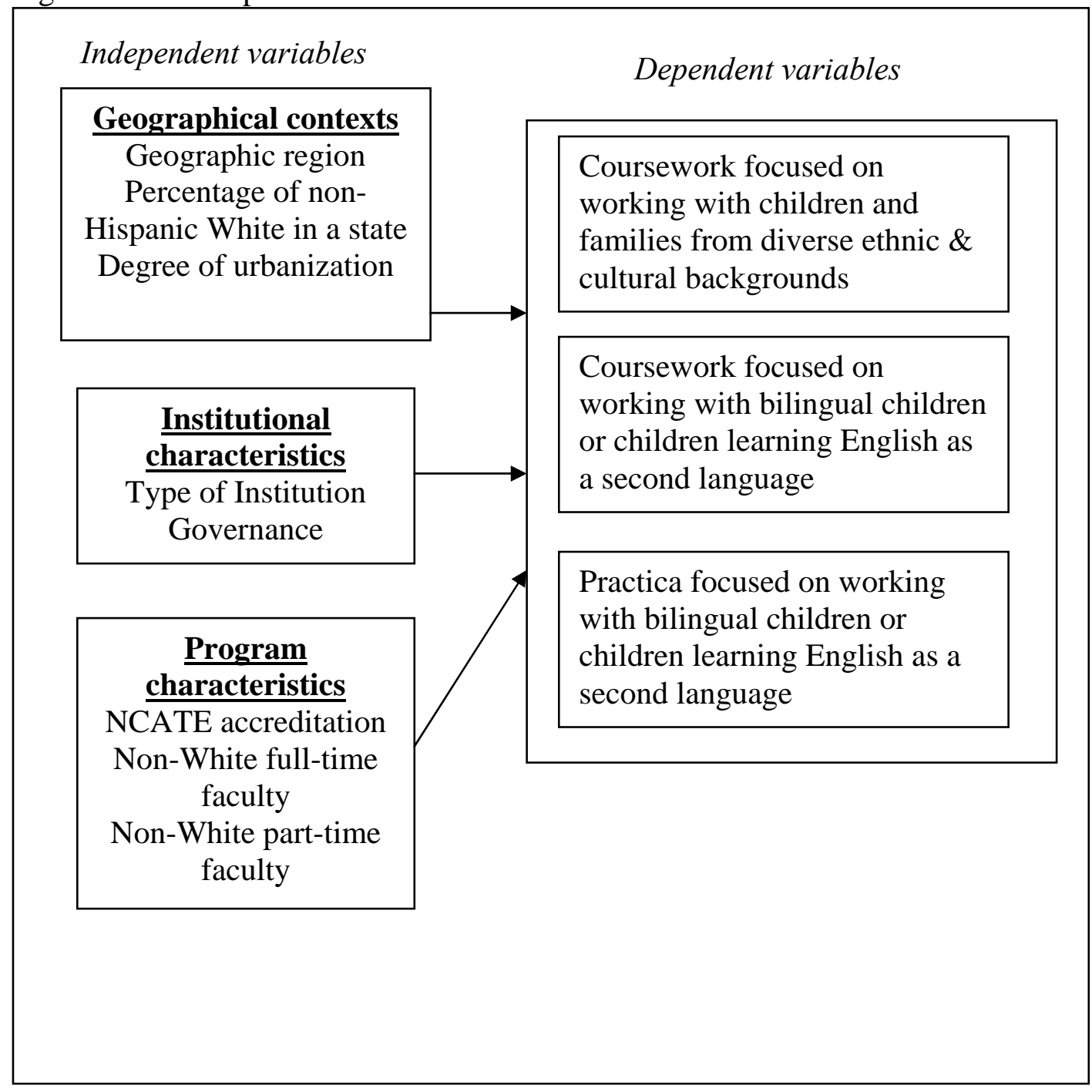

\section{Hypotheses and Assumptions}

From the literature reviewed, it was found to a certain extent that geographical contexts, institutional, and program variables may influence teacher preparation programs. Existing studies may be limited as they have examined course content and experiences and enrollment of diverse teacher candidates from a bivariate / univariate perspective (e.g. 2-year programs versus 4-year programs or accredited versus non-accredited programs). The complexities of interactions between the predictors and outcomes have not been examined. Using an ecological perspective on cultural and linguistic diversity practices in early 
childhood teacher preparation programs as a framework for inquiry, this study examined which characteristics predict outcome, and which characteristics increase, decrease, or have no effect on the probability of the outcome. Two assumptions guided this research:

1) Responses to cultural and linguistic diversity by early childhood teacher preparation programs are influenced by geographical / institutional / program needs and beliefs, thus there may be variation within one context as much as there may be variation between different contexts.

2) Infused coursework on cultural and linguistic diversity, and the requirement of practica experiences working with diverse children and families are considered as outcome measures of efforts to create a positive climate to address diversity.

The hypothesis for each of the research questions are presented in Table 1.

Table 2.1: Research Questions and Hypotheses

RQ1: To what extent does the location of institution (i.e., percentage of White, nonHispanic population in a state, geographic region, and degree of urbanization) predict cultural and linguistic diversity course and practica requirements in early childhood teacher preparation programs?

H1 A higher percentage of non-White population in the state which an institution is located will be associated with more course requirements focused on cultural and linguistic diversity, and the requirement of a practicum focused on linguistic diversity.

H2 Variations in course and practica requirements will be predicted by the geographic regions in which an institution is situated in.

H3 Course and practica requirements will be associated positively with institutions 
located within an urban setting

$R Q 2$ : To what extent do institutional characteristics (i.e., governance and type of institution) predict cultural and linguistic diversity course and practica requirements in early childhood teacher preparation programs?

H4 Course and practica requirements will be associated positively with public universities / colleges

H5 Course and practica requirements will be associated positively with HBCUs $R Q 3:$ To what extent do program characteristics (i.e., NCATE accreditation status and non-White full-time and part-time faculty) predict cultural and linguistic diversity course and practica requirements in early childhood teacher preparation programs?

H6 Course and practica requirements will be associated positively with the presence of non-White faculty

H7 Course and practica requirements will be associated positively with programs that are NCATE-accredited 


\section{III: METHODOLOGY}

In this chapter, the study methodology is presented. Data utilized were from the 2004 early childhood teacher preparation program survey conducted by the National Prekindergarten Center (NPC) as well as the Integrated Postsecondary Education Data System (IPEDS) by the National Center for Educational Statistics (NCES). Both are large scale datasets with a wide range of variables (See Table 3.1). Descriptions of the data collection procedures and instrumentation of each study are presented in Table 3.1. In addition to variables extracted from the NPC and IPEDS datasets, two additional variables were extracted from other data sources: 1) the NCATE variable was derived from the 2005 NCATE accreditation list (NCATE, n.d.), and 2) the percentage of non-Hispanic White in a state was extracted from the 2004 American Community Survey (ACS) (U.S. Census Bureau, 2004a). NCATE accreditation was used as a measure for accreditation because NCATE is the largest accreditation agency in teacher preparation and therefore a larger sample size was available to compare with non-NCATE accredited programs. For example, about 550 schools, colleges or departments of education were NCATE accredited as opposed to about 65 programs that either have received or were in the process of applying for Teacher Education Accreditation Council (TEAC) accreditation (Allen, 2003). 


\section{National Survey of Early Childhood Teacher Preparation Programs}

\section{Selection of Participants}

The NPC national survey of early childhood teacher preparation programs study has a sample of 1,179 early childhood teacher preparation programs. To create the initial list of possible participants, institutions of higher education (IHEs) which have programs preparing teachers to work with children from birth through kindergarten were identified from over 6000 IHEs, both degree-granting and non-degree granting, from the National Center for Education Statistics (NCES) IPEDS. IPEDS is a single, comprehensive system that collects institution-level data in such areas as enrollments, program completions, faculty, staff, and finances from all institutions and educational organizations whose primary purpose is to provide postsecondary education. From this comprehensive list of all IHEs in the United States and its territories, IHEs that reported offering one or more programs (Graduate level or below) that might prepare students to work with young children were selected. Typical programs include Early Childhood Education, Child Care, Child \& Family Studies, and Home Economics. This led to the identification of 1,336 institutions. This list was further supplemented with 245 IHEs housing early childhood programs whose names were obtained from various early childhood professional organizations.

If a satellite site or an extended campus were on one of the lists from various professional organizations, it would be included only if it was listed in IPEDS; otherwise, only the main campus would be included in the final list. For example, Harrisburg Area Community College - Lebanon as well as Harrisburg Area Community College - Lancaster were both included in the final list even though the main campus was already in the list, because they were both also listed in IPEDS. For schools that have two programs in different 
departments preparing individuals to work with children younger than five, (e.g. Arizona State University has both an early childhood education program in the College of Education and a child development program in the Department of Family and Human Development), we asked respondents to determine which program was the largest program that provided teacher licensure standards, and included only that program in the study. Thus, 1,581 IHEs were identified for participation. These included all types of postsecondary institutions including public and private schools, 2- and 4-year institutions, community colleges, technical institutes, Tribal colleges, and Historically Black Colleges and Universities (HBCU).

At each IHE, an interview with the early childhood department chair, program director, or coordinator was sought. This was done by searching individual school websites for the appropriate sample member, verifying contacts with various state-level organizations, individual departments, or directly with the contact person. It is important to note that in cases where the early childhood program was housed within a larger school or department (e.g. School of Education), the lead person in the early childhood program, not the chair or director of the larger school or department was interviewed. In some cases where there were different lead persons for the graduate and undergraduate programs, the lead person for the undergraduate program was the primary contact, while the lead person for the graduate program answered only questions pertinent to the graduate program. Thus the interviewee was very knowledgeable about the requirements and experiences of the early childhood students. 


\section{Data Collection Procedures}

A packet of information about the survey was mailed to the 1,581 sample members between January 2004 and April 2004. The packet included: 1) a cover letter explaining the purpose of the survey, asking for their help, notifying them that telephone interviews would begin in January, and directing them to a web page to see the questionnaire in advance, 2) a page that could be faxed to NPC to indicate convenient times for the call, 3) a sheet to be used during the interview that displayed the response scales, and 4) a copy of Frank Porter Graham Child Development Institute’s (FPG) national magazine, Early Developments as a gesture of appreciation for their time and effort.

Approximately a month after the first batch of packets was mailed, trained interviewers telephoned each sample member. Each interview lasted approximately 40 to 50 minutes. Between February and September 2004, interviews were conducted using a computer-aided telephone interviewing (CATI) system, ensuring little error in data collection or entry.

\section{Instrumentation}

In 1999, the National Center for Early Development and Learning (NCEDL) developed a telephone survey to collect data from faculty in response to the field's need to have a central research base of systematic information about the context, content, and needs of early childhood teacher preparation programs (see Early \& Winton, 2001). The sample in the study included over 400 schools representative of the early childhood teacher preparation program population.

The primary purpose of the NPC study was to replicate this national survey, thus much of the questionnaire's content was drawn from the 1999 questionnaire. Additions and 
revisions to the questionnaire were made by a team of researchers primarily to reflect new areas of interest. For example, information on graduate level programs was also collected in order to better understand the field's capacity for leadership. The questionnaire included questions about 1) coursework content and practica requirements, 2) the characteristics of the faculty, including educational background, race/ethnicity, and tenure status, 3) the characteristics of students enrolled in the programs, including their racial and ethnic backgrounds, and 4) the challenges faced by early childhood preparation programs (See Appendix for the full survey). This 104-item instrument uses dichotomous scale (Yes or No), and 5-point Likert scale formats ranging from 1 (None) to 5 (Entire required course, plus coverage in other courses), or ranging from 1 (Not a challenge) to 5 (A large challenge). Items about faculty and student characteristics require respondents to provide percentages or numbers.

For this study, only items related to Bachelor's coursework and practica focused on cultural and linguistic diversity and faculty race and ethnicity were used (see Tables 3.2 and 3.4).

\section{Response Rate and final sample characteristics}

The initial frame included 1,581 IHEs, and the final sample consisted of 1,179 degree-granting schools. Interviews were completed for 1,142 programs. Data for another 37 programs were obtained through self-administered surveys when sample members were unable to participate in or complete the interview by phone due to scheduling conflicts. Two hundred and thirty two programs were deemed ineligible because (1) they did not have an early childhood program, (2) were non-degree granting institutions, (3) the respondent was unavailable for the length of the study, (4) the listed telephone number had changed or was 
no longer in service during the length of the study, or the respondent did not speak English. Another 96 programs (6\%) were excluded because we could not determine if they had an early childhood programs. Seventy-four (5\%) sample members refused to participate. A minimum of ten attempts was made to contact each nonrespondent, and a message was left each time. Thus the overall response rate was $87 \%$ of those eligible.

The 1,179 participating IHEs were located in all 50 states, plus Washington DC, Puerto Rico, Micronesia, Northern Marianas, America Samoa, and Guam. Forty-four percent ( $n=522)$ of the participating IHEs were 4-year institutions, and 56\% ( $n=657)$ were 2-year institutions. Seventy-nine percent $(n=931)$ were public institutions and the remaining 21\% ( $n$ = 248) were private institutions. For this study, only 416 Bachelor's degree programs were used in the analytic sample.

\section{NCES IPEDS}

\section{Selection of participants}

As delineated above, IPEDS is a single, comprehensive system that collects institution-level data in such areas as enrollments, program completions, faculty, staff, and finances from all institutions and educational organizations whose primary purpose is to provide postsecondary education. Postsecondary education is defined as "the provision of a formal instructional program whose curriculum is designed primarily for students who are beyond the compulsory age for high school. This includes programs whose purpose is academic, vocational, and continuing professional education, and excludes avocational and adult basic education programs” (NCES, n.d.). It is mandated by the Higher Education Act of 1992 that all institutions that participate, as well as applicants for participation in the federal student financial assistance program authorized by Title IV of the Higher Education Act of 
1965, as amended (20 U.S.C. 1094(a)(17)) complete the IPEDS surveys (NCES). In 1993, NCES began collecting data from all IHEs in the United States and territories, and effort was made to ensure that all institutions which have Program Participation Agreements (PPAs) with the Department of Education's Office of Postsecondary Education (OPE) were included. Currently, IPEDS categorizes IHEs based on their degree-granting and PPA status.

For this study, data from 2003/2004 will be extracted from IPEDS to merge with the data from the NPC study. In the 2003/2004 universe, there were 4,527 degree-granting IHEs in the United States and its territories. However, only data for the 416 institutions with Bachelor's degree programs in early childhood education will be included in this study.

\section{Data Collection Procedures}

The surveys for 2003/2004 were administered via a comprehensive web-based system. All schools with PPAs were expected to complete the IPEDS surveys, and follow-up for nonresponse was extensive. There is no requirement for IHEs without PPAs to complete the online surveys, and participation is voluntary. However, they have to go through a onetime telephone interview to collect a minimum set of data items.

The data for IPEDS 2003/2004 were collected three times per institution: 1) Fall Collection, 2) Winter Collection, and 3) Spring Collection, and respondents chose either to key in the data directly, or to upload existing files from the institution to IPEDS. The fall collection spanned a 12-month period from July 12003 through June 30 2004, with an extended data collection period for 6 weeks from September to mid October. Components collected included institutional characteristics and basic information such as street address and telephone number. The winter collection involved collecting data on faculty and staff. The data collection spanned 8 weeks from December 2003 through February 2004. The 
spring collection involved components on student enrollment, financial aid and graduation rate. The data were collected for 6 weeks from March 2004 through mid April 2004.

Attempts are also made to minimize institutional response burden by coordinating efforts with state educational agencies and other federal or state offices that also collect data from IHEs. Currently, numerous federal agencies and offices such as the Census Bureau and Bureau of Economic Analysis as well as state agencies extract data from IPEDS rather than conduct their own survey.

\section{Instrumentation}

Although the surveys are administered at different times of the year, the data elements and the IPEDS components are all interrelated, and there is no duplication of information reported. Data collection screens and data items for each institution are tailored according to a series of screening questions or institutional characteristics. For example, a private forprofit institution will receive a different finance form than a public nonprofit institution.

The 9 components that constitute the IPEDS surveys are: 1) Institutional

Characteristics (IC), 2) Completions (C), 3) Enrollment (EF), 4) Graduation Rates (GRS), 5) Student Financial Aid (SFA), 6) Employees by Assigned Position (EAP), 7) Fall Staff (S), 8) Salaries (SA), and 9) Finance (F). For this study, I used variables from the IC component. The IC is used as a control file for all of IPEDS, as it constitutes the sampling frame for all NCES surveys of IHEs. It also helps determine the IPEDS screens that are shown to each institution on the web. Basic information collected include institution name, address, telephone number, website URL, control or affiliations, levels of degree, types of programs, admissions criteria, tuition, required fees, and room and board charges. All information related to the price of attendance was also collected, and made available to prospective 
students, parents, and counselors via the IPEDS website. For this study, only select variables measuring geographical and institutional characteristics are used (see Table 3.3).

\section{Variable Measurement}

\section{Recoding and Dummy-Coding}

The variable, non-White full-time faculty was a recoded variable based on the variables, Black, non-Hispanic, American Indian / Native Alaskan, Asian / Pacific Islander, and Hispanic full-time faculty. The number of Black, American Indian / Native Alaskan, Asian / Pacific Islander, and Hispanic full-time faculty for each participating program within an institution were summed up and a percentage of the total faculty members in the program was derived. Similarly, the variable, non-White part-time faculty was recoded by summing up the number of Black, American Indian / Native Alaskan, Asian / Pacific Islander, and Hispanic part-time faculty for each participating program within an institution and deriving a percentage of the total faculty members in the program.

Descriptive statistics showed that the predictor variables, non-White full-time faculty and non-White part-time faculty were positively skewed for each of the outcomes across all degree programs, with many programs reporting not having any non-White faculty. To reduce the skewness and to account for the nonlinearity of the data, non-White full-time and part-time faculty were recoded as categorical variables. Responses to each question were examined before variables were categorized into four categories: 1) None, 2) More than 0 but less than or equal to $25 \%$, 3) More than $25 \%$ but less than or equal to 50\%, 4) More than $50 \%$ but less than or equal to $100 \%$. Dependent variables related to coursework were also recoded from 6 categories to 3 categories to allow for better interpretation of multinomial analyses. Responses for both coursework variables were recategorized into: 1) No coverage 
or 1 class of 1 course, 2) Multiple classes of 1 required course or multiple classes of multiple courses, and 3) Entire required course or entire required course plus coverage in other courses.

Seven of the eight predictor variables were dummy coded because of their categorical nature. For all variables, one group was designated as the reference group. Specifically, reference groups used were 1) institutions in the Far West for geographic region, 2) institutions in large cities for degree of urbanization, 3) publicly funded institutions for governance of institution, 4) HBCUs for type of institution, 5) NCATE-accredited programs for accreditation status, 6) no non-White full-time faculty for non-White full-time faculty, and 7) no non-White part-time faculty for non-White part-time faculty. For variables with more than 2 categories (i.e., geographic region, degree of urbanization, non-White full-time faculty, and non-White part-time faculty), different reference groups were used in separate bivariate logistic regression equations to fully understand the overall effect of each predictor variable.

Tables 3.2 to 3.4 present the dependent and independent variables used in this study and how they were measured.

\section{Analytic Strategy}

The unit of analysis was early childhood teacher preparation programs at the Bachelor's degree level within institutions of higher education (IHEs). All analyses were conducted by using SPSS ver.13.0. Logistic regression analyses were used to examine patterns of relationships between the multiple independent variables and a single dependent variable for each of the questions. For example, institutional characteristics such as

governance and type of institution were entered into a logistic regression model to 
understand the effect of each variable on coursework focused on linguistic diversity. Logistic regression techniques were most appropriate because 1) there was a need to predict a discrete outcome from a set of continuous, categorical independent variables, and 2) the distribution of responses on the dependent variables may be nonlinear with one or more of the independent variables (Tabachnick \& Fidell, 2001). A decision was also made to exclude Tribal colleges from the analyses as opposed to placing these institutions in the non-HBCUs category so that results will not be confounded when examining if HBCUs differed from non-HBCUs in predicting differences in coursework and practicum (see Figures 3.1 for numbers of Tribal Colleges that were excluded).

\section{Treatment of Missing Data}

A combination of systematic deletion and data imputation was used to handle the presence of missing values (see Figures 3.1). First, cases with four or more missing values for any of the variables were dropped from the sample. Next, cases with missing values on each of the dependent variables were dropped. For each dependent variable sample, cases with two independent variables missing were first dropped. This was followed by deletion of cases with 1 missing independent variable, excluding independent variables, non-White fulltime and part-time faculty. Cases that were dropped from the final analysis were not significantly different from the remaining cases in the dataset. Therefore, it was assumed that the remaining cases were representative of the dataset. Missing values on independent variables, non-White full-time and non-White part-time faculty were imputed with unbiased estimates based on the participants' other responses. For example, if a participant had a response for full-time faculty but not for part-time faculty, the value for part-time faculty was 
imputed for the value of full-time faculty. Figure 3.1 presents how the different datasets were derived from the original analytic sample of 1,179 colleges and universities.

\section{Logistic Regressions}

Analyses were conducted on a total of three datasets that were derived from the 1,179 cases in the original dataset. For each research question, separate analyses were conducted for each dependent variable, i.e., 1) coursework focused on cultural diversity, 2) coursework focused on working with bilingual children and linguistically diverse children, and 3) practica focused on working with bilingual or linguistically diverse children (see Figures 3.2 for analytic framework).

Two levels of analyses, bivariate, and multivariate were conducted for all the dependent and independent variables. Given that the two dependent variables related to coursework had more than 2 outcome levels, ordinal logistic regressions were conducted. Results from the test of parallel lines were significant; indicating the null hypothesis of having the same slope coefficients across response categories should be rejected. Thus, multinomial logistic regressions were used for dependent variables related to coursework. For the dependent variable related to practica focused on linguistic diversity, binary logistic regressions were performed, given that the response for the variable is dichotomous. The following describes how each research question was analyzed, with Figures 3.2 illustrating the analytic framework.

Research Question 1 (RQ1): To what extent does the geographical context of institutions (i.e., percentage of White, non-Hispanic population in a state, geographic region, and degree of urbanization) predict cultural and linguistic diversity course and practica requirements in early childhood teacher preparation programs? 
The purpose of this question was to explore whether the location of institutions explains the variations in cultural and linguistic diversity coursework and practica requirements. In the first model, percentage of White, non-Hispanic population was entered as the only predictor. Then, geographic region was entered as the only predictor in the second model. Degree of urbanization was then entered as the only predictor in the third model. For each block of predictors excluding percentage of White, non-Hispanic population, bivariate analyses were performed thrice, each time with a different reference group. This is to allow for full understanding of the effect of geographic region and degree of urbanization. For example, institutions in rural locations may be significantly different when institutions in large cities are used as the reference group, but they may not be significantly different from institutions in small towns. This process was repeated with each of the three dependent variables. All three predictors were then entered into a final model to examine the contribution of each variable above and beyond all other geographical context predictor variables.

Research Question 2 (RQ2): To what extent do institutional characteristics (i.e., governance and type of institution) predict cultural and linguistic diversity course and practica requirements in early childhood teacher preparation programs?

The purpose of this question was to explore whether institutional characteristics such as governance and type of institution explain the variations in cultural and linguistic diversity coursework and practica requirements. Governance was entered as the only predictor in the first model. Then, type of institution was entered as the only predictor in the second model. These processes were repeated with each of the three dependent variables. Both predictors 
were then entered into a final model to examine the contribution of each variable to the predictive ability of the model.

Research Question 3 (RQ3): To what extent do program characteristics (i.e., NCATE accreditation status and non-White full-time and part-time faculty) predict cultural and linguistic diversity course and practica requirements in early childhood teacher preparation programs?

The purpose of this question was to explore whether program characteristics explain the variations in cultural and linguistic diversity coursework and practica requirements. NCATE accreditation status was entered as the only predictor in the first model. Full-time faculty was entered as the only predictor in the second model. Then, part-time faculty was entered as the only predictor in the next model. For each block of predictors excluding NCATE accreditation, bivariate analyses were performed thrice, each time with a different reference group. This is to allow for full understanding of the effect of non-White full-time and part-time faculty. All three predictors were then entered into a final model to examine the contribution of each variable over and beyond all other predictor variables related to program characteristics.

Full models. Finally, all the predictor variables for each dataset were entered in final models. The final models determine which predictor variable account for coursework or practica focused on diversity above and beyond all other predictor variables. 
Table 3.1: Summary of the National Survey of Early Childhood Teacher Preparation Programs and Integrated Postsecondary Education Data System (IPEDS)

\begin{tabular}{|c|c|c|}
\hline & $\begin{array}{c}\text { National Survey of Early } \\
\text { Childhood Teacher } \\
\text { Preparation Programs } \\
\end{array}$ & IPEDS \\
\hline Geographical Location & $\begin{array}{l}\text { National (All states and } \\
\text { territories) }\end{array}$ & $\begin{array}{l}\text { National (All states and } \\
\text { territories) }\end{array}$ \\
\hline Participants & $\begin{array}{l}\text { Early childhood teacher } \\
\text { preparation programs in } \\
\text { degree-granting } \\
\text { postsecondary education } \\
\text { institutions }\end{array}$ & $\begin{array}{l}\text { All postsecondary education } \\
\text { institutions }\end{array}$ \\
\hline $\begin{array}{l}\text { Time Frame of Data } \\
\text { Collection }\end{array}$ & April - September 2004 & $\begin{array}{l}3 \text { times a year beginning } \\
\text { 1993* }\end{array}$ \\
\hline & & $\begin{array}{l}\text { Fall: } 12 \text { month period of } \\
\text { July } 1 \text { - June } 30\end{array}$ \\
\hline & & $\begin{array}{l}\text { Winter: } 8 \text { week period of } \\
\text { December - February }\end{array}$ \\
\hline & & $\begin{array}{l}\text { Spring: } 6 \text { week period of } \\
\text { March - mid April }\end{array}$ \\
\hline Instrumentation & Self-report Survey & Self-report Surveys \\
\hline Method of Administration & Telephone Interview & $\begin{array}{l}\text { Self-administered web- } \\
\text { based system (with effect } \\
\text { from 2000/2001) }\end{array}$ \\
\hline Frame & 1,581 & 4,527 \\
\hline Response Rate & $87 \%$ of the sampling frame & Not available \\
\hline Sample Size & 1,179 & 1,179 \\
\hline Analytic sample & \multicolumn{2}{|c|}{416 Bachelor’s degree programs } \\
\hline
\end{tabular}

* For this study, only data collected for 2003/2004 will be used. 
Table 3.2: Dependent Variables in this study and how they were measured

\begin{tabular}{|c|c|c|c|c|}
\hline Variables & Dataset & Question Asked & $\begin{array}{l}\text { Type of Score and } \\
\text { Range (Original) }\end{array}$ & $\begin{array}{l}\text { Recoding } \\
\text { (if any) }\end{array}$ \\
\hline \multicolumn{5}{|l|}{$\begin{array}{l}\text { Required Course } \\
\text { coverage }\end{array}$} \\
\hline Working with & & For each content area & Categorical & \\
\hline children and & & listed below, please & Range 1-5 & \\
\hline families & & indicate how much & (None / One class & \\
\hline from diverse & & coursework coverage & session of one & \\
\hline ethnic \& cultural & & students have received & required course / & \\
\hline backgrounds & & & multiple class & \\
\hline Working with & & the time they complete & sessions / Entire & \\
\hline bilingual children & & their Bachelor’s & required course / & \\
\hline & & training. & Entire required & \\
\hline children learning & & & course plus & \\
\hline English as a & & & coverage in other & \\
\hline second & & & courses) & \\
\hline \multicolumn{5}{|l|}{ language } \\
\hline $\begin{array}{l}\text { Required } \\
\text { practica } \\
\text { coverage }\end{array}$ & NPC & & & \\
\hline Working with & & Please indicate if & Categorical & \\
\hline $\begin{array}{l}\text { bilingual children } \\
\text { or children }\end{array}$ & & $\begin{array}{l}\text { practica exposure to } \\
\text { these areas is reauired }\end{array}$ & (Yes / No) & \\
\hline learning English & & as part of the & & \\
\hline $\begin{array}{l}\text { as a second } \\
\text { Language }\end{array}$ & & Bachelor’s program. & & \\
\hline
\end{tabular}


Table 3.3: Independent Variables (from IPEDS and U.S. Census) used in this study and how they were measured

\begin{tabular}{|c|c|c|c|c|c|}
\hline Variable & Source & $\begin{array}{c}\text { IPEDS } \\
\text { VarName }\end{array}$ & Variable Definition & $\begin{array}{l}\text { Type of Score } \\
\text { and Range } \\
\text { (Original) }\end{array}$ & $\begin{array}{c}\text { Recoding } \\
\text { (if any) }\end{array}$ \\
\hline \multicolumn{6}{|l|}{ Geographical context } \\
\hline $\begin{array}{l}\text { Percentage of White, } \\
\text { non-Hispanic } \\
\text { population }\end{array}$ & $\begin{array}{l}\text { U.S. } \\
\text { Census } \\
\text { (ACS) }\end{array}$ & - & $\begin{array}{l}\text { This variable measures the percentage of White, non- } \\
\text { Hispanic population in each state. It is extracted from } \\
\text { the } 2004 \text { American Community Survey (ACS). The } \\
\text { ACS is a large, continuous survey conducted by the } \\
\text { U.S. Census and is considered to be a definitive source } \\
\text { of up-to-date demographic information. }\end{array}$ & Continuous & - \\
\hline $\begin{array}{l}\text { Geographical } \\
\text { Location }\end{array}$ & IPEDS & OBERG & $\begin{array}{l}\text { Categorical } \\
\text { Range 1-8 } \\
1 \text { - New England } \\
2 \text { - Mid East } \\
3 \text { - Great Lakes } \\
4 \text { - Plains } \\
5 \text { - Southeast } \\
6 \text { - Southwest } \\
7 \text { - Rocky Mountains } \\
8 \text { - Far West } \\
9 \text { - Outlying areas }\end{array}$ & $\begin{array}{l}\text { Categorical } \\
\text { Range 1-9 }\end{array}$ & - \\
\hline $\begin{array}{l}\text { Degree of } \\
\text { urbanization }\end{array}$ & IPEDS & LOCALE & $\begin{array}{l}\text { 1: Large City - A central city of a CMSA or MSA with } \\
\text { the city having a population greater than or equal to } \\
\text { 250,000. } \\
\text { 2: Mid-size City - A central city of a CMSA or MSA, } \\
\text { with the city having a population less than } 250,000 . \\
\text { 3: Urban Fringe of Large City - Any incorporated } \\
\text { place, CDP, or non-place territory within a CMSA or } \\
\text { MSA of a Large City and defined as urban } \\
\text { by the Census Bureau. } \\
\text { 4: Urban Fringe of Mid-size City - Any incorporated }\end{array}$ & $\begin{array}{l}\text { Categorical } \\
\text { Range } 1 \text {-7 }\end{array}$ & $\begin{array}{l}\text { Reverse } \\
\text { coded (i.e., } \\
1 \text { (Rural) - } \\
7 \text { (Large } \\
\text { City) }\end{array}$ \\
\hline
\end{tabular}




\begin{tabular}{|c|c|c|c|c|c|}
\hline Variable & Source & $\begin{array}{c}\text { IPEDS } \\
\text { VarName }\end{array}$ & Variable Definition & $\begin{array}{l}\text { Type of Score } \\
\text { and Range } \\
\text { (Original) }\end{array}$ & $\begin{array}{c}\text { Recoding } \\
\text { (if any) }\end{array}$ \\
\hline & & & $\begin{array}{l}\text { place, CDP, or non-place territory within a CMSA or } \\
\text { MSA of a Large City of a Mid-size } \\
\text { City and defined as urban by the Census Bureau } \\
\text { 5: Large Town - An incorporated place or CDP with a } \\
\text { population greater } \\
\text { than or equal to 25,000 and located outside a CMSA or } \\
\text { MSA. } \\
\text { 6: Small Town - An incorporated place or CDP with a } \\
\text { population less than } \\
\text { 25,000 and greater than or equal to 2,500 and located } \\
\text { outside a CMSA or MSA. } \\
\text { 7: Rural - Any incorporated place, CDP, or non-place } \\
\text { territory designated } \\
\text { as rural by the Census Bureau. }\end{array}$ & & \\
\hline \multicolumn{6}{|l|}{$\begin{array}{l}\text { Institutional } \\
\text { characteristics }\end{array}$} \\
\hline Type of Institution & IPEDS & HBCU & $\begin{array}{l}\text { HBCU variable - coded } 1 \text { (Yes) if school is a } \\
\text { Historically Black College or University, and coded } 2 \\
\text { (No) if it's not. Tribal colleges are excluded from the } \\
\text { analyses }\end{array}$ & $\begin{array}{l}\text { Categorical } \\
\text { Range } 1 \text { (Yes) - } \\
2 \text { (No) }\end{array}$ & \\
\hline Governance & IPEDS & CONTROL & $\begin{array}{l}\text { 1: Public institution - "An educational institution } \\
\text { whose programs and activities are operated by publicly } \\
\text { elected or appointed school officials and which is } \\
\text { supported primarily by public funds." } \\
\text { 2: Private not-for-profit institution - "A private } \\
\text { institution in which the individual(s) or agency in } \\
\text { control receives no compensation, other than wages, } \\
\text { rent, or other expenses for the assumption of risk. } \\
\text { These include both independent not-for-profit schools } \\
\text { and those affiliated with a religious organization." } \\
\text { 3: Private for-profit institution - "A private institution } \\
\text { in which the individual(s) or agency in control receives }\end{array}$ & $\begin{array}{l}\text { Categorical } \\
\text { Range 1-3 }\end{array}$ & $\begin{array}{l}\text { Private for } \\
\text { profit and } \\
\text { Private, } \\
\text { non-profit } \\
\text { categories } \\
\text { are } \\
\text { recoded } \\
\text { into } 1 \\
\text { category. } \\
\text { Thus 1: } \\
\text { Public, 2: } \\
\text { Private }\end{array}$ \\
\hline
\end{tabular}




\begin{tabular}{|c|c|c|c|c|c|}
\hline Variable & Source & $\begin{array}{c}\text { IPEDS } \\
\text { VarName }\end{array}$ & Variable Definition & $\begin{array}{c}\text { Type of Score } \\
\text { and Range } \\
\text { (Original) }\end{array}$ & $\begin{array}{l}\text { Recoding } \\
\text { (if any) }\end{array}$ \\
\hline & & & $\begin{array}{l}\text { her than wages, rent, or other } \\
\text { assumption of risk.” }\end{array}$ & & \\
\hline
\end{tabular}


Table 3.4: Independent Variables (from NCATE and NPC) used in this study and how they were measured

\begin{tabular}{|c|c|c|c|c|}
\hline Variables & Dataset & Question Asked & $\begin{array}{l}\text { Type of Score } \\
\text { and Range } \\
\text { (Original) }\end{array}$ & Recoding (if any) \\
\hline \multicolumn{5}{|l|}{$\begin{array}{l}\text { Program } \\
\text { characteristics }\end{array}$} \\
\hline $\begin{array}{l}\text { NCATE } \\
\text { accreditation }\end{array}$ & $\begin{array}{l}\text { NCATE list } \\
\text { of } \\
\text { accredited } \\
\text { schools } \\
\text { (2005) }\end{array}$ & & $\begin{array}{l}\text { Categorical } \\
0 \text { (No) /1 (Yes) }\end{array}$ & $\begin{array}{l}\text { Recoded for } 1 \text { if a school is } \\
\text { accredited and a } 2 \text { if a school } \\
\text { is not accredited. }\end{array}$ \\
\hline $\begin{array}{l}\text { Non-White Full- } \\
\text { time Faculty }\end{array}$ & NPC & $\begin{array}{l}\text { What are the racial or ethnic backgrounds of the } \\
\text { full-time faculty? }\end{array}$ & Continuous & $\begin{array}{l}\text { The variables measuring the } \\
\text { number of full-time faculty } \\
\text { who are Black, Asian / } \\
\text { Pacific Islander, American } \\
\text { Indian / Alaskan Native, and } \\
\text { Hispanic will be recoded into } \\
1 \text { continuous variable to } \\
\text { measure the percentage of } \\
\text { non-White full-time faculty } \\
\text { in a program }\end{array}$ \\
\hline $\begin{array}{l}\text { Non-White Part- } \\
\text { time Faculty }\end{array}$ & NPC & $\begin{array}{l}\text { What are the racial or ethnic backgrounds of the } \\
\text { part-time faculty? }\end{array}$ & Continuous & $\begin{array}{l}\text { The variables measuring the } \\
\text { number of part time faculty } \\
\text { who are Black, Asian / } \\
\text { Pacific Islander, American } \\
\text { Indian / Alaskan Native, and } \\
\text { Hispanic will be recoded into } \\
1 \text { continuous variable to } \\
\text { measure the percentage of } \\
\text { non-White part-time faculty } \\
\text { in a program }\end{array}$ \\
\hline
\end{tabular}


Figure 3.1: Derivation of Analytic Samples

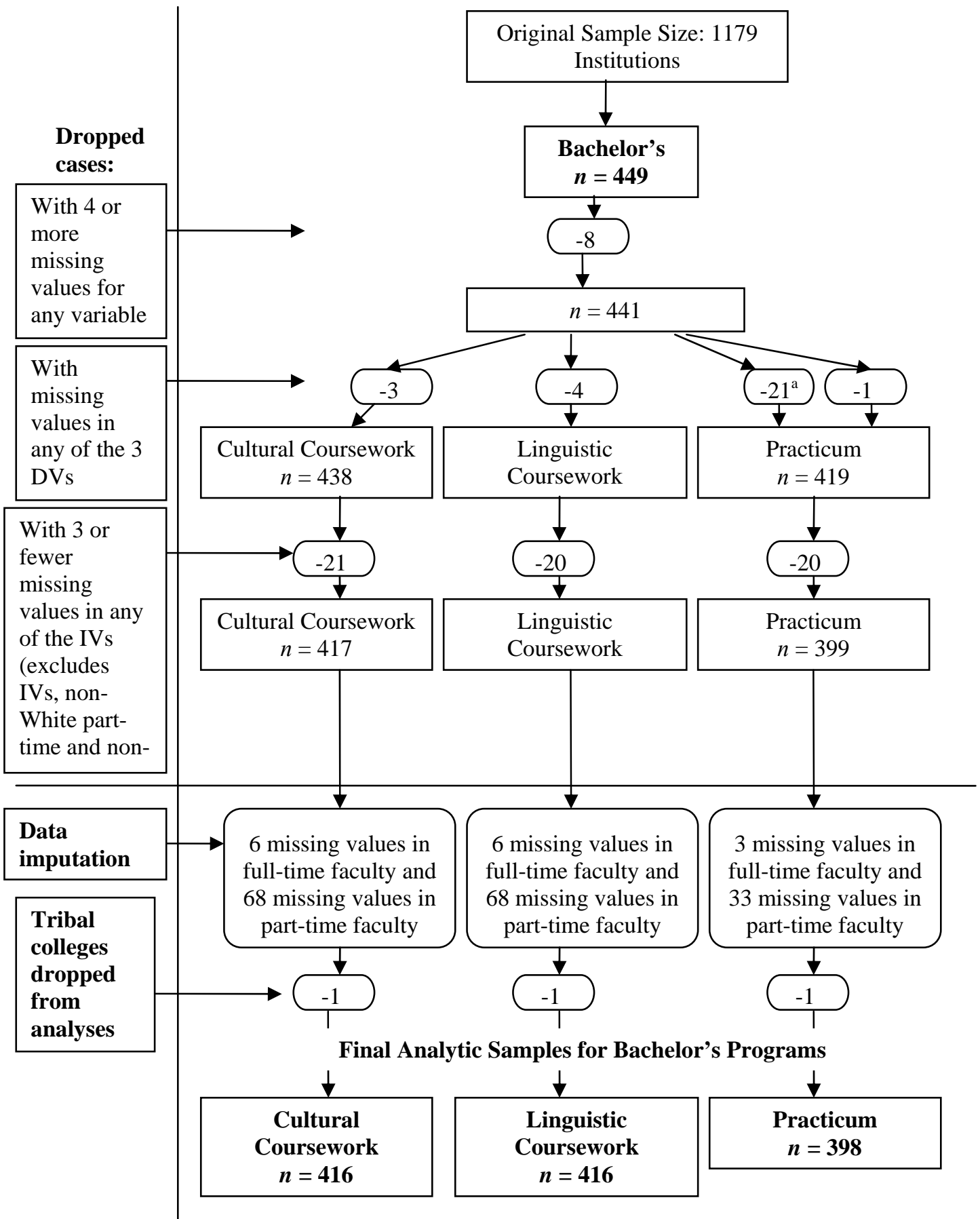

a 21 Bachelor’s programs did not require a practicum 
Figure 3.2: Analytic Framework

Independent variables

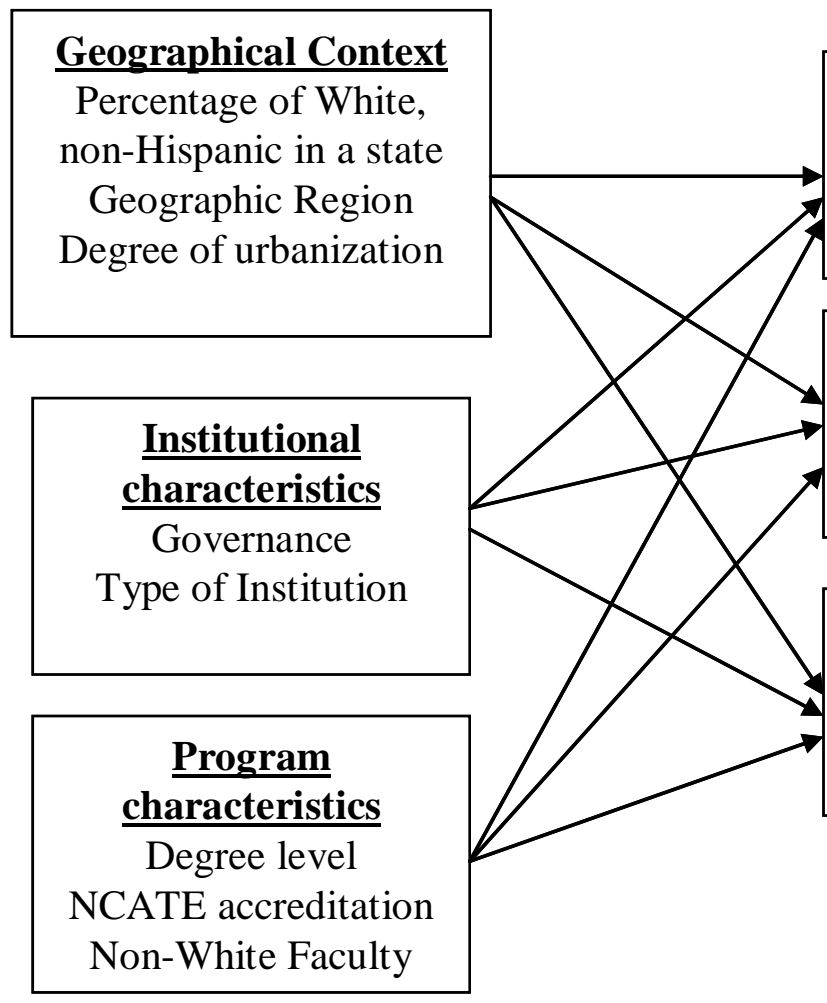

Dependent variables

Coursework focused on working with children and families from diverse ethnic \& cultural backgrounds

Coursework focused on working with bilingual children or children learning English as a second language

Practica focused on working with bilingual children or children learning English as a second language 


\section{RESULTS}

In this chapter, descriptive statistics are presented first, followed by results from bivariate logistic regression analyses, multivariate logistic regression analyses within context, and multivariate logistic regression analyses across contexts. Finally, a summary of the effects of each predictor variable on each of the three dependent variables in the bivariate, context specific, and across contexts models is presented. Although the samples for coursework and practica were slightly different (i.e., 416 vs. 398), the descriptive statistics were quite similar for the predictor variables so the larger coursework sample $(n=416)$ was used. All tables and figures will be presented at the end of the chapter. Given that the six outcome categories for coursework were re-categorized into three outcome categories for the logistic regressions, outcome categories for coursework will be defined as 1) No or minimal requirements for no coverage or 1 class of 1 required course, 2) some requirements for multiple classes of one required course or multiple classes of multiple courses, and 3) at least one complete course for entire required course or entire required course and coverage in other courses.

\section{Descriptive Statistics}

\section{Coursework and Practica}

Approximately equal numbers of Bachelor’s programs required multiple class sessions of one required course or an entire required course plus coverage in other courses that included working with children and families from diverse ethnic and cultural 
backgrounds. Close to half of the Bachelor's programs required multiple class sessions of one required course with regard to working with bilingual children or children learning English as a second language, while only about one in ten programs required an entire required course plus coverage in other courses. Thirty percent of Bachelor's programs required practica focused on working with bilingual children or children learning English as a second language (see Table 4.1).

\section{Contextual Characteristics}

As presented in Table 4.3, most of the population in the states are White, nonHispanic. About one-quarter of the Bachelor's programs were located in the Southeast region, and most were also public institutions (see Table 4.2). More than three-fifths of the Bachelor's programs were accredited by NCATE (see Table 4.2), and about a quarter of fulltime faculty were non-White (see Table 4.3).

\section{Logistic Regression Results}

For all the categorical predictor variables, one group was designated as the reference group. Specifically, reference groups used were 1) institutions in the Far West for geographic region, 2) institutions in large cities for degree of urbanization, 3) publicly funded institutions for governance of institution, 4) HBCUs for type of institution, 5) NCATE-accredited programs for accreditation status, 6) no non-White full-time faculty for non-White full-time faculty, and 7) no non-White part-time faculty for non-White part-time faculty. The designation of reference groups was based on the following considerations: 1) usefulness as a comparison group (i.e., hypothesized to be most likely or least likely to predict coursework or practica), 2) relatively large sample sizes as compared to the rest, and 3) clear definition of group (Hardy, 1993, as cited in Cohen, Cohen, West, \& Aiken, 2003). However, for variables 
with more than 2 categories (i.e., geographic region, degree of urbanization, non-White fulltime faculty, and non-White part-time faculty), different reference groups were used in separate bivariate regression equations to compare differences between other categories (e.g. rural vs. mid-size city). These analyses help provide a more complete understanding of each predictor variable (Cohen, Cohen, et al.).

Bivariate logistic regressions were first conducted to examine individual predictors’ effects on each of the three outcome variables without taking into account other predictors. In the next step of analysis, multivariate within context logistic regressions were conducted to understand the effect of each significant predictor separately when other predictors within the same context were controlled. Each model excluded one variable or block of variables, with the final model including all the predictor variables. Chi-square differences between the final model and each of the models were then calculated to understand the predictive power of a predictor variable after controlling for all other predictors. Multivariate logistic regressions were then conducted to understand the effect of predictors when all predictors across contexts were controlled. Similar to the procedures taken to understand the effect of predictors within context, each logistic regression model excluded one variable or block of variables, with the final model including all the predictor variables. Chi-square differences between the final model and each of the models were then calculated to understand the predictive power of a predictor variable after controlling for all predictors across contexts. In interpreting the results, each model was first examined for its goodness of fit. Statistically significant $\chi^{2}$ values indicate that the model has predictive ability. Chi-squares, degrees of freedom, and odds ratios will be presented in Tables 4.4 to 4.21 . Statistically significant $(p<.05)$ results will be discussed in terms of odds ratios. Odds ratios measure 
effect size, indicating "the increase (or decrease if the ratio is less than one) in odds of being in one outcome category when the value of the predictor increases by one unit” (Tabachnick and Fidell, 2001, p. 548). Because odds ratios are based on changes in one unit, for the only continuous predictor variable, percentage of White, non-Hispanic population, odds ratios were recalculated to represent a more substantive change (i.e.,10 percentage point increase). Specifically, a ten percentage point increase in White, non-Hispanic population will lead to an odds ratio change of $e^{\beta(10)}$, where $\beta$ is the additive logistic regression coefficient.

The interpretation of the results is also guided by the study's conceptual framework. The framework recognizes the interaction among the multiple levels of contexts in which teacher preparation programs reside. The independent variables never act in isolation in the real world. Therefore, interpretation of the results relies more heavily on findings from the multivariate logistic regressions across contexts rather than those from the bivariate and multivariate logistic regressions within contexts.

\section{Bivariate and within context models}

Research Question 1: To what extent do geographical contexts (i.e., percentage of White, non-Hispanic population, geographic region, and degree of urbanization) predict cultural and linguistic course and practica requirements in early childhood teacher preparation programs?

Nine bivariate and three multivariate multinomial regressions were conducted to predict geographical contexts' effect on 1) cultural diversity course requirements, 2) linguistic diversity course requirements, and 3) linguistic practica requirements.

Coursework focused on cultural diversity. From the goodness of fit tests, it was found that none of the bivariate or multivariate logistic regression models were significant. 
Specifically, percentage of White, non-Hispanic population, geographical region or degree of urbanization did not significantly predict the amount of required coursework focused on cultural diversity (see Tables 4.4 and 4.5).

Coursework focused on linguistic diversity. Table 4.6 presents the bivariate multinomial logistic regression results examining geographical context and course requirements focused on linguistic diversity. Without controlling for the other two predictor variables, percentage of White, non-Hispanic population was predictive of the amount of coursework focused on linguistic diversity. Specifically, for every 10 percentage point increase in White, non-Hispanic population in the states, early childhood teacher preparation programs were about 1.5 times [i.e., $\mathrm{e}^{0.042(10)}$ ] more likely to have no or minimal requirements than to have at least one complete course focused on linguistic diversity [Odds Ratio (OR): 1.04; 95\% Confidence Interval (CI): 1.02, 1.07]. With every 10 percentage point increase in White, non-Hispanic population, early childhood teacher preparation programs were also about 1.6 times [i.e., $\mathrm{e}^{0.044(10)}$ ] more likely to have only some coursework and not at least one complete course focused on linguistic diversity (OR:1.05; 95\% CI: 1.02, 1.07). These findings are expected. Overall, programs in states with higher non-White populations were more likely to have more course requirements focused on working with children and families who are linguistically diverse.

From the bivariate multinomial regression analyses, geographic region was also found to be a significant predictor of coursework focused on linguistic diversity when none of the other variables were in the model. Early childhood teacher preparation programs in the Plains and Rocky Mountains regions were more likely to have less than one complete course focused on linguistic diversity as compared to programs in the Far West (OR: 18; 95\% CI: 
2.0, 162.6 and OR: 28.69; 95\% CI: 3.4, 244.1). Bivariate multinomial regression analyses using different regions as the reference category also revealed that programs in the Plains and Rocky Mountains were different from programs in all other regions (i.e., New England, the Mid East, Great Lakes, Southeast, and Southwest). Specifically, when compared to programs in all other regions, programs in the Plains and Rocky Mountains were the most likely to have no or minimal and some requirements than to require at least one complete course when it comes to coursework focused on linguistic diversity (OR range: 9.9-24.2; 95\% CI range: 1.2-3.3, 82.8-203.7). In summary, as compared to programs in all other regions in the United States, programs in the Plains and Rocky Mountains were the least likely to require at least one complete course focused on working with children and families who are bilingual or linguistically diverse.

Additionally, degree of urbanization was a significant predictor without controlling for other variables. Specifically, as compared to programs in large cities, programs in small towns were close to 4 times more likely to offer only some coursework than to offer at least one complete course focused on working with children and families who are bilingual or linguistically diverse (OR: 3.85; 95\% CI: 1.15, 12.85).

Further bivariate multinomial regression analyses using other degrees of urbanization as reference categories revealed that programs in rural areas were also different from programs in small towns, urban fringes of large cities, and mid-size cities. When compared to programs in rural areas, programs in small towns, urban fringes of large cities, and mid-size cities were less likely to have no or minimal requirements than to require some coursework respectively (OR: 0.19; 95\% CI: 0.06, 0.6, OR: 0.25; 95\% CI: 0.07, 0.9, and OR: 3.81; 95\% CI: 1.2, 12.2). These analyses also indicated that programs in small towns were different 
from programs in rural areas, urban fringes of large cities, and mid-size cities. As compared to programs in small towns, programs in rural areas, urban fringes of large cities, and midsize cities were less likely to have only some requirements than to offer at least one complete course focused on linguistic diversity respectively (OR: 0.13; 95\% CI: 0.02, 0.8, OR: 0.16; 95\% CI: 0.05, 0.5, and OR: 0.31; 95\% CI: 0.10, 0.97). Programs in urban fringes of large cities were also $21 \%$ less likely to offer no or minimal requirements than to have at least one course requirements focused on linguistic diversity when compared to programs in small towns (OR: $0.21 ; 95 \%$ CI: 0.06, 0.8). Generally, results seem to indicate that programs in rural areas and small towns were least likely to require at least one complete course focused on working with children and families who are bilingual or linguistically diverse.

Table 4.7 presents the multivariate multinomial logistic regression results. This full model includes all the predictor variables in geographic context, and is significant, indicating its predictive ability $\left(\chi^{2}=56.46, d f=26, p<.001\right)$. In order to test if each variable or each block of variables was significantly contributing to the predictive power of the full model within geographic context, model comparisons were made separately against the full model. This was done by comparing the differences in chi-square and degrees of freedom. Model comparisons indicated that degree of urbanization was a significant predictor of course requirements focused on linguistic diversity $\left(\chi^{2}=23.03, d f=12, p=0.027\right)$ even when the percentage of White, non-Hispanic population and geographic region were controlled. As compared to programs in large cities, programs in urban fringes of large cities were about $31 \%$ less likely to have no or minimal requirements than to have at least one complete course focused on linguistic diversity (OR: 0.31; 95\% CI: 0.1, 0.92). Additionally, programs in urban fringes of large cities were also 36\% less likely to have some course requirements than 
to have at least one complete course focused on linguistic diversity as compared to programs in large cities (OR: 0.36; 95\% CI: 0.14, 1.0). Percentage of White, non-Hispanic population did not contribute to the overall model at the .05 level $\left(\chi^{2}=5.782, d f=2, p=0.056\right)$. Geographic region was also not a significant predictor when percentage of White, nonHispanic population and degree of urbanization were controlled $\left(\chi^{2}=16.70, d f=12, p=\right.$ $0.16)$.

In sum, degree of urbanization was a significant predictor when other geographic context variables were controlled. Specifically, programs in urban fringes of large cities were more likely to have at least a complete course to address linguistic diversity. Percentage of White, non-Hispanic populations in the states and geographic region, however did not significantly predict coursework focused on linguistic diversity.

Practica focused on linguistic diversity. Table 4.8 presents the bivariate binary logistic regression results examining geographical context and practicum requirements focused on linguistic diversity. For every 10 percentage point increase in White, nonHispanic population, early childhood teacher preparation programs were about 76\% [i.e., e ${ }^{-}$ $\left.{ }^{0.028(10)}\right]$ less likely to require practica focused on linguistic diversity (OR: 0.97). Without controlling for other predictor variables, geographic region and degree of urbanization were not significant predictors of practicum requirements focused on linguistic diversity. In sum, programs in states with higher non-White populations were more likely to require practica focused on working with children who are bilingual or linguistically diverse without controlling for other geographic context variables.

Table 4.9 presents the multivariate multinomial logistic regression results. This full model that has all three predictors measuring geographic context entered in it was significant, 
indicating that the model has predictive ability $\left(\chi^{2}=34.52, d f=14, p<.01\right)$. Degree of urbanization was not a significant predictor of practica focused on linguistic diversity when all three predictors were entered $\left(\chi^{2}=6.65, d f=6, p=0.35\right.$ ). Model comparisons indicated that both percentage of White, non-Hispanic population, and geographic region both significantly contributed to the predictive power of the context-specific model $\left(\chi^{2}=11.80, d f\right.$ $=1, p=0.006$ and $\left.\chi^{2}=18.79, d f=7, p=0.009\right)$. An examination of bivariate logistic regressions indicated that geographic region was a nonsignificant predictor, suggesting that there is a suppressor effect between the degree of urbanization and another geographic context variable.

With every 10 percentage point increase in White, non-Hispanic population, programs were $64 \%$ [i.e., $\mathrm{e}^{-0.044(10)}$ ] less likely to require practica focused on linguistic diversity (OR: 0.96). Programs in all the regions with the exception of programs in the Great Lakes were different from programs in the Far West. Programs in New England were 9 times more likely to require a practicum focused on linguistic diversity (OR: 9.23), while programs in the Mid East and Southwest were about 5 times more likely to require a practicum focused on linguistic diversity (OR: 5.28 and OR: 5.12 respectively). Additionally, programs in the Plains and Southeast were close to 7 times more likely to require a practicum related to linguistic diversity (OR: 6. 79 and OR: 6.69 respectively). Programs in the Rocky Mountains were also about 15 times more likely to require practica focused on linguistic diversity as compared to programs in the Far West (OR: 15.49). In conclusion, programs in states with more non-White populations were more likely to require practica focused on linguistic diversity when the other 2 geographic context predictors were controlled. Additionally, programs in the Far West were also less likely to offer practica focused on linguistic 
diversity. However, this result may need to be interpreted with caution given that there was a suppressor effect indicating a complicated relationship between geographic region and the other geographic context predictor variables.

Research Question 2: To what extent do institutional characteristics (i.e., governance, type of institution) predict cultural and linguistic diversity course and practicum requirements in early childhood teacher preparation programs?

Coursework focused on cultural diversity. Governance of institutions was entered as the only predictor in the first model. Then, type of institution was then entered as the only predictor in the second model. Table 4.10 presents the results of the logistic regressions predicting course requirements focused on cultural diversity. Governance of institutions was not a statistically significant predictor of coursework focused on cultural diversity. Type of institution had to be excluded from further analyses with regard to coursework focused on cultural diversity because none of the HBCUs in the Bachelor's degree sample was in the category "No coverage or 1 class of 1 required course" as opposed to 21 (5\%) of nonHBCUs.

Coursework focused on linguistic diversity. Governance of institutions was entered as the only predictor in the first model. Then, type of institutions was entered as the only predictor in the second model, and finally both predictors were entered into the full model. Table 4.11 presents results of the logistic regressions predicting course requirements focused on linguistic diversity. Both governance and type of institution did not predict coursework focused on working with children with bilingual children or children learning English as a second language at the Bachelor's degree level. 
Practica focused on linguistic diversity. Governance of institutions was entered as the only predictor in the first model. Then, type of institutions was then entered as the only predictor in the second model, and finally both were entered into the full model. Table 4.12 presents results of the logistic regressions predicting practicum requirements focused on linguistic diversity. Results indicated that governance and type of institutions did not predict practicum requirements focused on working with bilingual children or children learning English as a second language at the Bachelor's degree level.

Research Question 3: To what extent do program characteristics (i.e., NCATE accreditation status, presence of non-White full-time and part-time faculty) predict cultural and linguistic diversity course and practicum requirements in early childhood teacher preparation programs?

Nine bivariate and three multivariate regressions were conducted to predict the effect of institutional characteristics on 1) cultural diversity course requirements, 2) linguistic diversity course requirements, and 3) linguistic practicum requirements. For the analyses of cultural diversity and linguistic diversity coursework, the categories for 'No non-White parttime faculty' and 'More than $0 \%$ but less than or equal to $25 \%$ of non-White part-time faculty' were merged because Bachelor's programs with more than $0 \%$ but less than or equal to $25 \%$ of non-White part-time faculty did not have any responses in the category 'No course coverage or 1 class of 1 required course', and therefore it was not possible to run the regression analyses. When presenting the results on coursework, more than $0 \%$ but less than or equal to $25 \%$ is referred to as ' $f$ ew', more than $25 \%$ but less than or equal to $50 \%$ is referred to as 'some', and more than $50 \%$ but less than or equal to $100 \%$ is referred to as 'more than half'. For results on practica, more than $0 \%$ but less than or equal to $25 \%$ is 
referred to as 'few', more than $25 \%$ but less than or equal to $50 \%$ is referred to as 'some', and more than $50 \%$ but less than or equal to $75 \%$ is referred to as 'more than half but less than three-quarters', and more than $75 \%$ but less than or equal to $100 \%$ is referred to as 'more than three-quarters'.

Coursework focused on cultural diversity. Table 4.13 presents bivariate multinomial logistic regression results. NCATE accreditation was entered as the only predictor in the first model. Non-White full-time faculty was entered as the only predictor in the next model followed by entering non-White part-time faculty as the only predictor in the third model. As seen in Table 4.13, without controlling for any other predictor variables, NCATEaccreditation, non-White full-time faculty, and non-White part-time faculty were all significant predictors of coursework focused on cultural diversity. Specifically, non-NCATE accredited programs were about 3.7 times more likely to have only no or minimal requirements rather than to have at least one complete course focused on cultural diversity (OR: 3.68; 95\% CI: 1.4, 9.6). Non-NCATE accredited programs were also close to 3 times more likely to have no or minimal requirements than to have some course requirements focused on cultural diversity (OR: 2.85; 95\% CI: 1.1, 7.4). Overall, without controlling for other program characteristics, non-NCATE accredited programs were more likely to have no or minimal requirements as compared to NCATE-accredited programs.

Additionally, as compared to Bachelor's programs with no non-White faculty, Bachelor's programs with some non-White full-time faculty were $48 \%$ less likely to have some course requirements rather than to have at least one complete course with regard to working with children and families from diverse ethnic and cultural backgrounds respectively (OR: 0.48; 95\% CI: 0.26, 0.87). Programs with more than half non-White full- 
time faculty were $24 \%$ less likely to have some requirements than to have at least one complete course focused on working with children and families from diverse ethnic and cultural backgrounds respectively (OR: 0.24; 95\% CI: 0.11, 0.56). Further bivariate multinomial analyses indicated that programs with few non-White full-time faculty were different from programs with some non-White full-time faculty and programs with more than half non-White faculty. As compared to programs with some non-White full-time faculty, programs with few non-White full-time faculty were twice more likely to have only some requirements rather than to have at least one complete course focused on working with children and families from diverse ethnic and cultural backgrounds (OR: 2.08; 95\% CI: 1.0, 4.2). Additionally, compared to programs with more than half of non-White full-time faculty, programs with few non-White full-time faculty were about four times more likely to have only some requirements rather than to have at least one complete course focused on working with children and families from diverse ethnic and cultural backgrounds (OR: 4.1; 95\% CI: 1.6, 10.0). Without controlling for other program characteristics, results indicated that programs with more non-White full-time faculty were more likely to require at least one complete course focused on working with children and families from diverse ethnic and cultural backgrounds.

With regard to non-White part-time faculty, Bachelor's programs with more than some non-White part-time faculty were about a third less likely to have some requirements than to have at least one complete course focused on working with children and families from diverse ethnic and cultural backgrounds as compared to programs with less than a quarter of non-White part-time faculty (OR: $0.33 \mathrm{CI}$ : 0.17, 0.61). In short, without 
controlling for other program characteristics, programs with $25-50 \%$ of non-White part-time faculty were more likely to require at least one complete course focused on cultural diversity.

Table 4.14 presents multivariate multinomial logistic regression results examining program characteristics and course requirements focused on cultural diversity. The goodness of fit test shows that the model with all three predictors measuring program characteristics was significant $\left(\chi^{2}=36.97, d f=12, p<0.001\right)$. Model comparisons indicated that all three predictors, NCATE accreditation, non-White full-time faculty, and non-White part-time faculty significantly contributed to the predictive ability of the context-specific model respectively $\left(\chi^{2}=6.77, d f=2, p=0.03 ; \chi^{2}=13.12, d f=6, p=0.04\right.$; and $\chi^{2}=10.91, d f=4, p$ $=0.03)$. Specifically, non-NCATE accredited programs were 3.5 times more likely to have no or minimal requirements rather than to have at least one complete course in content related to cultural diversity (OR: 3.51; 95\% CI: 1.3, 9.5). Non-NCATE accredited programs were also close to 3 times more likely to have no or minimal requirements rather than to have some requirements focused on cultural diversity (OR: 2.74; 95\% CI: 1.0, 7.4). Additionally, programs with more than half non-White full-time faculty members were $20 \%$ less likely to have only some requirements than to have at least one complete course (OR: 0.20; 95\% CI: $0.07,0.6)$. As compared to programs with none or few non-White part-time faculty, programs with some non-White part-time faculty members were close to $40 \%$ less likely to offer some requirements than to have at least one complete course focused on cultural diversity (OR: 0.39; 95\% CI: 0.2, 0.7). In sum, with other program characteristics controlled, non-NCATE accredited programs tended to have no or minimal course requirements. Programs with more than half non-White full-time faculty members were also more likely to require at least one complete course focused on cultural diversity. Similarly, programs with $25-50 \%$ of non- 
White part-time faculty members were more likely to offer at least one complete course focused on cultural diversity.

Coursework focused on linguistic diversity. Table 4.15 presents the results of the bivariate multinomial regressions predicting course requirements focused on linguistic diversity. Results indicated that the presence of non-White full-time faculty and NCATE accreditation did not significantly predict coursework focused on working with bilingual children or children learning English as a second language even without controlling for other variables. The presence of non-White part-time faculty was a significant predictor of coursework focused on linguistic diversity. As compared to programs with no non-White part-time faculty, Bachelor’s programs with few non-White part-time faculty were about $20 \%$ less likely to have no or minimal requirements rather than to have at least one complete course focused on linguistic diversity (OR: 0.19 95\% CI: 0.07, 0.48). Additionally, as compared to programs without any non-White part-time faculty, programs with some nonWhite part-time faculty were $30 \%$ less likely to have no or minimal requirements rather than to have at least one complete course focused on working with bilingual children or children learning English as a second language (OR: 0.30 95\% CI: 0.13, 0.72). Additionally, all Bachelor's programs with few, some, or more than half non-White part-time faculty were different from programs without any non-White part-time faculty. All of these programs were about $30 \%$ less likely to have some requirements rather than to have at least one complete course focused on working with bilingual children or children learning English as a second language respectively (OR: 0.31 95\% CI: 0.15, 0.67; OR: 0.28 95\% CI: 0.13, 0.62 and OR: 0.36 95\% CI: 0.15, 0.88). Overall, programs with a presence of non-White part-time 
faculty were more likely to require at least one complete course focused on working with bilingual children or children learning English as a second language.

Table 4.16 presents multivariate multinomial logistic regression results examining program characteristics and course requirements focused on linguistic diversity. The overall model with all the predictors measuring program characteristics was significant $\left(\chi^{2}=29.72\right.$, $d f=14, p<0.01$ ), indicating that it is a good fit. Only the presence of non-White part-time faculty was a significant predictor of course requirements focused on linguistic diversity when NCATE accreditation and non-White full-time faculty were controlled $\left(\chi^{2}=14.51, d f\right.$ $=6, p=0.02$ ). As compared to programs without any non-White part-time faculty, programs with few non-White part-time faculty were $21 \%$ less likely to have no or minimal coverage rather than to offer at least one complete course focused on linguistic diversity (OR: 0.21; 95\% CI: 0.08, 0.5). Similarly, programs with some non-White part-time faculty were also $33 \%$ less likely to have no or minimal requirements rather than to have at least one complete course focused on linguistic diversity (OR: 0.33; 95\% CI: 0.1, 0.8). In addition, programs with few or some non-White part-time faculty were $35 \%$ less likely to require some coverage rather than to have at least one complete course focused on linguistic diversity (OR: 0.35; 95\% CI: 0.2, 0.8 and OR: 0.35; 95\% CI: 0.2, 0.8). In sum, programs with some non-White part-time faculty members were more likely to require at least one complete course focused on linguistic diversity.

Practica focused on linguistic diversity. Table 4.17 presents results of the bivariate binary regressions predicting practica focused on linguistic diversity. NCATE accreditation was not a significant predictor of practicum requirements focused on linguistic diversity. However, the presence of full-time as well as the presence of non-White part-time faculty 
were each separately significant predictors of practicum requirements without controlling for other predictors. Specifically, programs with some or more than three-quarters of non-White full-time faculty were at least twice more likely to require practica focused on linguistic diversity than programs with no non-White full-time faculty (OR: 2.1 and OR: 2.6). Further bivariate binary regression analyses indicated that programs with few non-White full-time faculty were also different from programs with some non-White full-time faculty. Specifically, programs with some non-White full-time faculty were twice more likely to require practica focused on linguistic diversity as compared to programs with few non-White full-time faculty $(\mathrm{OR}=2.10)$. Overall, without controlling for other program characteristics, programs with a presence of non-White full-time faculty were more likely to require a practicum focused on linguistic diversity.

When compared to programs without any non-White part-time faculty, programs with few non-White part-time faculty were about twice more likely to require practica focused on linguistic diversity (OR: 1.94). Programs with more than three-quarters non-White part-time faculty were close to three times more likely to require practica focused on linguistic diversity than programs without any non-White part-time faculty (OR: 2.83). Programs with some non-White part-time faculty were also significantly different from programs with more than three-quarters non-White part-time faculty. When programs have more than threequarters non-White part-time faculty, they were 2.6 times more likely to require practica focused on linguistic diversity $(\mathrm{OR}=2.6)$. Thus, without controlling for other program characteristics, this indicates that programs with a presence of non-White part-time faculty were more likely to require a practicum focused on linguistic diversity. 
Table 4.18 presents the full model where all three predictor variables measuring program characteristics are entered. Results showed that this context-specific model was significant $\left(\chi^{2}=22.71, d f=9, p<.01\right)$. NCATE accreditation did not significantly contribute to the context-specific model's predictive ability $\left(\chi^{2}=1.984, d f=1, p<0.159\right)$. Both fulltime and non-White part-time faculty were however significant predictors of practica related to linguistic diversity $\left(\chi^{2}=9.65, d f=4, p=0.047\right.$ and $\chi^{2}=10.6, d f=4, p=0.03$ ) (see Table 4.18). Programs with some non-White full-time faculty were 2.5 times more likely to require practica focused on linguistic diversity than programs without any non-White full-time faculty (OR: 2.46), while programs with few non-White part-time faculty were twice more likely to require practica focused on linguistic diversity than programs without any nonWhite full-time faculty (OR: 2.03). In conclusion, programs with a presence of full-time and non-White part-time faculty were more likely to require a practicum focused on linguistic diversity, when all program characteristics were controlled.

Models with Geographical Context, Institutional, and Program Characteristics as Predictors Multivariate logistic regressions across contexts were conducted to understand the effect of each significant predictor when all other predictors across all three contexts were controlled. Each model excluded one variable or block of variables, with the final model including all the predictor variables. Chi-square differences between the final model and each of the models were then calculated to understand the predictive power of a predictor variable after controlling for all other predictors.

Coursework focused on cultural diversity. Table 4.19 presents the model with all contextual characteristics entered. Type of institutions was excluded from this analysis given the large odds ratios and confidence intervals. With all the predictors measuring all three 
contexts entered into the model, the model was significant at the .05 level, indicating a goodness of fit $\left(\chi^{2}=63.30, d f=40, p=0.01\right)$. Results from the model comparisons showed that NCATE accreditation did not significantly contribute to the model at the .05 level $\left(\chi^{2}=\right.$ 5.27, $d f=2, p=0.07)$. Neither did non-White part-time faculty $\left(\chi^{2}=7.58, d f=4, p=\right.$ 0.11).Only non-White full-time faculty was a significant contribution over and beyond all other predictor variables $\left(\chi^{2}=12.79, d f=6, p=0.047\right)$. Specifically, when all other predictor variables are taken into account, programs with more than half non-White full-time faculty were $19 \%$ less likely to have only some requirements rather than have at least one complete course focused on cultural diversity (OR: 0.19; 95\% CI: 0.06, 0.6). In sum, both NCATE accreditation and non-White part-time faculty became no longer significant predictors after controlling for all variables across contexts. Non-White full-time faculty however, remained a significant predictor. Specifically, programs with more than half non-White full-time faculty were more likely to have at least one complete course focused on cultural diversity.

Coursework focused on linguistic diversity. Table 4.20 presents results from multivariate multinomial logistic regression analyses examining the relationship between all the predictor variables and coursework focused on linguistic diversity. When all the predictor variables across contexts were entered, the full model was significant, indicating its predictive ability $\left(\chi^{2}=84.41, d f=44, p<.001\right)$. Model comparisons indicated that degree of urbanization, NCATE accreditation and governance of institutions contributed to the significance of this model $\left(\chi^{2}=21.88, d f=12, p=0.039, \chi^{2}=9.04, d f=2, p=0.01\right.$, and $\chi^{2}$ $=7.07, d f=2, p=0.029)$. An examination of bivariate and multivariate regressions at each contextual level indicated that NCATE accreditation and governance were both nonsignificant predictors, suggesting that there is a suppressor effect between the two 
variables. When other predictor variables were controlled, NCATE accreditation and governance of institutions became significant predictors of coursework focused on linguistic diversity, however neither was significant when one or the other was constrained in a model.

From the full model, it is clear that programs in urban fringes of large cities were over $30 \%$ less likely to have no or minimal requirements or some requirements rather than to have at least one complete course (OR: 0.27; 95\% CI: 0.09, 0.9 and OR: 0.31; 95\% CI: 0.1, 0.9). Programs in rural areas were also 3.6 times more likely to have no or minimal requirements as opposed to requiring some coverage in courses focused on linguistic diversity (OR: 3.60; 95\% CI: 1.0, 12.8). Programs in private institutions were 2.7 times more likely to have some requirements rather than to have at least one complete course focused on linguistic diversity (OR: 2.68; 95\% CI: 1.2, 5.9). Non-NCATE accredited programs were also 31\% less likely to have some course requirements than to have at least one complete course focused on linguistic diversity (OR: 0.31; 95\% CI: 0.1, 0.7). This is puzzling given that accreditation is expected to have a more positive impact on course requirements. Overall, the suppressor effect between the two variables, governance and NCATE accreditation suggests that there is a complicated relationship which is beyond our understanding. Nevertheless, results indicate programs in public institutions as being more likely to require one complete course in linguistic diversity, and NCATE-accredited programs as being more likely to require only some linguistic diversity course requirements. Programs in urban fringes of large cities were also more likely to require at least one complete course in linguistic diversity.

Practica focused on linguistic diversity. Table 4.21 presents results from multivariate binary logistic regression analyses examining the relationship between all the predictor variables and practica focused on linguistic diversity. When all predictors across all three 
contexts were entered, the model was statistically significant $\left(\chi^{2}=50.49, d f=25, p=0.02\right)$. Model comparisons indicated that percentage of White, non-Hispanic population and geographic regions were significant predictors of practica focused on linguistic diversity respectively $\left(\chi^{2}=9.25, d f=1, p=0.002\right.$ and $\left.\chi^{2}=15.21, d f=7, p=0.03\right)$.Full-time and nonWhite part-time faculty which were individual significant predictors at the bivariate level became no longer significant when other predictors were entered into the model $\left(\chi^{2}=6.52\right.$, $d f=4, p=0.16$ and $\left.\chi^{2}=9.2, d f=4, p=0.057\right)$. From the model, it was found that for every 10 percentage point increase in White, non-Hispanic population, programs were $66 \%$ [i.e., $e^{-}$ ${ }^{0.041(10)}$ ] less likely to require a practicum focused on linguistic diversity ( $\left.O R=0.96\right)$.

Programs in all regions except the Great Lakes were different from programs in the Far West in being more likely to require practica focused on linguistic diversity (OR range $=4.6-$ 14.3). In conclusion, results suggest that programs in states with more non-White populations were more likely to require a practicum focused on linguistic diversity. Programs in the Far West were also less likely to require a practicum focused on linguistic diversity.

\section{Summary}

Table 4.22 presents a summary of the predictors of coursework and practica focused on cultural and linguistic diversity. Results will be discussed according to the effect of each predictor on each of the 3 dependent variables in the bivariate, context specific, and across contexts models.

Required course coverage on working with children and families from diverse ethnic and cultural backgrounds

Geographical context and institutional characteristics. All the predictors measuring geographical context (i.e., percentage of White, non-Hispanic population, geographical 
region, and degree of urbanization) did not significantly predict the amount of required coursework focused on cultural diversity in the 3 models. Governance of institutions also did not significantly predict the amount of required coursework focused on cultural diversity in all three models. Type of institution was excluded from all levels of analyses because none of the HBCUs was in the category "No coverage or 1 class of 1 required course".

Program characteristics. NCATE accreditation was a significant predictor of coursework focused on cultural diversity in both bivariate and context specific models. Specifically, non-NCATE accredited programs were more likely to have no or minimal requirements as compared to NCATE-accredited programs. However, when all variables across contexts were entered into the model, NCATE accreditation was no longer a significant predictor. The presence of non-White full-time faculty was a significant predictor in all three models, and was the only significant predictor when all variables across contexts were entered into the final model. Results indicated that programs with more non-White fulltime faculty were more likely to require at least one complete course focused on working with children and families from diverse ethnic and cultural backgrounds. The presence of non-White part-time faculty was a significant predictor in the bivariate and context specific models. Results from these 2 models indicated when compared to programs without any nonWhite part-time faculty, programs with some presence of non-White part-time faculty were more likely to require at least one complete course focused on cultural diversity. However, when all the variables across contexts were controlled, it no longer was significant. 
Required course coverage on working with bilingual children or children learning English as a second language

Geographical context. When none of the other variables were controlled, programs in states with higher non-White populations were more likely to have more course requirements focused on working with bilingual children. However, when all other variables were controlled for within geographical context and across contexts, percentage of White, nonHispanic population in states was no longer a significant predictor. Similarly, geographic region was a significant predictor when none of the variables were controlled, and became nonsignificant when all variables within geographic context and across contexts were controlled. Specifically, results from the bivariate model indicated that programs in the Plains and Rocky Mountains were the least likely to require at least one complete course focused on working with children and families who are bilingual or linguistically diverse. Degree of urbanization was a significant predictor in all 3 models. Specifically, programs in urban fringes of large cities are more likely to have at least a complete course to address linguistic diversity.

Institutional characteristics. Type of institution was not a significant predictor in all three models. Governance was not a significant in the bivariate and context specific models. However, it became a significant predictor when all other variables across contexts were controlled. Results indicated programs in public institutions as being more likely to require one complete course in linguistic diversity,

Program characteristics. The presence of non-White full-time faculty was nonsignificant in all three models. NCATE accreditation was nonsignificant in both bivariate and context specific models. However, when all variables across contexts were entered into 
the model, it became a significant predictor. The presence of non-White part-time faculty a significant predictor in both bivariate and context-specific models. Programs with non-White part-time faculty were more likely to require at least one complete course focused on working with bilingual children or children learning English as a second language. However, when all other variables across contexts were entered into the model, non-White part-time faculty became nonsignficant. Required practicum coverage on working with bilingual children or children learning English as a second language

Geographical context and institutional characteristics. Percentage of White, nonHispanic population in states was a significant predictor in all three models. Specifically, programs in states with higher non-White populations were more likely to require practica focused on working with children who are bilingual or linguistically diverse. Geographic region was not a significant predictor without controlling for other variables. However, it became significant when other variables were controlled. Results indicated that programs in the Far West were less likely to offer practica focused on linguistic diversity. This result may need to be interpreted with caution given that there was a suppressor effect indicating a complicated relationship between geographic region and the other geographic context predictor variables. Additionally, degree of urbanization was not a significant predictor in all three models. Both institutional characteristics, i.e., governance and type of institution, were not significant in all three models.

Program characteristics. NCATE accreditation was not a significant predictor in all three models. Both non-White full-time and non-White part-time faculty were significant in both bivariate and context specific models, but were no longer significant when variables 
across contexts were entered into the model. From the bivariate and context specific models, programs with a presence of non-White full-time and non-White part-time faculty were more likely to require a practicum focused on linguistic diversity. 
Table 4.1: Coverage and Presence of Cultural and Linguistic Diversity Coursework and Practica for Bachelor's Programs (Frequencies with percentages in parentheses)

\begin{tabular}{|c|c|c|c|c|c|c|}
\hline & \multicolumn{6}{|c|}{ Dependent Variables } \\
\hline & \multicolumn{2}{|c|}{$\begin{array}{l}\text { Required course } \\
\text { coverage on } \\
\text { working with } \\
\text { children and } \\
\text { families from } \\
\text { diverse ethnic \& } \\
\text { cultural } \\
\text { backgrounds } \\
n=416\end{array}$} & \multicolumn{2}{|c|}{$\begin{array}{l}\text { Required course } \\
\text { coverage on } \\
\text { working with } \\
\text { bilingual children } \\
\text { or children } \\
\text { learning English } \\
\text { as a second } \\
\text { language } \\
n=416\end{array}$} & \multicolumn{2}{|c|}{$\begin{array}{l}\text { Required } \\
\text { practicum } \\
\text { coverage on } \\
\text { working with } \\
\text { bilingual } \\
\text { children or } \\
\text { children learning } \\
\text { English as a } \\
\text { second language } \\
n=398 \\
\end{array}$} \\
\hline \multicolumn{7}{|l|}{$\underline{\text { Coverage }}$} \\
\hline No coverage & 2 & $(0.5)$ & 52 & (12.5) & - & \\
\hline $\begin{array}{l}\text { One class session of } \\
\text { one required course } \\
\text { (non-elective) }\end{array}$ & 19 & $(4.6)$ & 65 & $(15.6)$ & - & \\
\hline $\begin{array}{l}\text { Multiple class } \\
\text { sessions of one } \\
\text { required course }\end{array}$ & 155 & (37.3) & 203 & $(48.8)$ & - & \\
\hline $\begin{array}{l}\text { Multiple class } \\
\text { sessions of multiple } \\
\text { required courses }\end{array}$ & 44 & $(10.6)$ & 36 & $(8.7)$ & - & \\
\hline $\begin{array}{l}\text { Entire required } \\
\text { course }\end{array}$ & 37 & $(8.9)$ & 15 & $(3.6)$ & - & \\
\hline $\begin{array}{l}\text { Entire required } \\
\text { course plus coverage } \\
\text { in other courses }\end{array}$ & 159 & (38.2) & 45 & (10.8) & - & \\
\hline \multicolumn{7}{|l|}{$\underline{\text { Presence }}$} \\
\hline No & & - & & - & 278 & (69.8) \\
\hline Yes & & - & & - & 120 & $(30.2)$ \\
\hline
\end{tabular}


Table 4.2: Contextual Characteristics of Early Childhood Teacher Preparation Programs

(Frequencies with percentages in parentheses) $(n=416)$

\begin{tabular}{|c|c|c|}
\hline \multirow{2}{*}{$\begin{array}{l}\text { Variables } \\
\text { Geographical Region } \\
\end{array}$} & \multicolumn{2}{|c|}{$\begin{array}{l}\text { Frequency of Institutions (with } \\
\text { percentages in parentheses) }\end{array}$} \\
\hline & & \\
\hline New England (CT, ME, MA, NH, RI, VI) & 35 & $(8.4)$ \\
\hline Mid East (DE DC MD NJ NY PA) & 63 & $(15.1)$ \\
\hline Great Lakes (IL IN MI OH WI) & 69 & $(16.6)$ \\
\hline Plains (IA KS MN MO NE ND SD) & 58 & $(13.9)$ \\
\hline Southeast (AL AR FL GA KY LA MS NC SC TN) & 102 & $(24.5)$ \\
\hline Southwest (AZ NM OK TX) & 40 & $(9.6)$ \\
\hline Rocky Mtns (CO ID MT UT WY) & 14 & $(3.4)$ \\
\hline Far West (AK CA HI NV OR WA) & 35 & (8.4) \\
\hline \multicolumn{3}{|l|}{ Degree of Urbanization } \\
\hline Rural & 17 & $(4.1)$ \\
\hline Small town & 71 & $(17.1)$ \\
\hline Large town & 20 & $(4.8)$ \\
\hline Urban fringe of mid size city & 42 & $(10.1)$ \\
\hline Urban fringe of large city & 65 & $(15.6)$ \\
\hline Mid size city & 128 & $(30.8)$ \\
\hline Large city & 73 & $(17.5)$ \\
\hline \multicolumn{3}{|l|}{ Governance } \\
\hline Private & 174 & $(41.8)$ \\
\hline Public & 242 & $(58.2)$ \\
\hline \multicolumn{3}{|l|}{ Type of Institution } \\
\hline HBCU & 27 & (6.5) \\
\hline All Others & 389 & $(93.5)$ \\
\hline \multicolumn{3}{|l|}{ Program Characteristics } \\
\hline \multicolumn{3}{|l|}{ NCATE-Accreditation } \\
\hline No & 165 & $(39.7)$ \\
\hline Yes & 251 & $(60.3)$ \\
\hline
\end{tabular}


Table 4.3: Mean Percentages of White, non-Hispanic Population and Non-White Faculty in Early Childhood Teacher Preparation Programs (standard deviations in parentheses) (n= 416)

\section{Variables}

White, non-Hispanic population

Non-White Faculty

Full-time

Part-time
Mean Percentage (with standard deviations in parentheses)

$16.3 \quad(25.9)$

$18.1 \quad(29.8)$ 
Table 4.4: Bivariate Multinomial Logistic Regression Examining Geographical Context and Course Requirements Focused on Cultural Diversity (Odds Ratios)

\begin{tabular}{|c|c|c|c|c|c|c|c|c|c|}
\hline \multirow[t]{2}{*}{ Predictor Variable } & \multicolumn{3}{|c|}{ Model 1} & \multicolumn{3}{|c|}{ Model 2} & \multicolumn{3}{|c|}{ Model 3} \\
\hline & $(1 \mathrm{vs} .3)^{\mathrm{a}}$ & $(2 \mathrm{vs} .3)^{\mathrm{a}}$ & $(1 \mathrm{vs} .2)^{\mathrm{a}}$ & $(1 \mathrm{vs} .3)^{\mathrm{a}}$ & $(2 \mathrm{vs} .3)^{\mathrm{a}}$ & $(1 \mathrm{vs} .2)^{\mathrm{a}}$ & $(1 \text { vs.3 })^{\mathrm{a}}$ & $(2 \mathrm{vs} .3)^{\mathrm{a}}$ & $(1 \mathrm{vs} .2)^{\mathrm{a}}$ \\
\hline \% White, non-Hispanic population & 1.01 & 1.01 & 1.00 & & & & & & \\
\hline \multicolumn{10}{|l|}{ Geographic Region } \\
\hline New England & & & & 1.75 & $2.96 *$ & 0.59 & & & \\
\hline Mid East & & & & 1.68 & 2.33 & 0.72 & & & \\
\hline Great Lakes & & & & 3.00 & 1.34 & 2.24 & & & \\
\hline Plains and Rocky Mountains & & & & 1.66 & 1.32 & 1.26 & & & \\
\hline Southeast & & & & 1.71 & 1.62 & 1.06 & & & \\
\hline Southwest & & & & 6.56 & 1.92 & 3.42 & & & \\
\hline \multicolumn{10}{|l|}{ Degree of Urbanization } \\
\hline Rural & & & & & & & 1.80 & 0.98 & 1.83 \\
\hline Small town & & & & & & & 1.39 & 1.73 & 0.80 \\
\hline Large town & & & & & & & 0.80 & 1.25 & 0.64 \\
\hline Urban fringe of mid size city & & & & & & & 0.42 & 1.59 & 0.27 \\
\hline Urban fringe of large city & & & & & & & 0.21 & 0.99 & 0.21 \\
\hline Mid-size city & & & & & & & 0.66 & 0.96 & 0.69 \\
\hline$\chi^{2}(d f)$ & & $(2)$ & & & $14.12 \quad(12)$ & & & $10.83 \quad(1$ & \\
\hline
\end{tabular}

Note: $N=416$. No coverage or 1 class of 1 required course $N=21$, multiple classes of 1 required course or multiple classes of multiple courses $N=199$, entire required course or entire required course and coverage in other courses $N=196$.

${ }^{a}$ Comparisons for each predictor variable for outcome level 1 vs. 3 (No coverage or 1 class of 1 required course vs. Entire required course or Entire required course and coverage in other courses), 2 vs. 3 (Multiple classes of 1 required course or multiple classes of multiple courses vs. Entire required course or Entire required course and coverage in other courses), and 1 vs. 2 ((No coverage or 1 class of 1 required course vs. Multiple classes of 1 required course or multiple classes of multiple courses).

${ }^{*} p<.05,{ }^{* *} p<.01,{ }^{* * *} p<.001$. 
Table 4.5: Multivariate Multinomial Logistic Regression Examining Geographical Context and Course Requirements Focused on Cultural Diversity (Odds Ratios)

\begin{tabular}{|c|c|c|c|}
\hline \multirow{2}{*}{ Predictor Variable } & \multicolumn{3}{|c|}{ Full Model } \\
\hline & $(1 \mathrm{vs} .3)^{\mathrm{a}}$ & $(2 \mathrm{vs} .3)^{\mathrm{a}}$ & $(1 \mathrm{vs} .2)^{\mathrm{a}}$ \\
\hline \% White, non-Hispanic population & 1.03 & 1.01 & 1.01 \\
\hline \multicolumn{4}{|l|}{ Geographic Region } \\
\hline New England & 1.11 & 2.12 & 0.52 \\
\hline Mid East & 1.48 & 1.94 & 0.76 \\
\hline Great Lakes & 1.75 & 0.97 & 1.80 \\
\hline Plains and Rocky Mountains & 0.62 & 0.76 & 0.82 \\
\hline Southeast & 1.14 & 1.24 & 0.92 \\
\hline Southwest & 5.86 & 1.83 & 3.21 \\
\hline \multicolumn{4}{|l|}{ Degree of Urbanization } \\
\hline Rural & 1.65 & 0.79 & 2.09 \\
\hline Small town & 1.52 & 1.66 & 0.92 \\
\hline Large town & 0.67 & 1.12 & 0.60 \\
\hline $\begin{array}{l}\text { Urban fringe of mid size } \\
\text { city }\end{array}$ & 0.49 & 1.25 & 0.39 \\
\hline Urban fringe of large city & 0.22 & 0.75 & 0.29 \\
\hline Mid-size city & 0.69 & 0.90 & 0.76 \\
\hline$\chi^{2}(d f)$ & $27.28 \quad(2$ & & \\
\hline
\end{tabular}

Note: $N=416$. No coverage or 1 class of 1 required course $N=21$, multiple classes of 1 required course or multiple classes of multiple courses $N=199$, entire required course or entire required course and coverage in other courses $N=196$.

${ }^{a}$ Comparisons for each predictor variable for outcome level 1 vs. 3 (No coverage or 1 class of 1 required course vs. Entire required course or Entire required course and coverage in other courses), 2 vs. 3 (Multiple classes of 1 required course or multiple classes of multiple courses vs. Entire required course or Entire required course and coverage in other courses), and 1 vs. 2 ((No coverage or 1 class of 1 required course vs. Multiple classes of 1 required course or multiple classes of multiple courses).

${ }^{*} p<.05, * * p<.01,{ }^{* * *} p<.001$. 
Table 4.6: Bivariate Multinomial Logistic Regression Examining Geographical Context and Course Requirements Focused on Linguistic Diversity (Odds Ratios)

\begin{tabular}{|c|c|c|c|c|c|c|c|c|c|}
\hline \multirow[t]{2}{*}{ Predictor Variable } & \multicolumn{3}{|c|}{ Model 1} & \multicolumn{3}{|c|}{ Model 2} & \multicolumn{3}{|c|}{ Model 3} \\
\hline & $(1 \mathrm{vs} .3)^{\mathrm{a}}$ & $(2 \mathrm{vs} .3)^{\mathrm{a}}$ & $(1 \mathrm{vs} .2)^{\mathrm{a}}$ & $(1 \text { vs. } 3)^{\mathrm{a}}$ & $(2 \mathrm{vs} .3)^{\mathrm{a}}$ & $(1 \mathrm{vs} .2)^{\mathrm{a}}$ & $(1 \text { vs. } 3)^{\mathrm{a}}$ & $(2 \text { vs.3 })^{\mathrm{a}}$ & $(1 \mathrm{vs} .2)^{\mathrm{a}}$ \\
\hline \% White, non-Hispanic population & $1.04^{* * *}$ & $1.05^{* * *}$ & 1.00 & & & & & & \\
\hline \multicolumn{10}{|l|}{ Geographic Region } \\
\hline New England & & & & 1.44 & 2.48 & 0.58 & & & \\
\hline Mid East & & & & 2.57 & 2.89 & 0.89 & & & \\
\hline Great Lakes & & & & 2.25 & 2.88 & 0.78 & & & \\
\hline Plains and Rocky Mountains & & & & $18.0^{*}$ & $28.69 * *$ & 0.63 & & & \\
\hline Southeast & & & & 1.16 & 1.45 & 0.80 & & & \\
\hline Southwest & & & & 1.20 & 1.19 & 1.01 & & & \\
\hline \multicolumn{10}{|l|}{ Degree of Urbanization } \\
\hline Rural & & & & & & & 1.64 & 0.56 & 3.19 \\
\hline Small town & & & & & & & 2.32 & $3.85^{*}$ & 0.60 \\
\hline Large town & & & & & & & 3.27 & 4.00 & 0.82 \\
\hline Urban fringe of mid size city & & & & & & & 1.77 & 1.92 & 0.92 \\
\hline Urban fringe of large city & & & & & & & 0.48 & 0.60 & 0.81 \\
\hline Mid-size city & & & & & & & 1.01 & 1.20 & 0.84 \\
\hline$\chi^{2}(d f)$ & 19 & $* * *$ & (2) & & $6.58 * *(12$ & & & $2.77 *(12)$ & \\
\hline
\end{tabular}

Note: $N=416$. No coverage or 1 class of 1 required course $N=117$, multiple classes of 1 required course or multiple classes of multiple courses $N=239$, entire required course or entire required course and coverage in other courses $N=60$.

${ }^{a}$ Comparisons for each predictor variable for outcome level 1 vs. 3 (No coverage or 1 class of 1 required course vs. Entire required course or Entire required course and coverage in other courses), 2 vs. 3 (Multiple classes of 1 required course or multiple classes of multiple courses vs. Entire required course or Entire required course and coverage in other courses), and 1 vs. 2 ((No coverage or 1 class of 1 required course vs. Multiple classes of 1 required course or multiple classes of multiple courses).

${ }^{*} p<.05,{ }^{* *} p<.01,{ }^{* * *} p<.001$. 
Table 4.7: Multivariate Multinomial Logistic Regression Examining Geographical Context and Course Requirements Focused on Linguistic Diversity (Odds Ratios)

\begin{tabular}{|c|c|c|c|}
\hline \multirow[t]{2}{*}{ Predictor Variable } & \multicolumn{3}{|c|}{ Full Model } \\
\hline & $(1 \mathrm{vs} .3)^{\mathrm{a}}$ & $(2 \mathrm{vs} .3)^{\mathrm{a}}$ & $(1 \mathrm{vs} .2)^{\mathrm{a}}$ \\
\hline \% White, non-Hispanic population & $1.04 *$ & 1.03 & 1.01 \\
\hline \multicolumn{4}{|l|}{ Geographic Region } \\
\hline New England & 0.50 & 1.28 & 0.39 \\
\hline Mid East & 1.80 & 2.39 & 0.75 \\
\hline Great Lakes & 0.85 & 1.38 & 0.62 \\
\hline Plains and Rocky Mountains & 3.81 & 8.23 & 0.46 \\
\hline Southeast & 0.43 & 0.65 & 0.67 \\
\hline Southwest & 0.80 & 0.84 & 0.95 \\
\hline \multicolumn{4}{|l|}{ Degree of Urbanization } \\
\hline Rural & 1.06 & 0.30 & 3.51 \\
\hline Small town & 1.53 & 2.42 & 0.63 \\
\hline Large town & 3.00 & 3.55 & 0.84 \\
\hline Urban fringe of mid size city & 1.82 & 1.83 & 0.99 \\
\hline Urban fringe of large city & $0.31 *$ & $0.36 *$ & 0.85 \\
\hline Mid-size city & 0.90 & 1.02 & 0.88 \\
\hline$\chi^{2}(d f)$ & & ;*** & (26) \\
\hline
\end{tabular}

Note: $N=416$. No coverage or 1 class of 1 required course $N=117$, multiple classes of 1 required course or multiple classes of multiple courses $N=239$, entire required course or entire required course and coverage in other courses $N=60$.

${ }^{\text {a }}$ Comparisons for each predictor variable for outcome level 1 vs. 3 (No coverage or 1 class of 1 required course vs. Entire required course or Entire required course and coverage in other courses), 2 vs. 3 (Multiple classes of 1 required course or multiple classes of multiple courses vs. Entire required course or Entire required course and coverage in other courses), and 1 vs. 2 ((No coverage or 1 class of 1 required course vs. Multiple classes of 1 required course or multiple classes of multiple courses).

${ }^{*} p<.05, * * p<.01, * * * p<.001$. 
Table 4.8: Bivariate Binary Logistic Regression Examining Geographical Context and Practicum Requirements Focused on Linguistic Diversity (Odds Ratios)

\begin{tabular}{|c|c|c|c|}
\hline Predictor Variable & Model 1 & Model 2 & Model 3 \\
\hline $\begin{array}{l}\text { Percentage of White, non- } \\
\text { Hispanic population }\end{array}$ & $0.97 * *$ & & \\
\hline \multicolumn{4}{|l|}{ Geographic Region } \\
\hline New England & & 1.74 & \\
\hline Mid East & & 2.05 & \\
\hline Great Lakes & & 0.96 & \\
\hline Plains & & 1.16 & \\
\hline Southeast & & 2.29 & \\
\hline Southwest & & $3.05 *$ & \\
\hline Rocky Mtns & & 2.67 & \\
\hline
\end{tabular}

\section{Degree of Urbanization}

Rural

0.32

Small town

0.59

Large town

0.35

Urban fringe of mid

0.53

size city

Urban fringe of large

0.74

city

Large city

0.60

$\chi^{2}(d f)$

$12.13^{* * *}(1)$

$12.95(7)$

$6.59(6)$

Note: $N=398$. No practicum requirement on working with bilingual children or children learning English as a second language $N=278$, practicum requirement on working with bilingual children or children learning English as a second language $N=120$.

${ }^{*} p<.05, * * p<.01,{ }^{* * *} p<.001$. 
Table 4.9: Multivariate Binary Logistic Regression Examining Geographical Context and Practicum Requirements Focused on Linguistic Diversity (Odds Ratios)

Predictor Variable $\quad$ Full Model

Percentage of White, non-Hispanic population $\quad 0.96^{* *}$

Geographic Region

New England

$9.23 * *$

Mid East

$5.28 * *$

Great Lakes

3.29

Plains

6.79*

Southeast

$6.69^{* *}$

Southwest

$5.12 * *$

Rocky Mountains

$15.49^{* *}$

\section{Degree of Urbanization}

Rural

0.35

Small town

0.68

Large town

0.29

Urban fringe of mid size city

0.46

Urban fringe of large city

0.75

Large city

0.59

$\chi^{2}(d f)$

$34.52 * *$ (14)

Note: $N=398$. No practicum requirement on working with bilingual children or children learning English as a second language $N=278$, practicum requirement on working with bilingual children or children learning English as a second language $N=120$

$* p<.05, * * p<.01, * * * p<.001$. 
Table 4.10: Bivariate Multinomial Logistic Regression Examining Institutional

Characteristics and Course Requirements Focused on Cultural Diversity (Odds Ratios)

\begin{tabular}{|c|c|}
\hline & Model 1 \\
\hline Predictor Variable & $(2 \text { vs. } 3)^{\mathrm{a}} \quad(1 \mathrm{vs} .2)^{\mathrm{a}}$ \\
\hline
\end{tabular}

\section{Governance}

\begin{tabular}{lccc} 
Private & $2.68 *$ & 1.28 & 2.09 \\
\hline$\chi^{2}(d f)$ & & $5.06(2)$ & \\
\hline
\end{tabular}

Note: $N=416$. No coverage or 1 class of 1 required course $N=21$, multiple classes of 1 required course or multiple classes of multiple courses $N=199$, entire required course or entire required course and coverage in other courses $N=196$.

${ }^{a}$ Comparisons for each predictor variable for outcome level 1 vs. 3 (No coverage or 1 class of 1 required course vs. Entire required course or Entire required course and coverage in other courses), 2 vs. 3 (Multiple classes of 1 required course or multiple classes of multiple courses vs. Entire required course or Entire required course and coverage in other courses), and 1 vs. 2 ((No coverage or 1 class of 1 required course vs. Multiple classes of 1 required course or multiple classes of multiple courses).

${ }^{b}$ Odds ratio and confidence intervals were too large for interpretation because none of the HBCUs was in outcome level 1 (No coverage or 1 class of 1 required course)

${ }^{*} p<.05,{ }^{* *} p<.01, * * * p<.001$. 
Table 4.11: Multinomial Logistic Regression Examining Institutional Characteristics and Course Requirements Focused on Linguistic Diversity in Bachelor’s Degree Programs (Odds Ratios)

\begin{tabular}{|c|c|c|c|c|c|c|c|c|c|}
\hline \multirow[b]{2}{*}{ Predictor Variable } & \multicolumn{3}{|c|}{ Model 1} & \multicolumn{3}{|c|}{ Model 2} & \multicolumn{3}{|c|}{ Full Model } \\
\hline & $(1 \mathrm{vs} .3)^{\mathrm{a}}$ & $(2 \text { vs. } 3)^{\mathrm{a}}$ & $(1 \mathrm{vs} .2)^{\mathrm{a}}$ & $(1 \mathrm{vs} .3)^{\mathrm{a}}$ & $(2 \text { vs. } 3)^{\mathrm{a}}$ & $(1 \mathrm{vs} .2)^{\mathrm{a}}$ & $(1 \mathrm{vs} .3)^{\mathrm{a}}$ & $(2 \text { vs. } 3)^{\mathrm{a}}$ & $(1 \mathrm{vs} .2)^{\mathrm{a}}$ \\
\hline
\end{tabular}

\section{Governance}

Private

1.59

$$
0.87
$$

\section{Type of}

Institution

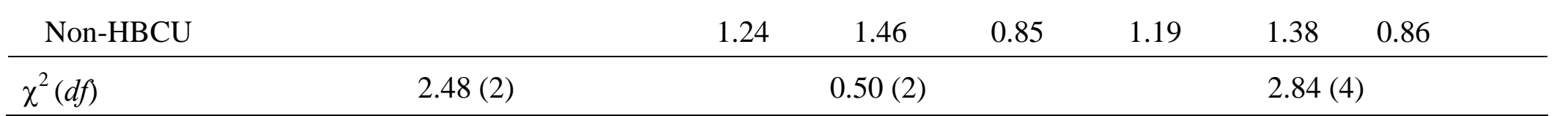

Note: $N=416$. No coverage or 1 class of 1 required course $N=117$, multiple classes of 1 required course or multiple classes of multiple courses $N=239$, entire required course or entire required course and coverage in other courses $N=60$.

${ }^{\text {a }}$ Comparisons for each predictor variable for outcome level 1 vs. 3 (No coverage or 1 class of 1 required course vs. Entire required course or Entire required course and coverage in other courses), 2 vs. 3 (Multiple classes of 1 required course or multiple classes of multiple courses vs. Entire required course or Entire required course and coverage in other courses), and 1 vs. 2 ((No coverage or 1 class of 1 required course vs. Multiple classes of 1 required course or multiple classes of multiple courses). 
Table 4.12: Binary Logistic Regression Examining Institutional Characteristics and Practicum Requirements Focused on Linguistic Diversity (Odds Ratios)

\begin{tabular}{cccc}
\hline Predictor Variable & Model 1 & Model 2 & Full Model \\
\hline
\end{tabular}

\section{Governance}

Private

1.06

1.08

\section{Type of Institution}

\begin{tabular}{llll} 
Non-HBCU & 0.57 & 0.56 \\
\hline$\chi^{2}(d f)$ & $0.08(1)$ & $1.84(1)$ & $1.97(2)$ \\
\hline
\end{tabular}

Note: $N=398$. No practicum requirement on working with bilingual children or children learning English as a second language $N=278$, practicum requirement on working with bilingual children or children learning English as a second language $N=120$

$* p<.05, * * p<.01, * * * p<.001$. 
Table 4.13: Bivariate Multinomial Logistic Regression Examining Program Characteristics and Course Requirements Focused on Cultural Diversity (Odds Ratios)

\begin{tabular}{|c|c|c|c|c|c|c|}
\hline \multirow[b]{2}{*}{ Predictor Variable } & \multicolumn{2}{|c|}{ Model 1} & \multicolumn{2}{|l|}{ Model 2} & \multicolumn{2}{|r|}{ Model 3} \\
\hline & $(1 \mathrm{vs} .3)^{\mathrm{a}}(2 \mathrm{vs} .3)^{\mathrm{a}}$ & $(1 \mathrm{vs} .2)^{\mathrm{a}}$ & $(1 \mathrm{vs} .3)^{\mathrm{a}} \quad(2 \mathrm{vs} .3)^{\mathrm{a}}$ & $(1 \mathrm{vs} .2)^{\mathrm{a}}$ & $(1 \mathrm{vs} .3)^{\mathrm{a}}$ & $(2 \text { vs. } 3)^{\mathrm{a}} \quad(1 \mathrm{vs} .2)^{\mathrm{a}}$ \\
\hline
\end{tabular}

\section{NCATE-accreditation}

Non-NCATE accreditation $3.68 * * 1.29 \quad 2.85^{*}$

\section{Non-White full-time faculty}

More than $0 \%$, less than or equal to $25 \%$

More than 25\% but less

than or equal to $50 \%$

More than $50 \%$ to $100 \%$

$\begin{array}{lll}0.37 & 0.99 \quad 0.37\end{array}$

$0.57 \quad 0.48 * \quad 1.19$

$0.25 \quad 0.24^{* *} \quad 1.04$

\section{Non-White part-time}

\section{faculty}

More than 25\% but less than or equal to $50 \%$

More than $50 \%$ to $100 \%$

Note: $N=416$. No coverage or 1 class of 1 required course $N=21$, multiple classes of 1 required course or multiple classes of multiple courses $N=199$, entire required course or entire required course and coverage in other courses $N=196$.

${ }^{\text {a }}$ Comparisons for each predictor variable for outcome level 1 vs. 3 (No coverage or 1 class of 1 required course vs. Entire required course or Entire required course and coverage in other courses), 2 vs. 3 (Multiple classes of 1 required course or multiple classes of multiple courses vs. Entire required course or Entire required course and coverage in other courses), and 1 vs. 2 ((No coverage or 1 class of 1 required course vs. Multiple classes of 1 required course or multiple classes of multiple courses).

${ }^{*} p<.05,{ }^{* *} p<.01,{ }^{* * *} p<.001$. 
Table 4.14: Multivariate Multinomial Logistic Regression Examining Program

Characteristics and Course Requirements Focused on Cultural Diversity (Odds Ratios)

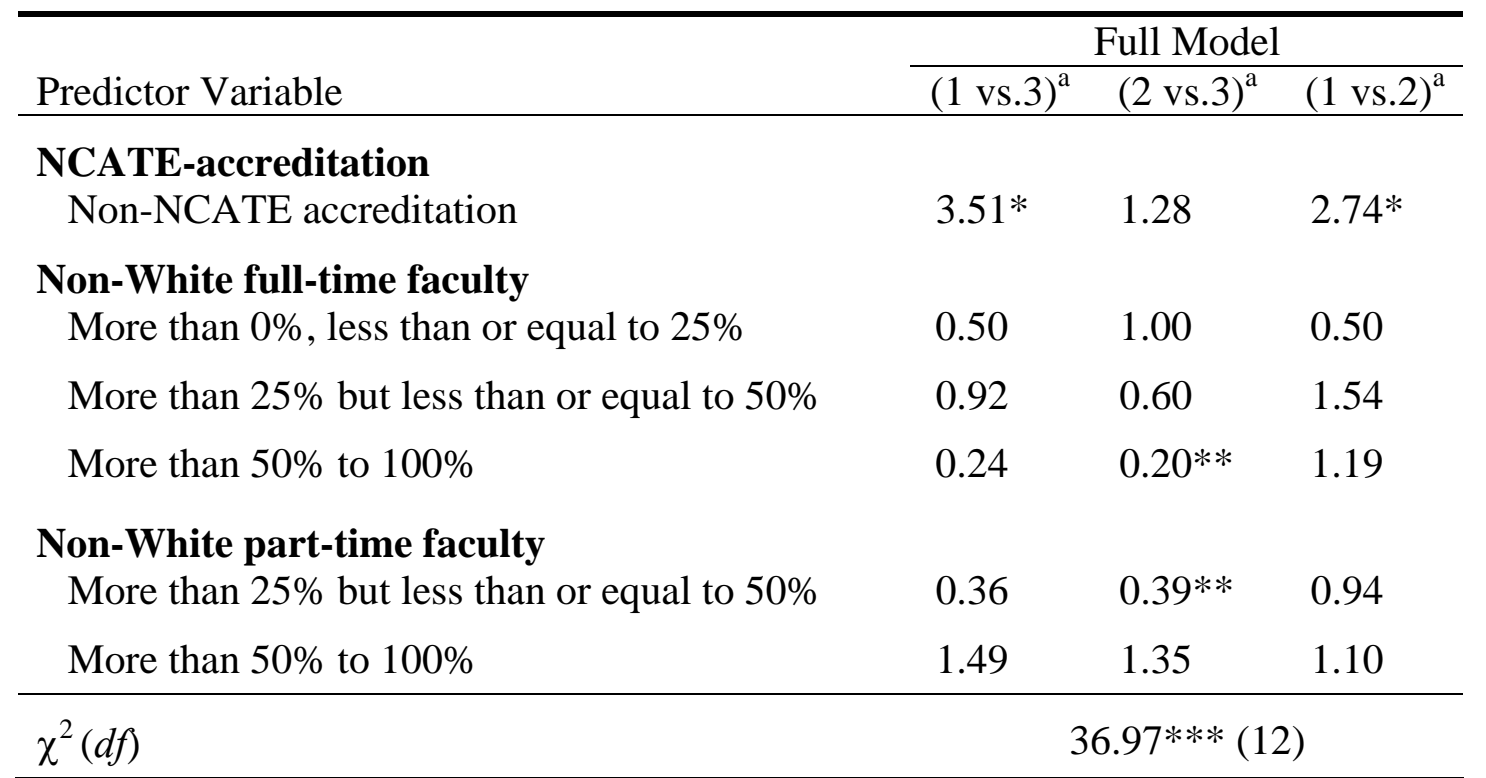

Note: $N=416$. No coverage or 1 class of 1 required course $N=21$, multiple classes of 1 required course or multiple classes of multiple courses $N=199$, entire required course or entire required course and coverage in other courses $N=196$.

${ }^{a}$ Comparisons for each predictor variable for outcome level 1 vs. 3 (No coverage or 1 class of 1 required course vs. Entire required course or Entire required course and coverage in other courses), 2 vs. 3 (Multiple classes of 1 required course or multiple classes of multiple courses vs. Entire required course or Entire required course and coverage in other courses), and 1 vs. 2 ((No coverage or 1 class of 1 required course vs. Multiple classes of 1 required course or multiple classes of multiple courses).

${ }^{*} \mathrm{p}<.05,{ }^{* *} \mathrm{p}<.01,{ }^{* * *} \mathrm{p}<.001$. 
Table 4.15: Bivariate Multinomial Logistic Regression Examining Program Characteristics and Course Requirements

Focused on Linguistic Diversity (Odds Ratios)

\begin{tabular}{|c|c|c|c|c|c|c|c|}
\hline \multirow[b]{2}{*}{ Predictor Variable } & \multicolumn{3}{|c|}{ Model 1} & \multicolumn{2}{|r|}{ Model 2} & \multicolumn{2}{|r|}{ Model 3} \\
\hline & $(1 \mathrm{vs} .3)^{\mathrm{a}}$ & $(2 \mathrm{vs} .3)^{\mathrm{a}}$ & $(1 \text { vs. } 2)^{\mathrm{a}}$ & $(1 \mathrm{vs} .3)^{\mathrm{a}}$ & $(2 \mathrm{vs} .3)^{\mathrm{a}}$ & $(1 \mathrm{vs} .2)^{\mathrm{a}}\left(^{(1 \mathrm{vs} .3)^{\mathrm{a}}}\right.$ & $(2 \text { vs. } 3)^{\mathrm{a}} \quad(1 \mathrm{vs} .2)^{\mathrm{a}}$ \\
\hline $\begin{array}{l}\text { NCATE-accreditation } \\
\text { Non-NCATE accreditation }\end{array}$ & 1.01 & 0.76 & 1.33 & & & & \\
\hline $\begin{array}{l}\text { Non-White full-time faculty } \\
\text { More than } 0 \% \text {, less than or } \\
\text { equal to } 25 \%\end{array}$ & & & & 0.47 & 0.52 & 0.90 & \\
\hline $\begin{array}{l}\text { More than } 25 \% \text { but less than or } \\
\text { equal to } 50 \%\end{array}$ & & & & 0.52 & $0.34 * *$ & 1.52 & \\
\hline More than $50 \%$ to $100 \%$ & & & & 0.44 & $0.35 *$ & 1.27 & \\
\hline
\end{tabular}

Non-White part-time faculty

More than $0 \%$, less than or

equal to $25 \%$

More than $25 \%$ but less than or

equal to $50 \%$

More than $50 \%$ to $100 \%$

$0.19 * * * \quad 0.31 * * \quad 0.60$

$0.30 * * \quad 0.28 * * \quad 1.07$

$0.44 \quad 0.36^{*} \quad 1.21$

$0.44 \quad 0.36^{*} \quad 1.21$

\begin{tabular}{llll}
\hline$\chi^{2}(d f)$ & $1.90(2)$ & $11.31(6)$ & $20.50^{* *}(6)$
\end{tabular}

Note: $N=416$. No coverage or 1 class of 1 required course $N=117$, multiple classes of 1 required course or multiple classes of multiple courses $N=$ 239, entire required course or entire required course and coverage in other courses $N=60$.

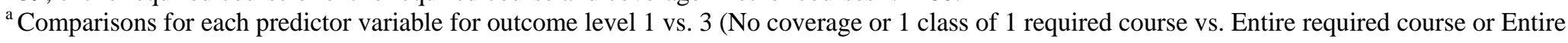
required course and coverage in other courses), 2 vs. 3 (Multiple classes of 1 required course or multiple classes of multiple courses vs. Entire required course or Entire required course and coverage in other courses), and 1 vs. 2 ((No coverage or 1 class of 1 required course vs. Multiple classes of 1 required course or multiple classes of multiple courses).

${ }^{*} p<.05,{ }^{* *} p<.01, * * * p<.001$. 
Table 4.16: Multivariate Multinomial Logistic Regression Examining Program

Characteristics and Course Requirements Focused on Linguistic Diversity (Odds Ratios)

\begin{tabular}{llll}
\hline & \multicolumn{3}{c}{ Full Model } \\
\cline { 2 - 5 } Predictor Variable & $(1 \mathrm{vs.3})^{\mathrm{a}}(2 \mathrm{vs.3})^{\mathrm{a}}(1 \mathrm{vs.2})^{\mathrm{a}}$ \\
\hline $\begin{array}{l}\text { NCATE Accreditation } \\
\quad \text { Non-NCATE accreditation }\end{array}$ & 0.78 & 0.56 & 1.39 \\
$\quad \begin{array}{llll}\text { Non-White full-time Faculty } \\
\quad \text { More than 0\%, less than or equal to 25\% }\end{array}$ & 0.57 & 0.53 & 1.07 \\
$\quad$ More than 25\% but less than or equal to 50\% & 0.70 & $0.41^{*}$ & 1.69 \\
$\quad$ More than 50\% to 100\% & 0.51 & 0.42 & 1.21 \\
$\quad$ Non-White part-time Faculty & & & \\
$\quad$ More than 0\%, less than or equal to 25\% & $0.21^{* *}$ & $0.35^{* *}$ & 0.61 \\
$\quad$ More than 25\% but less than or equal to 50\% & $0.33^{*}$ & $0.35^{*}$ & 0.92 \\
$\quad$ More than 50\% to 100\% & 0.57 & 0.51 & 1.14 \\
\hline$\chi^{2}(d f)$ & \multicolumn{3}{c}{$29.72^{* *}(14)$} \\
\hline
\end{tabular}

Note: $N=416$. No coverage or 1 class of 1 required course $N=117$, multiple classes of 1 required course or multiple classes of multiple courses $N=239$, entire required course or entire required course and coverage in other courses $N=60$.

${ }^{a}$ Comparisons for each predictor variable for outcome level 1 vs. 3 (No coverage or 1 class of 1 required course vs. Entire required course or Entire required course and coverage in other courses), 2 vs. 3 (Multiple classes of 1 required course or multiple classes of multiple courses vs. Entire required course or Entire required course and coverage in other courses), and 1 vs. 2 ((No coverage or 1 class of 1 required course vs. Multiple classes of 1 required course or multiple classes of multiple courses).

${ }^{*} p<.05, * * p<.01,{ }^{* * *} p<.001$. 
Table 4:17: Bivariate Binary Logistic Regression Examining Program Characteristics and Practicum Requirements Focused on Linguistic Diversity (Odds Ratios)

Model $1 \quad$ Model $2 \quad$ Model 3

Predictor Variable

\section{NCATE Accreditation}

Non-NCATE Accreditation

\subsection{7}

\section{Non-White full-time faculty}

More than $0 \%$ but less than or equal to $25 \%$

More than $25 \%$ but less than or equal to $50 \%$

More than $50 \%$ but less than or equal to $75 \%$

More than $75 \%$ but less than or equal to $100 \%$

Non-White part-time faculty

More than $0 \%$ but less than or equal to $25 \%$

More than 25\% but less than or equal to $50 \%$

More than $50 \%$ but less than or equal to $75 \%$

More than $75 \%$ but less than or equal to $100 \%$

\begin{tabular}{llll}
\hline$\chi^{2}(d f)$ & $0.51(1)$ & $10.90 *(4)$ & $11.46 *(4)$ \\
\hline
\end{tabular}

Note: $N=398$. No practicum requirement on working with bilingual children or children learning English as a second language $N=278$, practicum requirement on working with bilingual children or children learning English as a second language $N=120$

${ }^{*} p<.05,{ }^{* *} p<.01, * * * p<.001$. 
Table 4:18: Multivariate Binary Logistic Regression Examining Program Characteristics and Practicum Requirements Focused on Linguistic Diversity (Odds Ratios)

\begin{tabular}{|c|c|}
\hline & Full Model \\
\hline \multicolumn{2}{|l|}{ Predictor Variable } \\
\hline \multicolumn{2}{|l|}{ NCATE Accreditation } \\
\hline Non-NCATE Accreditation & 1.41 \\
\hline \multicolumn{2}{|l|}{ Non-White full-time faculty } \\
\hline More than $0 \%$ but less than or equal to $25 \%$ & 0.91 \\
\hline More than $25 \%$ but less than or equal to $50 \%$ & $2.46 * *$ \\
\hline More than $50 \%$ but less than or equal to $75 \%$ & 2.36 \\
\hline More than $75 \%$ but less than or equal to $100 \%$ & 2.23 \\
\hline \multicolumn{2}{|l|}{ Non-White part-time faculty } \\
\hline More than $0 \%$ but less than or equal to $25 \%$ & $2.03 *$ \\
\hline More than $25 \%$ but less than or equal to $50 \%$ & 0.76 \\
\hline More than $50 \%$ but less than or equal to $75 \%$ & 0.35 \\
\hline More than $75 \%$ but less than or equal to $100 \%$ & 1.93 \\
\hline$\chi^{2}(d f)$ & $22.71 * *(9)$ \\
\hline
\end{tabular}

Note: $N=398$. No practicum requirement on working with bilingual children or children learning English as a second language $N=278$, practicum requirement on working with bilingual children or children learning English as a second language $N=120$ $* p<.05, * * p<.01, * * * p<.001$. 
Table 4:19: Multivariate Multinomial Logistic Regression Examining All Contextual

Characteristics and Course Requirements Focused on Cultural Diversity (Odds Ratios)

\begin{tabular}{|c|c|c|c|}
\hline \multirow[b]{2}{*}{ Predictor Variable } & \multicolumn{3}{|c|}{ Full Model } \\
\hline & $(1 \mathrm{vs} .3)^{\mathrm{a}}$ & $(2 \mathrm{vs} .3)^{\mathrm{a}}$ & $(1 \mathrm{vs} .2)^{\mathrm{a}}$ \\
\hline \% White, non-Hispanic population & 1.04 & 1.01 & 1.03 \\
\hline \multicolumn{4}{|l|}{ Geographic Region } \\
\hline New England & 0.52 & 2.06 & 0.25 \\
\hline Mid East & 0.64 & 1.79 & 0.36 \\
\hline Great Lakes & 1.09 & 0.96 & 1.14 \\
\hline Plains and Rocky Mountains & 0.28 & 0.77 & 0.37 \\
\hline Southeast & 1.66 & 1.52 & 1.09 \\
\hline Southwest & 6.17 & 1.74 & 3.54 \\
\hline \multicolumn{4}{|l|}{ Degree of Urbanization } \\
\hline Rural & 1.81 & 0.70 & 2.58 \\
\hline Small town & 1.64 & 1.24 & 1.32 \\
\hline Large town & 0.65 & 0.87 & 0.75 \\
\hline Urban fringe of mid size city & 0.41 & 1.05 & 0.39 \\
\hline Urban fringe of large city & 0.21 & 0.61 & 0.35 \\
\hline Mid-size city & 0.73 & 0.77 & 0.96 \\
\hline \multicolumn{4}{|l|}{ Governance } \\
\hline Private & 1.71 & 1.06 & 1.62 \\
\hline \multicolumn{4}{|l|}{ NCATE-accreditation } \\
\hline Non-NCATE accredited & $3.97^{*}$ & 1.29 & 3.08 \\
\hline \multicolumn{4}{|l|}{ Non-White full-time faculty } \\
\hline More than $0 \%$, less than or equal to $25 \%$ & 0.50 & 1.03 & 0.49 \\
\hline More than $25 \%$ but less than or equal to $50 \%$ & 1.03 & 0.63 & 1.65 \\
\hline More than $50 \%$ to $100 \%$ & 0.22 & $0.19 * *$ & 1.15 \\
\hline \multicolumn{4}{|l|}{ Non-White part-time faculty } \\
\hline More than $25 \%$ but less than or equal to $50 \%$ & 0.38 & $0.43^{*}$ & 0.88 \\
\hline More than $50 \%$ to $100 \%$ & 0.97 & 1.26 & 0.77 \\
\hline$\chi^{2}(d f)$ & & $63.30 *(40$ & \\
\hline
\end{tabular}

Note: $N=416$. No coverage or 1 class of 1 required course $N=21$, multiple classes of 1 required course or multiple classes of multiple courses $N=199$, entire required course or entire required course and coverage in other courses $N=196$.

${ }^{a}$ Comparisons for each predictor variable for outcome level $1 \mathrm{vs.} 3$ (No coverage or 1 class of 1 required course vs. Entire required course or Entire required course and coverage in other courses), 2 vs. 3 (Multiple classes of 1 required course or multiple classes of multiple courses vs. Entire required course or Entire required course and coverage in other courses), and 1 vs. 2 ((No coverage or 1 class of 1 required course vs. Multiple classes of 1 required course or multiple classes of multiple courses).

${ }^{*} \mathrm{p}<.05,{ }^{* *} \mathrm{p}<.01,{ }^{* * *} \mathrm{p}<.001$. 
Table 4:20: Multivariate Multinomial Logistic Regression Examining All Contextual

Characteristics and Course Requirements Focused on Linguistic Diversity (Odds Ratios)

\begin{tabular}{|c|c|c|c|}
\hline \multirow[b]{2}{*}{ Predictor Variable } & \multicolumn{3}{|c|}{ Full Model } \\
\hline & $(1 \mathrm{vs} .3)^{\mathrm{a}}$ & $(2 \text { vs.3 })^{\mathrm{a}}$ & (1 vs.2) \\
\hline \% White, non-Hispanic population & $1.04 *$ & 1.03 & 1.01 \\
\hline \multicolumn{4}{|l|}{ Geographic Region } \\
\hline New England & 0.28 & 0.78 & 0.36 \\
\hline Mid East & 1.29 & 1.75 & 0.74 \\
\hline Great Lakes & 0.47 & 0.75 & 0.63 \\
\hline Plains and Rocky Mountains & 2.54 & 5.94 & 0.43 \\
\hline Southeast & 0.27 & 0.36 & 0.75 \\
\hline Southwest & 0.71 & 0.76 & 0.94 \\
\hline \multicolumn{4}{|l|}{ Degree of Urbanization } \\
\hline Rural & 1.12 & 0.31 & $3.60 *$ \\
\hline Small town & 1.12 & 1.86 & 0.60 \\
\hline Large town & 2.75 & 3.60 & 0.76 \\
\hline Urban fringe of mid size city & 1.60 & 1.64 & 0.98 \\
\hline Urban fringe of large city & $0.27 *$ & $0.31 *$ & 0.87 \\
\hline Mid-size city & 0.86 & 1.02 & 0.84 \\
\hline \multicolumn{4}{|l|}{ Governance } \\
\hline Private & 1.72 & $2.68 *$ & 0.64 \\
\hline \multicolumn{4}{|l|}{ Type of Institution } \\
\hline Non-HBCU & 0.69 & 0.57 & 1.22 \\
\hline \multicolumn{4}{|l|}{ NCATE-accreditation } \\
\hline Non-NCATE Accredited & 0.54 & $0.31 * *$ & 1.73 \\
\hline \multicolumn{4}{|l|}{ Non-White full-time faculty } \\
\hline More than $0 \%$, less than or equal to $25 \%$ & 0.63 & 0.61 & 1.03 \\
\hline More than $25 \%$ but less than or equal to $50 \%$ & 0.54 & 0.53 & 1.58 \\
\hline More than $50 \%$ to $100 \%$ & 0.63 & 0.47 & 1.00 \\
\hline \multicolumn{4}{|l|}{ Non-White part-time faculty } \\
\hline More than $0 \%$, less than or equal to $25 \%$ & $0.85 * *$ & 0.42 & 0.52 \\
\hline More than $25 \%$ but less than or equal to $50 \%$ & 0.47 & 0.44 & 0.89 \\
\hline More than $50 \%$ to $100 \%$ & 0.22 & 0.52 & 1.29 \\
\hline$\chi^{2}(d f)$ & \multicolumn{3}{|c|}{$84.41 * * *(44)$} \\
\hline
\end{tabular}

Note: $N=416$. No coverage or 1 class of 1 required course $N=117$, multiple classes of 1 required course or multiple classes of multiple courses $N=239$, entire required course or entire required course and coverage in other courses $N=60$.

${ }^{a}$ Comparisons for each predictor variable for outcome level 1 vs. 3 (No coverage or 1 class of 1 required course vs. Entire required course or Entire required course and coverage in other courses), 2 vs. 3 (Multiple classes of 1 required course or multiple classes of multiple courses vs. Entire required course or Entire required course and coverage in other courses), and 1 vs. 2 ((No coverage or 1 class of 1 required course vs. Multiple classes of 1 required course or multiple classes of multiple courses).

${ }^{*} p<.05,{ }^{* *} p<.01,{ }^{* * *} p<.001$. 
Table 4:21: Multivariate Binary Logistic Regression Examining All Contextual

Characteristics and Practicum Requirements Focused on Linguistic Diversity (Odds Ratios)

\begin{tabular}{|c|c|}
\hline Predictor Variable & Full Model \\
\hline Percentage of White, non-Hispanic population & $0.96 * *$ \\
\hline \multicolumn{2}{|l|}{ Geographic Region } \\
\hline New England & $9.01 * *$ \\
\hline Mid East & $5.02 *$ \\
\hline Great Lakes & 3.42 \\
\hline Plains & $5.85 *$ \\
\hline Southeast & $5.90 * *$ \\
\hline Southwest & $4.55^{*}$ \\
\hline Rocky Mtns & $14.31 * *$ \\
\hline \multicolumn{2}{|l|}{ Degree of Urbanization } \\
\hline Rural & 0.33 \\
\hline Small town & 0.79 \\
\hline Large town & 0.32 \\
\hline Urban fringe of mid size city & 0.42 \\
\hline Urban fringe of large city & 0.76 \\
\hline Mid-size city & 0.58 \\
\hline \multicolumn{2}{|l|}{ Governance } \\
\hline Private & 0.87 \\
\hline \multicolumn{2}{|l|}{ Type of Institution } \\
\hline Non-HBCU & 1.17 \\
\hline \multicolumn{2}{|l|}{ NCATE accreditation } \\
\hline Non-NCATE Accreditation & 1.49 \\
\hline \multicolumn{2}{|l|}{ Non-White full-time faculty } \\
\hline More than $0 \%$ but less than or equal to $25 \%$ & 0.85 \\
\hline More than $25 \%$ but less than or equal to $50 \%$ & $2.10 *$ \\
\hline More than $50 \%$ but less than or equal to $75 \%$ & 1.78 \\
\hline More than $75 \%$ but less than or equal to $100 \%$ & 2.46 \\
\hline \multicolumn{2}{|l|}{ Non-White part-time faculty } \\
\hline More than $0 \%$ but less than or equal to $25 \%$ & $2.03 *$ \\
\hline More than $25 \%$ but less than or equal to $50 \%$ & 0.73 \\
\hline More than $50 \%$ but less than or equal to $75 \%$ & 0.27 \\
\hline More than $75 \%$ but less than or equal to $100 \%$ & 1.37 \\
\hline$\chi^{2}(d f)$ & $50.49 * *(25)$ \\
\hline
\end{tabular}

Note: $N=398$. No practicum requirement on working with bilingual children or children learning English as a second language $N=278$, practicum requirement on working with bilingual children or children learning English as a second language $N=120$

${ }^{*} p<.05,{ }^{* *} p<.01, * * * p<.001$. 
Table 4.22: Predictors of Coursework and Practica Focused on Cultural and Linguistic Diversity $(\mathrm{p}<.05)$

\begin{tabular}{|c|c|c|c|c|c|c|c|c|c|}
\hline \multirow[t]{2}{*}{ Predictor } & \multicolumn{3}{|c|}{$\begin{array}{l}\text { Coursework focused on cultural } \\
\text { diversity }\end{array}$} & \multicolumn{3}{|c|}{$\begin{array}{l}\text { Coursework focused on linguistic } \\
\text { diversity }\end{array}$} & \multicolumn{3}{|c|}{$\begin{array}{l}\text { Practica focused on linguistic } \\
\text { diversity }\end{array}$} \\
\hline & Bivariate & $\begin{array}{l}\text { Context } \\
\text { Specific }\end{array}$ & $\begin{array}{l}\text { Across } \\
\text { Contexts }\end{array}$ & Bivariate & $\begin{array}{l}\text { Context } \\
\text { Specific }\end{array}$ & $\begin{array}{l}\text { Across } \\
\text { Contexts }\end{array}$ & Bivariate & $\begin{array}{l}\text { Context } \\
\text { Specific }\end{array}$ & $\begin{array}{l}\text { Across } \\
\text { Contexts }\end{array}$ \\
\hline $\begin{array}{l}\text { Geographical } \\
\text { Context }\end{array}$ & & & & & & & & & \\
\hline $\begin{array}{l}\text { Percentage of White, } \\
\text { non-Hispanic }\end{array}$ & & & & $\checkmark$ & & & $\checkmark$ & $\checkmark$ & $\checkmark$ \\
\hline Geographic Region & & & & $\checkmark$ & & & & $\checkmark$ & $\checkmark$ \\
\hline $\begin{array}{l}\text { Degree of } \\
\text { Urbanization }\end{array}$ & & & & $\checkmark$ & $\checkmark$ & $\checkmark$ & & & \\
\hline $\begin{array}{l}\text { Institutional } \\
\text { Characteristics }\end{array}$ & & & & & & & & & \\
\hline Governance & & & & & & $\checkmark$ & & & \\
\hline Type of Institution & - & - & - & & & & & & \\
\hline $\begin{array}{l}\text { Program } \\
\text { Characteristics }\end{array}$ & & & & & & & & & \\
\hline $\begin{array}{l}\text { NCATE } \\
\text { Accreditation }\end{array}$ & $\checkmark$ & $\checkmark$ & & & & $\checkmark$ & & & \\
\hline $\begin{array}{l}\text { Non-White Full-time } \\
\text { Faculty }\end{array}$ & $\checkmark$ & $\checkmark$ & $\checkmark$ & & & & $\checkmark$ & $\checkmark$ & \\
\hline $\begin{array}{l}\text { Non-White Part-time } \\
\text { Faculty }\end{array}$ & $\checkmark$ & $\checkmark$ & & $\checkmark$ & $\checkmark$ & & $\checkmark$ & $\checkmark$ & \\
\hline
\end{tabular}




\section{DISCUSSION}

In this chapter, a summary of major findings will first be presented, followed by recommendations, a review of the study limitations, and future research.

\section{Summary of Major Findings}

This study addressed three research questions: 1) to what extent do geographical contexts (i.e., percentage of White, non-Hispanic population, geographic region, and degree of urbanization) predict cultural and linguistic course and practica requirements in early childhood teacher preparation programs?, 2) to what extent do institutional characteristics (i.e., governance, type of institution) predict cultural and linguistic diversity course and practica requirements in early childhood teacher preparation programs? and 3) to what extent do program characteristics (i.e., NCATE accreditation status, presence of non-White fulltime and part-time faculty) predict cultural and linguistic diversity course and practica requirements in early childhood teacher preparation programs? Table 5.1 presents results of the hypotheses in the bivariate, within context, and across contexts models. Only significant results from the multivariate logistic regressions across contexts will be discussed. The discussion of the findings is organized by the geographical, institutional, and program characteristics and followed by a discussion of the need for equal emphasis on linguistic and cultural diversity.

Geographical characteristics

Percentage of non-Whites in the state tied to practica requirements focused on linguistic diversity. Results from the study show that Bachelor's programs in states with a 
larger non-White population were more likely to require a practicum focused on linguistic diversity when all variables were controlled as compared to programs in states with more non-Hispanic White population. In states with more non-Whites, it is probably more common to have children and families who speak a language other than English. For example, 56.9\% of the population in New Mexico were non-Whites, and 36.4\% of the population spoke a language other than English at home (U.S. Census Bureau, 2004a). As compared to New Mexico, West Virginia has 5.4\% of non-Whites in the state population, and only $2.1 \%$ of the state population spoke a language other than English at home (US Census Bureau, 2004a). Therefore it is possible that programs in states like New Mexico may feel more urgency than programs in states like West Virginia to prepare early childhood teachers to respond to the needs of linguistically diverse populations in their communities.

States with more non-Whites in the population also may have policies in place that mandate teacher preparation programs to have coverage in diversity issues. For example, New Mexico, which has a large multilingual population, requires a teacher licensure model including cultural competence for all teaching licenses (Stayton, Jones, Smith-Bonahue, Strangis, Conroy, Derer, et al., 2003). State policies may also affect practica requirements (Isenberg, 2001; Morgan, 2002; Weiner, Rand, \& Pagano, 2001).

Finally, it is likely that programs in states with more non-Whites in the population are able to require practicum focused on linguistic diversity because they have the resources and field sites available in their community to provide student teachers with opportunities to work with children and families who are bilingual or who speak a language other than English. 
Practica requirements in linguistic diversity differ in different regions in the United

States. All regions in the United States except for the Great Lakes were more likely to require a practicum in linguistic diversity as compared to programs in the Far West. Compared to all other regions, there was a higher percentage of the population who spoke a language other than English in the Far West (U.S. Census Bureau, 2004a). Given this, it would be expected that programs in the Far West might be more likely to require practica focused on linguistic diversity. However, descriptive statistics from this current study indicate that only about $8 \%$ of Bachelor's degree programs in the Far West required practica working with bilingual children learning English as a second language as compared to 25\% of programs in the Southeast. Results from a study on early childhood teacher preparation programs in California also indicated that many programs in California still do not provide coverage in bilingualism and dual language learning although the number of dual language learners is increasing (Whitebook, Belm, Lee, \& Sakai, 2005). It is also possible that programs in other parts of the country required more practica in linguistic diversity because of the rapid growth in non-native English speakers, rather than simply the current percentage of non-native English speakers. A recent study by the Center for Immigration Studies showed that states with historically less linguistic diversity such as Georgia, Virginia, North Carolina, Tennessee, Rhode Island, South Dakota, and Wyoming had statistically significant growth in immigration population between 2000 to 2005 (Camarota, 2005).

In sum, there is an urgent need for early childhood programs across the states, especially those in the Far West, to require practica focused on linguistic diversity given the changing demographics. 
Degree of urbanization. As expected, programs in rural areas were less likely to require coursework focused on linguistic diversity when compared to programs in large cities. These results are supported by data from the 2005 American Community Survey (U.S. Census, 2005) that indicated about $40 \%$ of the population in urban areas was nonWhite as compared to $15 \%$ of the population in rural areas. Similar to findings regarding other geographical variables, it is possible that programs tend to cater to the needs of their local communities, thus providing training in linguistic diversity may not be as high of a priority for programs in rural areas than for programs in urban areas.

It is interesting that programs in urban fringes of large cities required more coursework focused on linguistic diversity than programs in large cities. One might expect teachers in urban schools to be most likely to work with more culturally and linguistically diverse children (Duarte \& Reed, 2004; Horm, 2003) and therefore expect teacher preparation programs in urban communities to have more requirements focused on linguistic diversity. A study on suburban migration trends by the Center on Urban and Metropolitan Policy at the Brookings Institution (Frey, 2001) using the 2000 Census data, suggests otherwise. Ethnic minority populations in the suburbs have grown by about $8 \%$ between 1990 and 2000 and were found to represent more than a quarter of the population in urban fringes of large cities. Non-Whites were also the largest contributors of the population boom in urban fringes of large cities such as Los Angeles, Houston, New York, Washington, D.C., and cities in the South. These findings suggest that non-White migration is no longer just limited to large cities, and that it is imperative for early childhood teacher preparation programs across the states to ensure that teachers are prepared to work with children and families who are linguistically and culturally diverse. These findings also suggest that 
programs in large cities may need to do more to ensure coursework focused on linguistic diversity is required.

\section{Institutional characteristics}

Governance of institution. Currently there is a lack of research in both early childhood and K-12 education regarding the relationship between the type of institution (public and private) and coursework and practica in teacher preparation programs. Results from this study indicate that programs in public universities were more likely to require at least one complete course in working with bilingual children. Only about 7\% of NCATEaccredited programs in private institutions required at least one complete course in working with bilingual children as did about $15 \%$ of NCATE-accredited programs in public universities. This may suggest that for more coursework focused on working with bilingual children to be required, a program had to be NCATE-accredited as well as be part of a public institution. However, the suppressor effect between the two variables suggests a complicated relationship that requires further study to fully understand.

\section{Program characteristics}

NCATE-accreditation. NCATE-accredited programs were less likely to require at least one complete course focused on linguistic diversity as compared to non-NCATEaccredited programs. As discussed earlier, this finding needs to be interpreted with caution because of the suppressor effect when both NCATE accreditation and governance of institutions were included in the same logistic regression model. NCATE accreditation may have had a different relationship in public versus private IHEs because many private IHEs may be accredited by TEAC instead of NCATE (Ewell, 2001). Ewell posited that private institutions may prefer to seek TEAC accreditation because NCATE places strong emphasis 
on several indicators such as facilities, faculty credentials, and research production that may be difficult for small private liberal arts colleges to meet.

The findings also suggest NCATE accreditation may emphasize cultural diversity over linguistic diversity. A review of the NCATE standard on diversity may help us understand the differential effects of NCATE accreditation on coursework focused on linguistic and cultural diversity. Throughout the document, there is a lack of emphasis on linguistic diversity. One of the main goals of this standard is "the development of educators who can help all students learn and who can teach from multicultural and global perspectives that draw on the histories, experiences, and representations of students from diverse cultural backgrounds” (NCATE, 2006). For example, for the standards on experiences working with diverse students in P-12 schools, a program that has acceptable diversity practices does not need to provide experiences working with linguistically diverse faculty, candidates or students. Instead, linguistic diversity is usually the component of diversity that is the target standard (NCATE, 2006), so it is possible for programs to have addressed cultural diversity but not linguistic diversity.

The presence of non-White faculty matters. The presence of non-White full-time faculty positively impact coursework focused on cultural diversity. This confirms the suggestion made by several researchers in the field that having a heterogeneous pool of faculty may be a promising strategy to prepare culturally competent early childhood personnel (Early \& Winton, 2001; Maxwell \& Clifford, 2004; Winton, McCollum, \& Catlett, in press). Ladson-Billings (2005) proposed non-Hispanic White faculty may be even more far removed from the realities of increasingly diverse classrooms because of their positions as higher education faculty. 
There are no existing studies in the field of early childhood education that examine why the presence of non-White faculty may make a positive difference on coursework focused on cultural diversity. Evidence from early intervention and higher education fields may shed light on this issue. Results from a study on early intervention personnel preparation indicate that the degree to which coursework and practica focused on infants and toddlers were infused in early intervention personnel preparation programs depended on faculty comfort level in teaching this content as well as their expertise (Stayton \& Bruder, 1999). Similarly, non-White faculty members may be more comfortable addressing diversity issues and may also have more personal experiences that they could apply to their teaching.

Higher education research has shown that non-White faculty are more likely than White faculty to address diversity issues in their coursework (Maruyama \& Moreno, 2000; Mayhew \& Grunwald, 2006). A survey conducted on a representative national sample of college and university faculty in social sciences, humanities, education, and business revealed that faculty of color significantly differed in their attitude towards diversity (Maruyama \& Moreno). For example, non-White faculty were found to see the benefits of diversity on classrooms, students, teaching, and research and were also more likely to feel more prepared to deal with diversity as compared to White, non-Hispanic faculty.

In summary, research from early intervention and higher education shed some light on why having heterogeneous faculty members is crucial in ensuring that diversity components are included in early childhood teacher preparation programs. Comfort level and having personal experiences and knowledge about diversity issues are some possible reasons why non-White faculty may impact the amount of coursework focused on cultural diversity. 
The need for equal emphasis on linguistic and cultural diversity

Most significant findings in this study were related to linguistic diversity, indicating that coursework or practica requirements focused on linguistic diversity were more variable across programs, and were more likely to be affected by contextual characteristics as compared to course requirements focused on cultural diversity. Linguistic diversity demands as much attention as cultural diversity.

Teachers need to understand that the process of maintaining children's home language while concurrently developing a second language will bring about positive cognitive, academic and linguistic outcomes because of a common underlying proficiency (Cummins, 2000). Findings from a longitudinal study examining literacy development in elementary school second-language learners suggest that first-language reading skills are related to second-language reading skills, and that children who were instructed bilingually achieved similar levels of English and Spanish proficiency as students who were instructed in one language or the other (August, et al., 2006). Similarly, a study examining English language learners' (ELLs) placement patterns in special education indicated that ELLs in English immersion programs were more likely to be placed in special education programs as compared to ELLs in other language support programs (Artiles, Rueda, Salazar, \& Higareda, 2005). In addition, children’s fluency in their home language helps them to communicate with parents and other members of the community who in turn provide socioemotional support and enhance children's self-worth and reinforce their identity (Wong-Fillmore, 1991). All these findings imply that teacher preparation programs should ensure that opportunities are made to support teachers in developing the necessary skills and knowledge in working with bilingual children learning English as a second language. 
As discussed earlier, this equal importance on both types of diversity should also be emphasized in standards such as NCATE accreditation that guide IHEs. Researchers may also need to consider treating linguistic and cultural diversity as two separate constructs in their effort to better understand diversity issues in early childhood teacher preparation programs.

\section{Recommendations}

Findings from this study indicate the importance of community context in early childhood teacher preparation programs. For example, states with more non-Whites in the population were more likely to require practica focused on working with bilingual children. Even for programs in communities with fewer minorities though, demographic data on the rapidly changing population suggest that it is critical for all programs to address diversity in coursework and practica. Within a short span of two years, the number of non-Hispanic White fell by over 3\% from 63.1\% to 59.8\% in Nevada (U.S. Census Bureau, 2003; 2005). Evidently, there is a need for faculty in early childhood teacher preparation programs to revise their current programs to include opportunities for teacher candidates to develop skills and competencies necessary to work with an increasingly diverse population.

In the field of early intervention, Bruder and Dunst (2005) found that faculty have not included content and recommended practices focused on family-centered practices that were introduced 15 years ago. Institutions are slow in responding to change (Levine, 2006). Teaching and service demands of faculty (Lim \& Able-Boone, 2005) and high studentfaculty ratios (Early \& Winton, 2001) may be reasons why many teacher preparation programs are lagging behind in revamping coursework and practica. 
In light of these findings and the barriers that exist in institutions of higher education, what can be done to encourage more diversity coverage in coursework and practica? Align standards, policies, curriculum, and professional development efforts

The Division for Early Childhood (DEC) and National Association for the Education of Young Children (NAEYC) have both delineated recommended practices for personnel preparation programs based on empirical research of practices that best predict positive outcomes for children and families. Both have recommended that personnel preparation programs provide early childhood professionals opportunities to (1) develop an awareness and knowledge of one’s own heritage and culture; (2) develop an understanding and knowledge of others (in a non-stereotypical way); (3) understand the influence of culture, ethnicity, and socioeconomic status; (4) balance children's cultural and linguistic needs with preparing them to meet societal needs; (5) recognize power differences between themselves and families and children; (6) develop a variety of alternative strategies to meet the diverse needs of children; and (7) develop good communication and interaction skills (see NAEYC, 2001 and Stayton, Miller, \& Dinnebeil, 2003).

Despite these guidelines, results from this study indicate that required coursework and practica focused on cultural and linguistic diversity were not consistent across the states, but were determined by contextual characteristics such as the presence of non-White faculty in a program or the diversity of the population in a state instead. These findings echo observations by Isenberg (2001) who commented that many early childhood programs in institutes of higher education were still not guided by NAYEC or DEC standards but were instead led by standards set by individual states. Additionally, the provision of early childhood teacher preparation may also be fragmented and vary in quality because of the lack 
of coordination and agreement among various stakeholders (Winton, McCollum, \& Catlett, in press). In a study on Schools of Education, Levine (2006) found that the required amount of preparation was different from program to program and, therefore, teachers with the same degree may be prepared differently to teach in the same schools. The inconsistency of course and practica requirements focused on diversity across programs may also explain why there is a lack of relationship between early childhood teachers with Bachelor's degrees and classroom quality and outcomes (Early, Bryant, Pianta, Clifford, Burchinal, Ritchie, et.al., 2006).

Winton, McCollum and Catlett (in press) posit that an alignment of personnel and program standards, policies, curriculum, assessment and professional development is necessary to bring about positive changes in teacher preparation programs. Currently the educational experience of a teacher candidate is driven mostly by state licensing standards and mandates and other nonprofessional political channels (Bredekamp, 1996; Isenberg, 2001; Welch-Ross, Wolf, Moorehouse, \& Rathgeb, 2005), and may not be aligned to the guidelines defined by early childhood professional organizations like DEC and NAEYC. Because teacher preparation programs are embedded within multiple social contexts, having various stakeholders come together to set common goals and priorities may bring about the allocation of more resources and better coordinated effort in ensuring that diversity issues are covered in coursework and practica. Dialogues that bring together various stakeholders in the field could be created at both local (e.g. state-level NAEYC annual meeting) and national (e.g. NAEYC or DEC annual conferences) levels. 


\section{Create opportunities for teachers to develop cultural competence}

It is critical that teachers across the country be given opportunities to develop skills, knowledge and dispositions to work with children and families who are culturally and linguistically diverse regardless of how many non-White children they have in their classroom. A review of literature by the AERA panel on K-12 teacher education showed that teacher candidates have limited experiences and may hold negative attitudes towards people who are different from themselves (Hollins \& Guzman, 2005).

Several strategies have been identified as promising in developing cultural competency: 1) infusion of cultural diversity into the entire program, 2) campus-community partnerships, 3) providing opportunities for teacher candidates to confront their own biases and prejudices, and 4) field experiences to work with children and families whose backgrounds are different from the teacher candidates’ (Lim \& Able-Boone, 2005). It is recognized, however, that finding a practicum site with culturally and linguistically diverse children may be hard if the community that a program is situated in is not diverse. Interinstitutional collaboration that enables relocation of teacher candidates from monocultural or rural settings to urban or more diverse settings may be a plausible strategy to enable teacher candidates from less diverse communities to have first-hand experience in working in diverse classrooms (Hollins \& Guzman, 2005). Additionally, programs in less diverse communities may have less expertise or resources to provide students with opportunities to acquire the necessary knowledge and skills to work with all children. This may be solved by having programs engage in inter-institutional videoconferencing and online learning, engaging diverse families as co-instructors, or school-community partnerships. 


\section{Recruit and retain more non-White faculty}

From this study, the presence of non-White full-time faculty positively affected course requirements focused on cultural diversity. Researchers in the field of early childhood education have suggested that having racial/ethnic diversity among faculty members may also encourage students of color to pursue advanced degrees because of the availability of role models (Isenberg, 2001; Washington, 2005). Given that the presence of non-White faculty may lead to better preparation of culturally competent teachers and a more diverse pool of early childhood teachers, programs need to make recruitment of non-White faculty a priority.

Early childhood teacher programs indicated that attracting and retaining ethnically and linguistically diverse faculty was a large challenge (Maxwell, Lim, \& Early, 2006). Efforts should be made at all levels to better understand barriers and supports in diversifying early childhood education faculty. For example, the Schott Foundation for Public Education held a series of dialogues on diversity in Massachusetts for various stakeholders with vested interest in early education and care (Washington, 2005). The foci of the dialogues were to 1) better understand the needs of children and professionals from Latino, Asian, and African American heritage, 2) examine how leadership is shared across ethnic groups within one state, and 3) identify the types of institutional challenges and leadership for communities of color. Besides developing effective strategies to involve communities of color as partners for systemic change and identifying needs and priorities in the state, one of the major outcomes of the series of dialogues was the development of the Schott Fellowship in Early Care and Education that supports and sustains diverse leaders in the field (Washington). 


\section{Professional development opportunities for existing faculty}

As suggested by findings in this study, the recruitment and retention of non-White faculty is critical. Yet about $80 \%$ of the faculty were White, non-Hispanic (Maxwell, Lim, \& Early, 2006). Faculty in teacher training programs may need to confront their own biases and values before they develop a program to address the needs of teachers and children so that they do not inadvertently prepare future teachers for a monolingual and monocultural society (Ray, Bowman, \& Robbins, 2006). Winton (2006) suggested that faculty members are knowledge mediators who need to have and use "a solid knowledge base of evidence-based practices in key early childhood content areas” (p.86). In order to have current faculty prepared to teach about diversity, it is suggested that state and federal resources be directed at professional development opportunities for faculty to gain expertise and comfort teaching about issues related to culture, race and racism, language and bias (Early \& Winton, 2001; Horm, 2003; Isenberg, 2001). Professional development initiatives such as Walking the Walk and Crosswalks (Winton \& Catlett, n.d.) helped faculty increase skills and knowledge in addressing cultural and linguistic diversity. The project began with the identification of needs and priorities for addressing diversity issues in urban communities in North Carolina; then provided materials and resources for community-based teams of family members, faculty, students, administrators, and practitioners to develop an action plan to address diversity issues. The project also provided technical assistance and follow-up training over an 18 month period to support the implementation of action plans.

\section{Limitations}

The following limitations should be taken into account when interpreting the results from the study. First, the use of existing databases limited this study in the number of 
contextual characteristics and the way these characteristics were measured. For instance, the response category for practica requirements was dichotomous and did not provide data about the variability or intensity of practica. With regard to coursework, data were gathered about course requirements only, with the assumption that more course coverage is better. Detailed data about the content and quality of instruction were not gathered. In short, the degree and quality of infusing diversity content into coursework were not available. We also only gathered information from one or two individuals at each institution instead of gathering information from program graduates, students, or other faculty. Collecting data from a range of stakeholders would have yielded a richer and more complete understanding of programs.

A third limitation of this study is its reliance on self-reported data. The individuals who provided the information were chairs or program directors who had a good knowledge of their programs. However, information was not verified by reviewing program reports or other data sources. Fourth, the scope of this study was limited to only cultural and linguistic diversity. Other forms of diversity such as differences in ability, learning styles, and gender are also important and require additional study.

Fifth, results from this study need to be interpreted with caution because there was a suppressor effect when both NCATE accreditation and governance of institutions were included in the same logistic regression model when coursework related to linguistic diversity was the outcome variable. The suppressor effect suggests there may be a more complicated relationship between NCATE accreditation and governance of institutions that requires further study to fully understand. Finally, the combination of "multiple class sessions of multiple required courses” and "multiple class sessions of multiple required courses” into one category for logistic regression reduced the variability of coursework 
requirements across contexts. However, the grouping was necessary because logistic regression analyses cannot be conducted when group sizes are too small as they were in this study.

\section{Future Research}

This study examined predictors of coursework and practica focused on cultural and linguistic diversity in early childhood Bachelor's degree programs. The results showed the extent to which the presence of non-White faculty, NCATE accreditation, percentage of nonHispanic White in individual states, geographic region, and degree of urbanization predicted coursework and practica focused on cultural and linguistic diversity. Although information from the NPC survey provided a snapshot of early childhood teacher preparation programs, it does not provide data about the quality and impact of personnel development efforts related to diversity. Neither does it inform us about the impact of these efforts on children and families. Results from this study should prompt efforts to expand knowledge in two key areas: 1) characteristics of programs that impact coursework and practica focused on both cultural and linguistic diversity and 2) the impact of diversity-related pre-service training on practitioners.

Characteristics that impact coursework and practica focused on cultural and linguistic diversity

Given that this research only focused on Bachelor's degree programs, future research should study predictors of diversity-related coursework and practica requirements in the Associate's and Master's degree programs. Studying coursework and practica requirements in the different degree programs will enable us to have a better understanding of the complexity and variation between and among programs, and provide knowledge on the 
different conditions and contexts of early childhood teacher preparation programs specifically related to diversity practices.

Although this study demonstrated the importance of the presence of non-White fulltime faculty on cultural diversity coursework, we do not know how and why the percentage of non-White full-time faculty affects what is taught in a teacher preparation program. Is it, for instance, non-White faculty’s comfort level and expertise in diversity issues? In-depth studies are needed to understand the mechanisms by which faculty race and ethnicity impact teacher preparation programs.

Results from this study should also prompt efforts to collect more comprehensive data on other contextual characteristics that may influence the quality of diversity in early childhood teacher preparation programs such as the impact of the presence of non-White students on White students or the overall institutional climate with regard to cultural and linguistic diversity, and the infusion of diversity content into existing curricula. Because teacher preparation programs are embedded within a social context, it is also important to examine the overall climate for racial and ethnic diversity of an institution. It is posited that campus climate such as attitudes, perceptions, expectations, and intentionality of the institution and its members intertwines with teaching and learning in institutions of higher education, and therefore requires careful assessment (Hurtado, Milem, Clayton-Pedersen, \& Allen, 1999). Winton McCollum, and Catlett (in press) recommend a conceptual framework for implementing and evaluating professional development. The framework addresses the complexities of professional development systems and recognizes the different layers of organizational, institutional and individual factors that affect program implementation and practices. These many contextual layers need future research to fully understand. 
The impact of diversity-related pre-service training efforts on practitioners

This study examined certain aspects of teacher preparation programs but did not study the impact of coursework and practica on teacher's practice in the classroom. Additional research is needed to understand how best to provide early childhood teachers with knowledge and skills to support English Language Learners and the contexts, pedagogy or instruction that may most effectively develop culturally competent practitioners.

Research on the impact of education on teacher practices would require the development of a valid and reliable measure would have to be developed. Currently, there is not a valid and reliable measure that adequately examines diversity practices in classroom environment. Researchers at the National Center for Early Development and Learning (NCEDL) developed the Anti-Bias Curriculum Measure adapted from the Anti-Bias curriculum (Dermon-Sparks \& the A.B.C. Taskforce, 1989) to measure a child care center's approach to anti-bias curriculum (Peisner-Feinberg, Howes, \& Jarvis-McMillan, 2004). The measure developed by NCEDL researchers is promising but needs to be tested for validity and internal consistency (Peisner-Feinberg, Howes, \& Jarvis-McMillan). Measurement tools that examine teacher beliefs and behavioral observation coding to study classroom practices related to cultural and linguistic diversity may also be developed to supplement global quality measures such as the ECERS-R (Harms, Clifford, \& Cryer, 2004).

\section{Conclusion}

This study identified contextual characteristics related to Bachelor's coursework and practica requirements for cultural and linguistic diversity. The contexts of teacher preparation programs are very important determinants of program outcomes, yet the contexts of programs are still relatively unknown (Cochran-Smith \& Zeichner, 2005; Hollins \& Guzman, 
2005; Winton, 2006). This study marks an important step in helping the field understand the different conditions and contexts of early childhood teacher preparation programs specifically related to diversity practices in terms of both cultural and linguistic diversity. There are still many gaps in knowledge regarding how best to prepare culturally responsive teachers. Given the current concerns about early childhood teacher education (Early, Bryant, et al., 2006), achievement gaps between children of color and Whites (Hair, Halle, Terry-Humen, Lavelle, \& Calkins, in press; Zill, Collins, \& West, 1995), and disproportionate representation of non-White students in special education programs (National Research Council, 2002), more needs to be done to improve research, teaching and learning focused on cultural and linguistic diversity in early childhood teacher education programs. Every child deserves to have quality care and experiences, and every teacher should have the skills and competencies necessary to support an increasingly diverse classroom of children. 
Table 5.1: Results of Hypotheses

\begin{tabular}{llll}
\hline Predictor & Hypothesis & Results \\
\hline $\begin{array}{l}\text { Percentage of } \\
\text { White, non- }\end{array}$ & H1 & $\begin{array}{l}\text { A higher percentage of non-White } \\
\text { population in the state which an }\end{array}$ & $\begin{array}{l}\text { Programs in states with more non-White population } \\
\text { were more likely to require a practicum focused on }\end{array}$ \\
$\begin{array}{l}\text { Hispanic population } \\
\text { institution is located will be associated }\end{array}$ & & $\begin{array}{l}\text { linguistic diversity. } \\
\text { ing }\end{array}$
\end{tabular}

in a state with more course requirements focused on cultural and linguistic diversity, and the requirement of a practicum focused on linguistic diversity.

Geographic Region H2 Variations in course and practica requirements will be predicted by the geographic regions in which an institution is situated in.

\section{Degree of urbanization}

\section{Governance of Institution}

Type of Institution
H3 Course and practica requirements will be associated positively with institutions located within an urban setting

H4 Course and practica requirements will be associated positively with public universities / colleges

H5 Course and practica requirements will be associated positively with HBCUs
As compared to programs in the Far West, programs in New England, Mid East, Southwest, Southeast, Rocky Mountains, and the Plains were more likely to require a practicum focused on working with children who were linguistically diverse.

When compared to programs in large cities, programs in urban fringes of large cities were more likely to require at least one complete course focused on linguistic diversity. Programs in rural areas were less likely to require at least one complete course focused on linguistic diversity.

Programs in public universities were more likely to require at least one complete course in working with bilingual children.

Type of institution was not a significant predictor of coursework and practicum requirements focused on linguistic diversity. 


\begin{tabular}{llll}
\hline Predictor & Hypothesis & Results \\
\hline $\begin{array}{l}\text { NCATE } \\
\text { Accreditation }\end{array}$ & H6 & $\begin{array}{l}\text { Course and practica requirements will } \\
\text { be associated positively with programs } \\
\text { that are NCATE-accredited. }\end{array}$ & $\begin{array}{l}\text { NCATE accredited programs were more likely to } \\
\text { require at least one complete course focused on } \\
\text { cultural diversity rather than no or minimal } \\
\text { requirements when context specific variables were } \\
\text { controlled. NCATE accredited programs were } \\
\text { however more likely to require some coursework } \\
\text { rather than to require at least one complete course in } \\
\text { working with linguistically diverse children. }\end{array}$ \\
& H7 & $\begin{array}{l}\text { Course and practica requirements will } \\
\text { be associated positively with the } \\
\text { presence of non-White faculty. }\end{array}$ & $\begin{array}{l}\text { Programs with a presence of non-White full-time } \\
\text { faculty were more likely to require coursework } \\
\text { focused on cultural diversity. }\end{array}$ \\
\hline
\end{tabular}




\section{APPENDIX}

\section{Early Childhood Teacher Preparation Programs in Post-Secondary Institutions}

1. We would like to publish your contact information and the basic information about the type of programs you offer in the National Directory of Early Childhood Teacher Preparation Institutions. All other information is strictly confidential. Is it okay with you to publish Yes No this information?

These first three pages are contact and basic program information to be published in the National Directory of Early Childhood Teacher Preparation Institutions.

2. Your Name:

3. Your Title:

4. Department or unit:

5. Which one of the following best describes where your department or unit is administratively housed?

a.) School of Education/Department of Education

b.) Child Development or Family Studies Department

c.) Consumer or Family Sciences Department

d.) Psychology Department

e.) Human Development Department

f.) Liberal Sciences Department

g.) Other?

6. Name of institution:

7. Address:

8. City:

9. State/Territory:

10. Zip Code:

11. Telephone number:

12. What is your email address:

13. Your gender:

Female Male

All questions in this interview are about your Early Childhood Teacher Preparation Programs that prepare individuals to work with children any ages from 0-4. For all of the following questions, please think of all the departments or programs at your institution preparing early childhood educators and include all courses, students, and faculty at branch or satellite campuses.

14. Aside from your department, are there any other departments at your institution that prepare students to educate or care for young children, any ages from $0-4$ ? 
15. Are there any satellite or branch campuses affiliated with your institution where students can take courses, but still receive their degree or credential from your institution?

Yes $\quad$ No

16. Does your institution offer CDA training or any coursework to prepare students for the Child Development Associate National Credential?

Yes No

17. If yes to question 16, do you give any college credit(s) for that CDA course work at your institution?

Yes No

18. Does your institution give transfer credits to students entering with a CDA credential (e.g., life experience or prior learning experience)?

Yes No

19. Do you offer a one-year certificate program?

Yes $\quad$ No

20. Does your institution offer at least a full course or practicum experiences in the following topic areas:

a.) Infant or toddler care or education?

Yes No

b.) Preschool care or education?

Yes No

c.) School-age care or education?

Yes No

d.) Home-visiting/parent education?

Yes No

e.) Working in a family childcare home?

Yes No

f.) Working with children with disabilities?

Yes No

g.) Administration of early childhood programs?

Yes No

21. Does your institution offer an Associate's Degree program in Early Childhood Education or Care, including any ages from $0-4$ ?

Yes $\quad$ No

22. If yes to question 21, what age range does your Associate’s program cover?

23. Does your institution offer a Bachelor's Degree program in Early Childhood Education or Care, including any ages from $0-4$ ?

Yes No

24. If yes to question 23, what age range does your Bachelor's program cover? 
25. Does your institution offer a Master's Degree program in Early Childhood Education or Care, including any ages from $0-4$ ?

26. If yes to question 25, what age range does your Master's program cover?

27. If yes to question 25, are you the appropriate contact person for answering more detailed questions about the Master's Degree program?

Yes No

28. If no to question 27, may I have the appropriate person's contact information (i.e., name, phone number, and email address)?

29. Does your institution offer a doctoral program in Early Childhood Education or Care, including any ages from $0-4$ ?

Yes No

30. If yes to question 29, what age range does your doctoral program cover?

31. Roughly how many students in the Early Childhood Teacher Preparation Programs are working toward:

a.) a CDA credential or other program that is less than an Associate's degree?

b.) an Associate's degree?

c.) a Bachelor's degree?

d.) a Master's degree?

e.) a Doctorate degree?

32. Does your institution have a distance learning option (e.g., web based instruction, videoconferencing, or using web based tools for syllabus and course dissemination) for your Early Childhood Teacher Preparation Programs?

The remainder of the information gathered in this survey will be kept strictly confidential. Information will be reported in aggregate form only and individuals and programs will never be identified by name. 


\section{YOUR CDA TRAINING OR OTHER PROGRAM HAVING FEWER REQUIREMENTS THAN AN ASSOCIATE'S}

This section is to be completed if your institution offers CDA training or other certificate program having fewer requirements than an Associate's. If your institution does not have either of these types of programs, please skip to page 6.

We define early childhood practicum as supervised work in a care or educational setting with children, any ages from 0 to 4 . Using our definition, practicum is the same as field placement or student teaching. However, practicum must include more than observation.

33. Do the students in your CDA training (or other program that has fewer requirements than an Associate's) have the opportunity to participate in a supervised practicum experience with children ages 4 or under?

Yes No

34. Please estimate the percent of students in your CDA (or other program having fewer requirements than an Associate's) who are working full-time while attending school?
None
A Few
Less than Half
(26\%-50\%)
Most
Almost All
$(1 \%-25 \%)$
(51\%-75\%)
(more than 75\%)

35. On average, how many students typically enroll each year in your CDA program?

36. How many of your students currently enrolled in your CDA program are from the following racial or ethnic backgrounds?

a.) Black, non-Hispanic

b.) American Indian or Alaskan Native

c.) Asian or Pacific Islander

d.) Hispanic

e.) White, non-Hispanic

f.) Race/ethnicity unknown

g.) Other, please specify

h.) Refuse

i.) Refuse, information unavailable

37. How many CDA's were awarded from your institution in 2003? 


\section{CDA Coursework}

For each content area listed below, please indicate how much coursework coverage students have received by the time they complete their CDA training or other program having fewer requirements than an Associate's.

\begin{tabular}{|c|c|c|c|c|c|}
\hline & \multicolumn{5}{|c|}{ Amount of Coursework Coverage } \\
\hline & None & $\begin{array}{l}\text { One class } \\
\text { session of one } \\
\text { required course }\end{array}$ & $\begin{array}{l}\text { Multiple } \\
\text { class } \\
\text { sessions }\end{array}$ & $\begin{array}{l}\text { Entire } \\
\text { required } \\
\text { course }\end{array}$ & $\begin{array}{l}\text { Entire required } \\
\text { course, plus } \\
\text { coverage in } \\
\text { other courses }\end{array}$ \\
\hline $\begin{array}{l}\text { a.) education and care of infants } \\
\text { and toddlers }\end{array}$ & 1 & 2 & 3 & 4 & 5 \\
\hline $\begin{array}{l}\text { b.) education and care of } \\
\text { preschool aged children }\end{array}$ & 1 & 2 & 3 & 4 & 5 \\
\hline $\begin{array}{l}\text { c.) education and care of young } \\
\text { children with disabilities }\end{array}$ & 1 & 2 & 3 & 4 & 5 \\
\hline d.) working with families & 1 & 2 & 3 & 4 & 5 \\
\hline $\begin{array}{l}\text { e.) working with children and } \\
\text { families from diverse ethnic \& } \\
\text { cultural backgrounds }\end{array}$ & 1 & 2 & 3 & 4 & 5 \\
\hline $\begin{array}{l}\text { f.) working with bilingual children } \\
\text { or children learning English as a } \\
\text { second language }\end{array}$ & 1 & 2 & 3 & 4 & 5 \\
\hline $\begin{array}{l}\text { g.) assessment/observation of } \\
\text { young children }\end{array}$ & 1 & 2 & 3 & 4 & 5 \\
\hline $\begin{array}{l}\text { h.) emergent literacy and literacy } \\
\text { strategies }\end{array}$ & 1 & 2 & 3 & 4 & 5 \\
\hline $\begin{array}{l}\text { i.) numeracy and math for young } \\
\text { children }\end{array}$ & 1 & 2 & 3 & 4 & 5 \\
\hline $\begin{array}{l}\text { j.) social and emotional } \\
\text { development of young children }\end{array}$ & 1 & 2 & 3 & 4 & 5 \\
\hline $\begin{array}{l}\text { k.) physical health and motor } \\
\text { development of young children }\end{array}$ & 1 & 2 & 3 & 4 & 5 \\
\hline $\begin{array}{l}\text { 1.) appropriate learning } \\
\text { environments and activities for } \\
\text { young children }\end{array}$ & 1 & 2 & 3 & 4 & 5 \\
\hline $\begin{array}{l}\text { m.) classroom or behavioral } \\
\text { management of young children }\end{array}$ & 1 & 2 & 3 & 4 & 5 \\
\hline $\begin{array}{l}\text { n.) early childhood program } \\
\text { administration }\end{array}$ & 1 & 2 & 3 & 4 & 5 \\
\hline $\begin{array}{l}\text { o.) collaborating with } \\
\text { professionals in other disciplines }\end{array}$ & 1 & 2 & 3 & 4 & 5 \\
\hline $\begin{array}{l}\text { p.) professional knowledge (e.g., } \\
\text { confidentiality, ethics, and codes } \\
\text { of conduct) }\end{array}$ & 1 & 2 & 3 & 4 & 5 \\
\hline $\begin{array}{l}\text { q.) adult learning and } \\
\text { development }\end{array}$ & 1 & 2 & 3 & 4 & 5 \\
\hline r.) leadership and advocacy & 1 & 2 & 3 & 4 & 5 \\
\hline $\begin{array}{l}\text { s.) research and evaluation } \\
\text { methods }\end{array}$ & 1 & 2 & 3 & 4 & 5 \\
\hline
\end{tabular}




\section{YOUR ASSOCIATE'S DEGREE PROGRAM}

This section is to be completed if your institution offers an Associate's Program in Early Childhood Education or Care that includes any ages from 0-4. If your institution does not offer this type of Associate's degree, please skip to page 10.

38. Is part of the mission of your Associate's program to prepare educators or care providers to work with young children, any age from $0-4$ ?

Yes No

39. Is part of the mission of your Associate's program to prepare early interventionists or early childhood special educators?

40. Is part of the mission of your Associate's program to train existing educators or care providers who work with young children, any age from Yes No $0-4$ ?

\section{If answers to questions 39-41 are all 'no,' please skip to page 10.}

41. Of students graduating from your Associate's program in Early Childhood Education or Care, about what percent:

a.) Go on to teach or work with children ages 0-4 in a center-based program?

b.) Go on to teach or work with children ages 0-4 in a home-based setting?

Yes No

c.) Go on to teach or work in a kindergarten or elementary setting?

d.) Go on to a 4-year early childhood education or care baccalaureate program?

e.) Do not go on to teach or work with children?

42. Is this an A. A., an A. S., or an A.A.S. program?

A.A.

A.S.

A.A.S.

a. If other than AA, AS, or AAS, please specify:

43. Does your Associate's program have articulation agreements with any other institutions that affect students wishing to enter your Associate's program?

44. Does your Associate's program have articulation agreements with any other institution that affect students wishing to go on for a Bachelor's degree?

45. Does your Associate's program use a formal process to award credits for Yes No prior learning (e.g. CDA, workshops, or non-college training)?

46. Please estimate the percent of the Associate's students enrolled in your Early Childhood Education or Care program who are working full-time while attending school.

None

$$
\text { A Few Less than Half }
$$

(26\%-50\%)

Most

Almost All

$(1 \%-25 \%)$

(51\%-75\%)

(more than 75\%) 
47. Currently, how many students are enrolled in your Associate's Early Childhood Education or Care program?

48. How many of your students currently enrolled in your Associate's Early Childhood Education or Care program are from the following racial or ethnic backgrounds?

38. Black, non-Hispanic

39. American Indian or Alaskan Native

40. Asian or Pacific Islander

41. Hispanic

42. White, non-Hispanic

43. Race/ethnicity unknown

44. Other, please specify

45. Refuse

46. Refuse, information unavailable

The sum of 49 should equal to the response to question 48.

50. How many Associates' degrees in Early Childhood Education or Care were awarded from your institution in 2003? 


\section{Associate's Coursework}

For each content area listed below, please indicate how much coursework coverage students have received by the time they complete their Associate's program.

\begin{tabular}{|c|c|c|c|c|c|}
\hline & \multicolumn{5}{|c|}{ Amount of Coursework Coverage } \\
\hline & None & $\begin{array}{l}\text { One class } \\
\text { session of one } \\
\text { required course }\end{array}$ & $\begin{array}{l}\text { Multiple } \\
\text { class } \\
\text { sessions }\end{array}$ & $\begin{array}{l}\text { Entire } \\
\text { required } \\
\text { course }\end{array}$ & $\begin{array}{l}\text { Entire required } \\
\text { course, plus } \\
\text { coverage in } \\
\text { other courses }\end{array}$ \\
\hline $\begin{array}{l}\text { a.) education and care of infants } \\
\text { and toddlers }\end{array}$ & 1 & 2 & 3 & 4 & 5 \\
\hline $\begin{array}{l}\text { b.) education and care of } \\
\text { preschool aged children }\end{array}$ & 1 & 2 & 3 & 4 & 5 \\
\hline $\begin{array}{l}\text { c.) education and care of young } \\
\text { children with disabilities }\end{array}$ & 1 & 2 & 3 & 4 & 5 \\
\hline d.) working with families & 1 & 2 & 3 & 4 & 5 \\
\hline $\begin{array}{l}\text { e.) working with children and } \\
\text { families from diverse ethnic \& } \\
\text { cultural backgrounds }\end{array}$ & 1 & 2 & 3 & 4 & 5 \\
\hline $\begin{array}{l}\text { f.) working with bilingual children } \\
\text { or children learning English as a } \\
\text { second language }\end{array}$ & 1 & 2 & 3 & 4 & 5 \\
\hline $\begin{array}{l}\text { g.) assessment/observation of } \\
\text { young children }\end{array}$ & 1 & 2 & 3 & 4 & 5 \\
\hline $\begin{array}{l}\text { h.) emergent literacy and literacy } \\
\text { strategies }\end{array}$ & 1 & 2 & 3 & 4 & 5 \\
\hline $\begin{array}{l}\text { i.) numeracy and math for young } \\
\text { children }\end{array}$ & 1 & 2 & 3 & 4 & 5 \\
\hline $\begin{array}{l}\text { j.) social and emotional } \\
\text { development of young children }\end{array}$ & 1 & 2 & 3 & 4 & 5 \\
\hline $\begin{array}{l}\text { k.) physical health and motor } \\
\text { development of young children }\end{array}$ & 1 & 2 & 3 & 4 & 5 \\
\hline $\begin{array}{l}\text { l.) appropriate learning } \\
\text { environments and activities for } \\
\text { young children }\end{array}$ & 1 & 2 & 3 & 4 & 5 \\
\hline $\begin{array}{l}\text { m.) classroom or behavioral } \\
\text { management of young children }\end{array}$ & 1 & 2 & 3 & 4 & 5 \\
\hline $\begin{array}{l}\text { n.) early childhood program } \\
\text { administration }\end{array}$ & 1 & 2 & 3 & 4 & 5 \\
\hline $\begin{array}{l}\text { o.) collaborating with } \\
\text { professionals in other disciplines }\end{array}$ & 1 & 2 & 3 & 4 & 5 \\
\hline $\begin{array}{l}\text { p.) professional knowledge (e.g., } \\
\text { confidentiality, ethics, and codes } \\
\text { of conduct) }\end{array}$ & 1 & 2 & 3 & 4 & 5 \\
\hline $\begin{array}{l}\text { q.) adult learning and } \\
\text { development }\end{array}$ & 1 & 2 & 3 & 4 & 5 \\
\hline r.) leadership and advocacy & 1 & 2 & 3 & 4 & 5 \\
\hline $\begin{array}{l}\text { s.) research and evaluation } \\
\text { methods }\end{array}$ & 1 & 2 & 3 & 4 & 5 \\
\hline
\end{tabular}




\section{Associate's Practicum Coverage}

We define early childhood practicum as supervised work in a care or educational setting with children, any ages from 0 to 4 . Using our definition, practicum is the same as field placement or student teaching. However, practicum must include more than observation.

Do your Associate's students have an early childhood practica requirement $\quad$ Yes $\quad$ No working with children any ages from 0 to 4 ?

If yes, please indicate if practica exposure to these areas is required as part of the Associate's program.

\begin{tabular}{|l|c|}
\hline & \multicolumn{2}{|c|}{\begin{tabular}{c} 
Exposure \\
\hline a.) education and care of infants and toddlers
\end{tabular}} & Yes \\
\hline b.) education and care of preschool aged children & Yes No \\
\hline c.) education and care of young children with disabilities & Yes \\
\hline $\begin{array}{l}\text { d.) working with bilingual children or children learning English as } \\
\text { a second language }\end{array}$ & Yes \\
\hline e.) working with families & Yes \\
\hline
\end{tabular}




\section{YOUR BACHELOR'S DEGREE PROGRAM}

This section is to be completed if your institution offers a Bachelor's Program in Early Childhood Education or Care that includes any ages from 0-4. If your institution does not offer this type of Bachelor's degree, please skip to page 14.

51. Is part of the mission of your Bachelor's program to prepare educators or care providers to work with young children, any age from 0-4?

Yes No

52. Is part of the mission of your Bachelor's program to prepare early interventionists or early childhood special educators?

Yes No

53. Is part of the mission of your Bachelor's program to train existing educators or care providers who work with young children, any age from 0-4?

Yes No

\section{If answers to questions 53-55 are all 'no' please skip to page 14, the Master's Program section.}

54. Does your Bachelor's program have an articulation agreement with any other institution that affects students wishing to enter your degree program?

55. Please estimate the percent of the Bachelor's students enrolled in your program who are working full-time while attending school.
None
A Few
Less than Half
Most
Almost All
$(1 \%-25 \%)$
(26\%-50\%)
(51\%-75\%)
(more than 75\%)

56. Currently, how many students are enrolled in your Bachelor's Early Childhood Education or Care program?

57. How many of the students currently enrolled in your Bachelor's Early Childhood Education or Care are from the following racial or ethnic backgrounds?
a) Black, non-Hispanic
b) American Indian or Alaskan Native
c) Asian or Pacific Islander
d) Hispanic
e) White, non-Hispanic
f) Race/ethnicity unknown
g) Other, please specify
h) Refuse
i) Refuse, information unavailable

\section{The sum of 59 should equal to the response to question 58.}

58. How many Bachelor's degrees in Early Childhood Education or Care were awarded from your institution in 2003? 
59. Of students graduating from your Bachelor's program in Early Childhood, about what percent:

a) Go on to teach or work with children ages 0-4 in a center-based $\%$ program?

b) Go on to teach or work with children ages 0-4 in a home-based setting?

c) Go on to teach or work in a kindergarten or elementary setting?

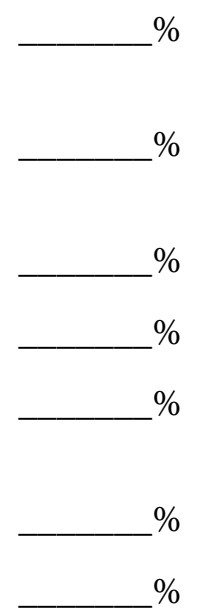

e) Go on to teach at the high school, community college, or

g) Do not go on to teach or work with children? 


\section{Bachelor's Coursework}

For each content area listed below, please indicate how much coursework coverage students have received by the time they complete their Bachelor's program.

\begin{tabular}{|c|c|c|c|c|c|}
\hline & \multicolumn{5}{|c|}{ Amount of Coursework Coverage } \\
\hline & None & $\begin{array}{l}\text { One class } \\
\text { session of one } \\
\text { required course }\end{array}$ & $\begin{array}{l}\text { Multiple } \\
\text { class } \\
\text { sessions }\end{array}$ & $\begin{array}{l}\text { Entire } \\
\text { required } \\
\text { course }\end{array}$ & $\begin{array}{l}\text { Entire required } \\
\text { course, plus } \\
\text { coverage in } \\
\text { other courses }\end{array}$ \\
\hline $\begin{array}{l}\text { a.) education and care of infants } \\
\text { and toddlers }\end{array}$ & 1 & 2 & 3 & 4 & 5 \\
\hline $\begin{array}{l}\text { b.) education and care of } \\
\text { preschool aged children }\end{array}$ & 1 & 2 & 3 & 4 & 5 \\
\hline $\begin{array}{l}\text { c.) education and care of young } \\
\text { children with disabilities }\end{array}$ & 1 & 2 & 3 & 4 & 5 \\
\hline d.) working with families & 1 & 2 & 3 & 4 & 5 \\
\hline $\begin{array}{l}\text { e.) working with children and } \\
\text { families from diverse ethnic \& } \\
\text { cultural backgrounds }\end{array}$ & 1 & 2 & 3 & 4 & 5 \\
\hline $\begin{array}{l}\text { f.) working with bilingual } \\
\text { children or children learning } \\
\text { English as a second language }\end{array}$ & 1 & 2 & 3 & 4 & 5 \\
\hline $\begin{array}{l}\text { g.) assessment/observation of } \\
\text { young children }\end{array}$ & 1 & 2 & 3 & 4 & 5 \\
\hline $\begin{array}{l}\text { h.) emergent literacy and } \\
\text { literacy strategies }\end{array}$ & 1 & 2 & 3 & 4 & 5 \\
\hline $\begin{array}{l}\text { i.) numeracy and math for } \\
\text { young children }\end{array}$ & 1 & 2 & 3 & 4 & 5 \\
\hline $\begin{array}{l}\text { j.) social and emotional } \\
\text { development of young children }\end{array}$ & 1 & 2 & 3 & 4 & 5 \\
\hline $\begin{array}{l}\text { k.) physical health and motor } \\
\text { development of young children }\end{array}$ & 1 & 2 & 3 & 4 & 5 \\
\hline $\begin{array}{l}\text { l.) appropriate learning } \\
\text { environments and activities for } \\
\text { young children }\end{array}$ & 1 & 2 & 3 & 4 & 5 \\
\hline $\begin{array}{l}\text { m.) classroom or behavioral } \\
\text { management of young children }\end{array}$ & 1 & 2 & 3 & 4 & 5 \\
\hline $\begin{array}{l}\text { n.) early childhood program } \\
\text { administration }\end{array}$ & 1 & 2 & 3 & 4 & 5 \\
\hline $\begin{array}{l}\text { o.) collaborating with } \\
\text { professionals in other } \\
\text { disciplines }\end{array}$ & 1 & 2 & 3 & 4 & 5 \\
\hline $\begin{array}{l}\text { p.) professional knowledge } \\
\text { (e.g., confidentiality, ethics, and } \\
\text { codes of conduct) }\end{array}$ & 1 & 2 & 3 & 4 & 5 \\
\hline $\begin{array}{l}\text { q.) adult learning and } \\
\text { development }\end{array}$ & 1 & 2 & 3 & 4 & 5 \\
\hline r.) leadership and advocacy & 1 & 2 & 3 & 4 & 5 \\
\hline $\begin{array}{l}\text { s.) research and evaluation } \\
\text { methods }\end{array}$ & 1 & 2 & 3 & 4 & 5 \\
\hline
\end{tabular}




\section{Bachelor's Practicum Coverage}

We define early childhood practicum as supervised work in a care or educational setting with children, any ages 0 to 4 . Using our definition, practicum is the same as field placement or student teaching. However, practicum must include more than observation.

Do your Bachelor's students have an early childhood practicum requirement, working with children any ages from 0-4?

Yes No

If yes, please indicate if practica exposure to these areas is required as part of the Bachelor's program.

\begin{tabular}{|l|l|}
\hline & \multicolumn{2}{|c|}{ Required Practicum } \\
\hline a.) education and care of infants and toddlers & Yes \\
\hline b.) education and care of preschool aged children & Yes \\
\hline c.) education and care of young children with disabilities & Yes \\
\hline $\begin{array}{l}\text { d.) working with bilingual children or children learning English as } \\
\text { a second language }\end{array}$ & Yes No \\
\hline e.) working with families & Yes No \\
\hline
\end{tabular}




\section{YOUR MASTER'S DEGREE PROGRAM}

This section is to be completed if your institution offers a Master's program in Early Childhood Education or Care that includes any ages from 0-4. If your institution does not offer this type of program, please skip to page 18.

60. Is part of the mission of your Master's program to prepare educators to work with young children, any age from $0-4$ ?

Yes No

61. Is part of the mission of your Master's program to prepare early interventionists or early childhood special educators?

Yes No

62. Is part of the mission of your Master's program to train existing educators or interventionists who work with young children, any age from 0-4?

63. Is part of the mission of your Master's program to prepare administrators to work in early childhood programs?

64. Is part of the mission of your Master's program to prepare individuals to teach at the high school, community college, or university level?

65. Is part of the mission of your Master's program to prepare individuals to conduct educational research with young children?

66. Is part of the mission of your Master's program to prepare individuals to analyze and develop policy related to early childhood programs?

If answer to questions 67-73 are all "no" please skip to page 18, the Doctoral Program section.

67. Of students graduating from your Master's program in Early Childhood Education or Care, about what percent:

a) Go on to teach or work with children ages 0-4 in a center-based program?

b) Go on to teach or work with children ages 0-4 in a home-based setting?

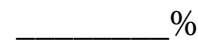

c) Go on to teach or work in a kindergarten or elementary setting?

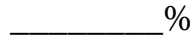

d) Go on to work in an administrative capacity?

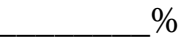

e) Go on to teach at the high school, community college, or university level?

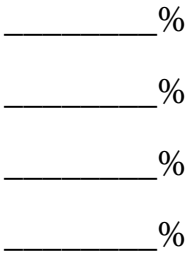

f) Go on to work in a research or policy capacity?

g) Do not go on to teach or work with children? $\%$

68. Please estimate the percent of Master's students currently enrolled in your Early Childhood Education or Care program who are working full-time while attending school.
None
A Few
Less than Half
Most
$(51 \%-75 \%)$
Almost All
$(1 \%-25 \%)$
(26\%-50\%)
(more than $75 \%$ )

69. Currently, how many students are enrolled in your Master's Early Childhood Education or Care program? 
How many of your students currently enrolled in your Master's Early

Childhood Education or Care program are from the following racial or ethnic backgrounds?

Black, non-Hispanic

American Indian or Alaskan Native

Asian or Pacific Islander

Hispanic

White, non-Hispanic

Race/ethnicity unknown

Other, please specify

Refuse

Refuse, information unavailable

The sum of 77 should equal the response to question 76 .

How many Master's degrees in Early Childhood Education or Care were awarded from your institution in 2003? 
For each content area listed below, please indicate how much coursework coverage students have received by the time they complete their Master's program.

\begin{tabular}{|c|c|c|c|c|c|}
\hline & \multicolumn{5}{|c|}{ Amount of Coursework Coverage } \\
\hline & None & $\begin{array}{l}\text { One class } \\
\text { session of one } \\
\text { required course }\end{array}$ & $\begin{array}{l}\text { Multiple } \\
\text { class } \\
\text { sessions }\end{array}$ & $\begin{array}{l}\text { Entire } \\
\text { required } \\
\text { course }\end{array}$ & $\begin{array}{l}\text { Entire } \\
\text { required } \\
\text { course, plus } \\
\text { coverage in } \\
\text { other courses }\end{array}$ \\
\hline $\begin{array}{l}\text { a.) education and care of } \\
\text { infants and toddlers }\end{array}$ & 1 & 2 & 3 & 4 & 5 \\
\hline $\begin{array}{l}\text { b.) education and care of } \\
\text { preschool aged children }\end{array}$ & 1 & 2 & 3 & 4 & 5 \\
\hline $\begin{array}{l}\text { c.) education and care of } \\
\text { young children with } \\
\text { disabilities }\end{array}$ & 1 & 2 & 3 & 4 & 5 \\
\hline d.) working with families & 1 & 2 & 3 & 4 & 5 \\
\hline $\begin{array}{l}\text { e.) working with children and } \\
\text { families from diverse ethnic } \\
\& \text { cultural backgrounds }\end{array}$ & 1 & 2 & 3 & 4 & 5 \\
\hline $\begin{array}{l}\text { f.) working with bilingual } \\
\text { children or children learning } \\
\text { English as a second language }\end{array}$ & 1 & 2 & 3 & 4 & 5 \\
\hline $\begin{array}{l}\text { g.) assessment/observation } \\
\text { of young children }\end{array}$ & 1 & 2 & 3 & 4 & 5 \\
\hline $\begin{array}{l}\text { h.) emergent literacy and } \\
\text { literacy strategies }\end{array}$ & 1 & 2 & 3 & 4 & 5 \\
\hline $\begin{array}{l}\text { i.) numeracy and math for } \\
\text { young children }\end{array}$ & 1 & 2 & 3 & 4 & 5 \\
\hline $\begin{array}{l}\text { j.) social and emotional } \\
\text { development of young } \\
\text { children }\end{array}$ & 1 & 2 & 3 & 4 & 5 \\
\hline $\begin{array}{l}\text { k.) physical health and motor } \\
\text { development of young } \\
\text { children }\end{array}$ & 1 & 2 & 3 & 4 & 5 \\
\hline $\begin{array}{l}\text { l.) appropriate learning } \\
\text { environments and activities } \\
\text { for young children }\end{array}$ & 1 & 2 & 3 & 4 & 5 \\
\hline $\begin{array}{l}\text { m.) classroom or behavioral } \\
\text { management of young } \\
\text { children }\end{array}$ & 1 & 2 & 3 & 4 & 5 \\
\hline $\begin{array}{l}\text { n.) early childhood program } \\
\text { administration }\end{array}$ & 1 & 2 & 3 & 4 & 5 \\
\hline $\begin{array}{l}\text { o.) collaborating with } \\
\text { professionals in other } \\
\text { disciplines }\end{array}$ & 1 & 2 & 3 & 4 & 5 \\
\hline $\begin{array}{l}\text { p.) professional knowledge } \\
\text { (e.g., confidentiality, ethics, } \\
\text { and codes of conduct) }\end{array}$ & 1 & 2 & 3 & 4 & 5 \\
\hline $\begin{array}{l}\text { q.) adult learning and } \\
\text { development }\end{array}$ & 1 & 2 & 3 & 4 & 5 \\
\hline r.) leadership and advocacy & 1 & 2 & 3 & 4 & 5 \\
\hline $\begin{array}{l}\text { s.) research and evaluation } \\
\text { methods }\end{array}$ & 1 & 2 & 3 & 4 & 5 \\
\hline
\end{tabular}




\section{Master's Practicum Coverage}

We define early childhood practicum as supervised work in a care or educational setting with children, any ages from 0 to 4 . Using our definition, practicum is the same as field placement or student teaching. However, practicum must include more than observation.

70. Do your Master's students have an early childhood practicum requirement, working with children any ages from $0-4$ ?

If yes, please indicate if practica exposure to these areas is required as part of the Master's program.

\begin{tabular}{|l|ll|}
\hline & \multicolumn{2}{|l|}{$\begin{array}{l}\text { Required Practicum } \\
\text { Exposure }\end{array}$} \\
\hline education and care of infants and toddlers & Yes & No \\
\hline education and care of preschool aged children & Yes & No \\
\hline education and care of young children with disabilities & Yes & No \\
\hline $\begin{array}{l}\text { working with bilingual children or children learning English as a } \\
\text { second language }\end{array}$ & Yes & No \\
\hline working with families & Yes & No \\
\hline
\end{tabular}




\section{YOUR DOCTORAL PROGRAM}

This section is to be completed if your institution offers a Doctoral program in Early Childhood that includes any ages from 0-4. If your institution does not offer this type of program, please skip to page 19.

71. Does the mission of your doctoral program include preparing early childhood professionals as:

h) faculty members?

i) program administrators?

j) researchers?

Yes No

Yes No

k) Other? Please specify

72. Is this an interdisciplinary program that involves faculty and students from $\quad$ Yes $\quad$ No other departments?

73. How many students are currently enrolled in your early childhood education doctoral program?

74. How many of your students currently enrolled in your doctoral Early Childhood Education program are from the following racial or ethnic backgrounds?

a.) Black, non-Hispanic

b.) American Indian or Alaskan Native

c.) Asian or Pacific Islander

d.) Hispanic

e.) White, non-Hispanic

f.) Race/ethnicity unknown

g.) Other, please specify

h.) Refuse

i.) Refuse, information unavailable

The sum of 84 should equal to the response to question 83 .

75. How many doctoral degrees in Early Childhood Education were awarded from your institution in 2003 ? 


\section{FOR ALL PROGRAMS}

\section{Faculty Information}

The next few questions are about faculty in your Early Childhood program(s). We define faculty as all persons whose principle activities are instruction, research, and/or public service and who hold titles of professor, associate professor, assistant professor, instructor, lecturer, or the equivalent of any of these. Chairs and deans are included in this category if their principle activity is instruction or research.

Please report your most current information.

How many full-time faculty are in your Early Childhood program(s), including all teacher preparation programs you indicated at the beginning of the interview?

Does your institution offer tenure?

Yes No

If yes to question 84, of the full-time faculty, how many are:

tenured?

non-tenured, on tenure track?

non-tenured, not on tenure track?

The sum of 85 should equal the response to question 83 .

Are any of the full-time faculty currently non-resident aliens, that is, a $\quad$ Yes No person of any racial or ethnic group who is not a citizen or national of the USA?

If yes to question 86 , how many?

What are the racial or ethnic backgrounds of the full-time faculty?

Black, non-Hispanic

American Indian or Alaskan Native

Asian or Pacific Islander

Hispanic

White, non-Hispanic

Race/ethnicity unknown

Other, please specify

Refuse

Refuse, information unavailable

The sum of 91 should equal to the response to question 86 . 
How many part-time and adjunct faculty are in your Early Childhood program(s) this term, including all teacher preparation programs indicated at the beginning of the survey?

Are any of the part-time or adjunct faculty currently non-resident aliens, Yes No that is, a person of any racial or ethnic group who is not a citizen or national of the USA?

If yes to question 90, how many?

What are the racial or ethnic backgrounds of the part-time or adjunct faculty?

Black, non-Hispanic

American Indian or Alaskan Native

Asian or Pacific Islander

Hispanic

White, non-Hispanic

Race/ethnicity unknown

Other, please specify

Refuse

Refuse, information unavailable

The sum of 92 should equal to the response to question 89.

Of all the faculty members in your department, including full-time, parttime, and adjunct, how many have a:

Doctorate degree?

Master's degree, but no Doctorate?

Bachelor's degree, but no Master's?

Associate's degree, but no Bachelor's?

High school degree, but no Associate's or Bachelor's?

The sum of 93 should equal to the sum of responses to questions 83 \& 89 . Of all the faculty members, how many have a degree in Early Childhood that specifically covers children ages $0-4$ ?

Of all the faculty members, how many have had direct employment experience working with children ages 0-4?

Of all the faculty members, how many are fluent in a language other than English?

Are there any Early Childhood courses taught in any languages other than English?

If yes to question 97, how many? 


\section{Program Challenges}

For the next set of questions, please think about the extent to which your Early Childhood program(s) faces each of the challenges listed below.

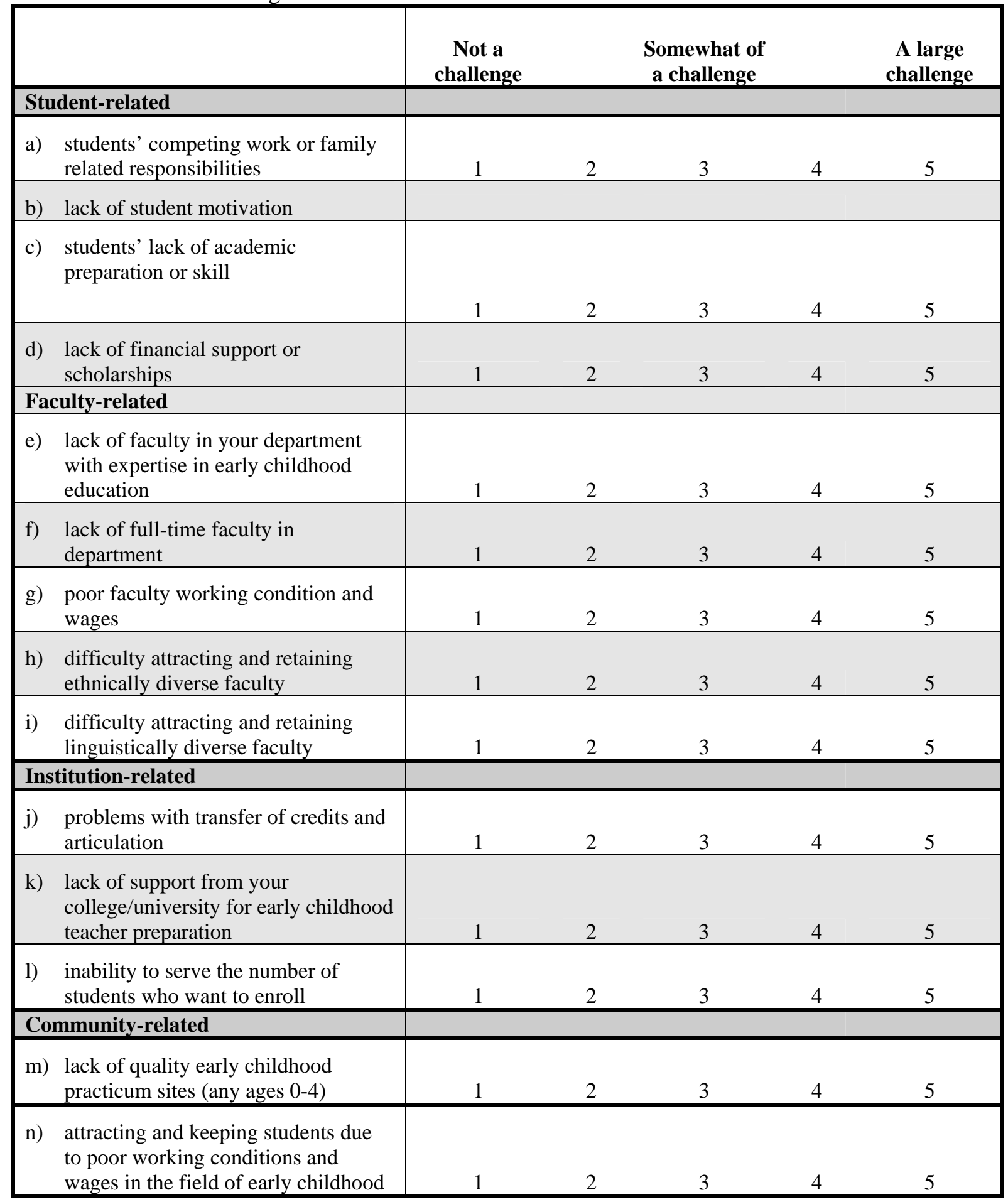




\section{QUESTIONS ABOUT YOU}

The next set of questions asks you about your academic background and current duties.

What is the highest degree you have earned?

Doctorate degree

Master's degree, but no doctorate

Yes No

Bachelor's degree, but no master's

Yes No

Other? Please specify

Do you typically teach?

If yes to question 101, how many courses per year?

Do you supervise practicum students?

Do you direct an early childhood center?

Yes No

Yes No

Yes No

Yes No

Thank you!

Your contribution to this effort is greatly appreciated.

This work was supported by the Foundation for Child Development. However, the contents of the survey do not necessarily represent the positions or policies of the Foundation for Child Development. 


\section{REFERENCES}

Allen, M. (2003). Eight questions on teacher preparation: What does research say?. Education Commission of the States (ECS). Denver, CO: Education Commission of the States.

Artiles, A.J. Rueda, R., Salazar, J.J., \& Higareda, I. (2005). Within-group diversity in minority disproportionate representation: English language learners in urban school districts. Exceptional Children, 71(3), 283-300.

August, D., Snow, C., Carlo, M., Proctor, P., Rollo de San Francisco, A., Duursma, E., Szuber, A. (2006). Literacy development in elementary school second-language learners. Top Language Disorders, 26 (4), 351-364.

Banks, J.A., \& Banks, C.A.M. (Eds.). (2004). Handbook of research on multicultural education ( $2^{\text {nd }}$ ed.). San Francisco: Jossey-Bass.

Berg-Cross, L., Craig, K., \& Wessel, T. (1998). Multiculturalism at Historically Black Colleges and Universities: A case study of Howard University. In J.G. Ponterotto, J.M. Casas, L.A. Suzuki, \& Alexander, C.M. (Eds.), Handbook of multicultural counseling ( $2^{\text {nd }}$ ed.). Thousand Oaks, CA: Sage Publication.

Bowman, B. T. (1994). The challenge of diversity. Phi Delta Kappan, 76(3), 218-225.

Bredekamp, S. (1996). Teacher education curriculum: Early childhood education. In J. Sikula, T. Buttery, \& E. Guyton (Eds.), Handbook of research on teacher education, $2^{\text {nd }}$ ed., (pp.223-348). New York: Simon \& Schuster MacMillan.

Bronfenbrenner, U. (1979). The ecology of human development: Experiments by nature and design. Cambridge, MA: Harvard University Press.

Bronfenbrenner, U. (2005). Making human beings human: Bioecological perspectives on human development. Thousand Oaks, CA: Sage Publications.

Bruder, M.B., Dunst, C.J. (2005). Personnel Preparation in Recommended Early Intervention Practices: Degree of Emphasis Across Disciplines. Topics in Early Childhood Special Education, 25(1), 25-33.

Camarota, S. A. (2005) Immigrants at mid-decade-A snapshot of America's foreign-born population in 2005, Washington, DC: Center for Immigration Studies.

Chisholm, I. M. (1994). Preparing teachers for multicultural classrooms. The Journal of Educational Issues of Language Minority Students, 14, 43-68. 
Clifford, R.M., Barbarin, O., Bryant, D., Howes, C., Burchinal, M., Pianta, R., Early, D., \& Chang, F. (2005). What is prekindergarten? Six states' efforts to develop a system of prekindergarten services. Applied Developmental Science, 9 (3), 126-143.

Cochran-Smith, M. (2004). Walking the road: Race, diversity, and social justice in teacher education. New York: Teachers College Press.

Cochran-Smith, M. \& Fries, K. (2005). The AERA panel on research and teacher education. In M. Cochran-Smith \& K.M. Zeichner (Eds.), Studying teacher education: The report of the AERA Panel on research and teacher education, (pp.3768). Mahwah, NJ: Lawrence Erlbaum Associates.

Cochran-Smith, M. \& Zeichner, K.M. (2005). Studying teacher education: The report of the AERA Panel on research and teacher education. Mahwah, NJ: Lawrence Erlbaum Associates.

Cohen, J., Cohen, P., West, S.G., \& Aiken, L.S. (2003). Applied multiple regression / correlation analysis for the behavioral sciences ( $3^{\text {rd }}$ ed.). Mahwah, NJ: Lawrence Erlbaum Associates.

Correa, V. I., Hudson, R. F., \& Hayes, M. T. (2004). Preparing early childhood special educators to serve culturally and linguistically diverse children and families: Can a multicultural education course make a difference? Teacher Education and Special Education, 27(4), 323-341.

Council of Chief State School Officers (CCSSO) (2002). Key state education policies on PK12 education: 2002. Washington, DC: Author.

Cummins, J. (1993). Empowering minority students: a framework for intervention. In M. Fine \& L. Wei (Eds.), Beyond Silenced Voices: Class, Race, and Gender in United States Schools. Albany, NY: State University of New York Press.

Cummins, J. (2000). Language, power and pedagogy: Bilingual children in the crossfire. Clevedon, United Kingdom: Multilingual Matters.

Cummins, J. (2001). Negotiating identities: Education for empowerment in a diverse society ( $2^{\text {nd }}$ ed.). Los Angeles: California Association for Bilingual Education.

Darling-Hammond, L. (1997). What matters most: 21st century teaching (Report of the National Commission on Teaching and America's Future). The Education Digest, 63, 4-9.

Dermon-Sparks, L. \& the A.B.C. Taskforce (1989). Anti-bias curriculum: Tools for empowering young children. Washington, D.C.: National Association for the Education of Young Children. 
Duarte, V. \& Reed, T. (2004). Learning to teach in urban settings. Childhood Education, $80(5), 245-250$.

Early, D.M., Bryant, D.M., Pianta, R.C., Clifford, R.M., Burchinal, M.R., Ritchie, S., Howes, C., \& Barbarin, O. (2006). Are teachers' education, major, and credentials related to classroom quality and children's academic gains in pre-kindergarten? Early Childhood Research Quarterly, 21(2), 174-195.

Early, D.M., Winton, P.J., \& Day, C. (2000). Early childhood teacher preparation: Teacher preparation programs struggle with diversity issues. NCEDL Spotlight, 28, 1-2.

Early, D.M. \& Winton, P.J. (2001). Preparing the workforce: Early childhood teacher preparation at 2- and 4-year institutions of higher education. Early Childhood Research Quarterly, 16, 285-306.

Educational Testing Service (2001). ETS study shows NCATE makes a difference. Retrieved October 1, 2004. from http://www.ncate.org/newsbrfs/etsstudy.htm.

Ewell, P.T. (2001). Piloting a new approach to accreditation in teacher education: An evaluation of TEAC / FIPSE Project. Boulder, CO: National Center for Higher Education Management Systems.

Frey, W.H. (2001). Melting pot suburbs: A Census 2000 study of suburban diversity. Washington DC: Brookings Institution Center on Urban \& Metropolitan Policy.

Gay, G. (2005). Politics of multicultural teacher education. Journal of Teacher Education, 56(3), 221-228.

Gay, G. \& Howard, T. C. (2000). Multicultural teacher education for the $21^{\text {st }}$ century. The Teacher Educator, 36, 1-16.

Gibson, M. A. (1995). Additive Acculturation as a Strategy for School. In Ruben G Rumbaur \& Wayne A. Cornelius (Eds), California's Immigrant Children. (pp.77106). San Diego: Center for U.S.-Mexican Studies.

Grottkau, B.J., \& Nickolai-Mays, S. (1989). An empirical analysis of a multicultural education paradigm for preservice teachers. Educational Research Quarterly, 13(4), 27-33.

Hair, E., Halle, T., Terry-Humen, E., Lavelle, B., \& Calkins, J. (in press). Children's school readiness in the ECLS-K: Predictions to academic, health, and social outcomes in first grade. Early Childhood Research Quarterly.

Han, M., Baker, D., \& Rodriguez, C. (1997). A profile of policies and practices for limited English proficient students: screening methods, program support, and teacher training. Washington, DC: U.S. Department of Education, NCES: 97-472. 
Harms, T., Clifford, R.M., \& Cryer, D. (2004). Early Childhood Environment Rating Scale, Revised Edition, Updated (ECERS-R). New York: Teachers College Press.

Harry, B. (2002). Trends and issues in serving culturally diverse families of children with disabilities. The Journal of Special Education, 36 (3), 131$138,147$.

Heston, M.L., Raschke, D., Kliewer, C., Fitzgerald, L.M., \& Kliewer, C. (1998). Transforming teacher preparation in early childhood education: Moving to inclusion. Teacher Education and Special Education, 21(4), 278-92.

Hollins, E. \& Guzman, M.T. (2005). Research on preparing teachers for diverse populations. In M. Cochran-Smith \& K.M. Zeichner (Eds.), Studying teacher education: The report of the AERA Panel on research and teacher education, (pp.477-548). Mahwah, NJ: Lawrence Erlbaum Associates.

Horm, D.M. (2003). Preparing early childhood educators to work in diverse urban settings. Teachers College Record, 105(2), 226-244.

Hurtado, S., Milem, J., Clayton-Pedersen, A., \& Allen, W. (1999). Enacting Diverse Learning Environments: Improving the Climate for Racial/Ethnic Diversity in Higher Education. ASHE-ERIC Higher Education Report Volume 26, No. 8. Washington, D.C.: The George Washington University, Graduate School of Education and Human Development.

Irvine, J.J. (2003). Educating teachers for diversity: Seeing with a cultural eye. New York: Teachers College Press.

Isenberg, J.P. (2001). The state of the art in early childhood professional preparation. In New teachers for a new century: The future of early childhood professional preparation (pp. 15-48). Jessup, MD: ED Pubs.

Jo, J., \& Rong, X. L. (2003). Historical struggles for equity: politics of education and language policies and its implications for Asian Americans. In R. Hunter and F. Brown (Eds.). Challenges of Urban Education and Efficacy of School Reform (pp. 25-48). Boston: JAI.

Kagan, S.L., \& Cohen, N. (1997). Not by chance: Creating an early care and education system. New Haven, CT: Bush Center for Child Development and Social Policy, Yale University.

Kennedy, M. (1997). The connection between research and policy. Educational Researcher, 26(7), 4-12. 
Kontos, S., Burchinal, M., Howes, C., Wisseh, S., \& Galinsky, E. (2002). An ecobehavioral approach to examining the contextual effects of early childhood classrooms. Early Childhood Research Quarterly, 17, 239-258.

Kushner, M., \& Ortiz, A.A. (2001). The preparation of early childhood teachers to serve English language learners. In New teachers for a new century: The future of early childhood professional preparation (pp. 125-154). Jessup, MD: ED Pubs.

Levine, A.(2006). Educating school teachers. Retrieved 10 October 2006 from http://www.edschools.org.

Lim, C.I., \& Able-Boone, H. (2005). Diversity competencies within early childhood teacher preparation: Innovative practices and future directions. Journal of Early Childhood Teacher Education, 26, 225-238.

Marshall, P.L. (1998). Toward developmental multicultural education: Case study of the issues exchange activity. Journal of Teacher Education, 49(1), 57-65.

Maruyama, G. \& Moreno, J.F. (2000). University faculty views about the value of diversity on campus and in the classroom. In American Council on Education and American Association of University Professors, Does diversity make a difference? Three research studies on diversity in college classrooms (pp.8-35). Washington, DC: American Council on Education and American Association of University Professors.

Maxwell, K.L., \& Clifford, R.M. (2004). Professional development issues in universal prekindergarten. In E. Zigler, W. Gilliam, \& S. M. Jones (Eds.). A vision of universal preschool education. New York: Cambridge University Press.

Maxwell, K.L., Lim, C.I., \& Early, D.M. (2006). Early childhood teacher preparation programs in the United States: National report. Chapel Hill, NC: The University of North Carolina, FPG Child Development Institute.

Mayhew, M. J. and Grunwald, H. E. (2006). Factors contributing to faculty incorporation of diversity-related course content. Journal of Higher Education, 77(1), 148-168.

Miller, P., Ostrosky, M. Laumann, B., Thorpe, E., Sanchez, S., \& Fader-Dunner, L. (2003). Quality field experiences underlying performance mastery. In V. D. Stayton, P. S. Miller, and L. A. Dinnebeil, (Eds.), DEC Personnel Preparation in Early Childhood Special Education: Implementing DEC Recommended Practices (pp. 113138). Longmont, CO: Sopris West.

Mitchell, A., \& Yamagishi, Y. (n.d.). The results are in: What deans and NCATE coordinators think about the NCATE unit standards. Retrieved 14 November, 2005, from http://www.ncate.org. 
Morgan, G. (2002). Staff roles, education, and compensation. In D. Cryer \& R.M. Clifford (Eds.), Early childhood education and care in the USA (pp.87-106). Baltimore, MD: Brookes Publishing Co.

National Center for Education Statistics. (n.d.). About IPEDS. Retrieved 14 November, 2005, from http://www.nces.ed.gov/ipeds/AboutIPEDS.asp.

National Council for Accreditation of Teacher Education (NCATE) (2005). List of accredited institutions. Retrieved 10 December, 2005, from http://www.ncate.org

National Council for Accreditation of Teacher Education (NCATE) (2006). NCATE 2006 standards. Washington, D.C.: Author.

NAEYC (1995). Responding to linguistic and cultural diversity: Recommendations for effective early childhood education. Retrieved 12 April, 2005, from http://www.naeyc.org.

NAEYC. (2001). NAEYC standards for early childhood professional preparation. Washington, DC: Author.

National Research Council (2002). Minority students in special and gifted education (Committee on Minority Representation in Special Education, M.S. Donovan \& C.T. Cross, Eds., Division of Behavioral and Social Sciences and Education). Washington, DC: National Academy Press.

Obidah, J.E. (2000). Mediating boundaries of race, class, and professional authority as a critical multiculturalist. Teachers College Record, 102(6), 1035-1060.

Ogbu, J.U., Simons, H.D. (1998). Voluntary and involuntary minorities: A culturalecological theory of school performance with some implications for education. Anthropology \& Education Quarterly, 29(2), 155-188.

Peisner-Feinberg, E., Howes, C., \& Jarvis-McMillan, V. (2004). Anti-bias and multicultural classroom observation development study. Chapel Hill, NC: FPG Child Development Institute.

Phillips, B.C. (1998). Preparing teachers to use their voices for change. Young Children, 53(3), 55-60.

Ray, A, Bowman, B., \& Robbins, J. (2006). Preparing early childhood teachers to successfully educate all children: The contribution of 4-year undergraduate teacher preparation programs. New York: Foundation for Child Development. 
Rong, X.L., \& Preissle, J. (1998). Educating immigrant students: What we need to know to meet the challenges. Thousand Oaks, CA: Corwin Press Inc.

Rogoff, B. (1990). Apprenticeship in thinking: Cognitive development in social context. New York: Oxford University Press.

Saluja, G., Early, D.M., \& Clifford, R.M. (2001). Demographic characteristics of early childhood teachers and structural elements of early care and education in the United States. Early Childhood Research and Practice, 4(1), 1-19.

Sleeter, C.E. (2001). Preparing teachers for culturally diverse schools: Research and the overwhelming presence of whiteness. Journal of Teacher Education, 52, 94-211.

Stayton, V., \& Bruder, M.B. (1999). Early intervention personnel preparation for the new millennium: Early childhood special education. Infants \& Young Children, 12(1), 5969.

Stayton, V., Jones, H. A., Smith-Bonahue, T., Strangis, D., Conroy, M., Derer, K., DeLeon, J., Martinez, C., \& Hill, J. (2003). Cultural and linguistic diversity in personnel preparation. In V. D. Stayton, P. S. Miller, and L. A. Dinnebeil, (Eds.), DEC Personnel Preparation in Early Childhood Special Education: Implementing DEC Recommended Practices (pp. 85-112). Longmont, CO: Sopris West.

Stayton, V., Miller, P., \& Dinnebeil, L. (2002). Personnel preparation in early childhood special education. Longmont, CO: Sopris West.

Tabachnick, B.G., \& Fidell, L.S. (2001). Using multivariate statistics (4 ${ }^{\text {th }}$ ed.). Boston, MA: Allyn and Bacon.

Tabors, P.O. (1997). One child, two languages: A guide for preschool educators of children learning English as a second language, p. 23-38, 171-184. Baltimore, MD: Brookes.

Tonya, H.A., et. al. (2003). Exploring patterns in time children spend in a variety of child care activities: associations with environmental quality, ethnicity, and gender. Early Childhood Research Quarterly, 18(1), 121-142.

U.S. Census Bureau (1990). U.S. Census 1990. Retrieved 13 March, 2005 from http://www.census.gov.

U.S. Census Bureau (2000). U.S. Census 2000. Retrieved 13 March, 2005 from http://www.census.gov.

U.S. Census Bureau (2003). American Community Survey 2003. Retrieved 4 January, 2007 from http://www.census.gov. 
U.S. Census Bureau (2004a). American Community Survey 2004. Retrieved 20 September, 2006 from http://www.census.gov.

U.S. Census Bureau (2004b). Hispanic and Asian Americans increasing faster than overall population. Retrieved 13 March, 2005 from http://www.census.gov/PressRelease/www/releases/archives/race/001839.html.

U.S. Census Bureau (2005). American Community Survey 2005. Retrieved 25 October, 2006 from http://www.census.gov.

U. S. Department of Education (1997). America's teacher: Profile of a profession, 1993-94. Washington, DC: National Center for Education Statistics.

U.S. Department of Education (2001). New teachers for a new century: The future of early childhood professional preparation. Jessup, MD: ED Pubs.

Villarruel, F. A., Imig, D. R., \& Kostelnik, M. J. (1995). The diverse culture of families. In E. E. Garcia \& B. M. McLaughlin (Eds.), Meeting the challenges of linguistic and cultural diversity in early childhood (pp. 103-124). New York: Teachers College Press.

Walton, P.H., Baca, L., Escamilla, K., Kim, R.H., Janosky, J.L., de Onis, C., Cordova, R.R., Constanza, L., Smith, B., deValenzuela, J., Walker, D. (2001). The National Study of Teacher Preparation Programs for Teachers of Linguistically and Culturally Diverse Students: Year 5 final report. Santa Cruz, CA: Center for Research on Education, Diversity, and Excellence.

Washington, V. (2005). Sharing leadership: A case study of diversity in our profession. Young Children, 60(1).

Weiner, L., Rand, M., \& Pagano, A. (2001). Illuminating the impact of state educational policy promoting school reform on curriculum and instruction in programs of urban teacher preparation. Educational Policy, 15(5), 644-673.

Welch-Ross, M., Wolf, A., Moorehouse, M., \& Rathgeb, C. (2005). Improving connections between professional development research and early childhood policies. In M. Zaslow \& Martinez-Beck, I. (Eds.), Critical issues in early childhood professional development. Baltimore, MD: Brookes Publishing Co.

White-Moore, C. (2003). Early childhood preservice teachers' perceptions of their multicultural preparation at Historically Black Colleges and Universities and NonHistorically Black Colleges and Universities. Unpublished doctoral dissertation. University of North Carolina at Chapel Hill. 
Whitebook, M., Belm, D., Lee, Y., \& Sakai, L. (2005). Time to revamp and expand: Early childhood teacher preparation programs in California's institutions of higher education. Berkeley, CA: Center for the Study of Child Care Employment.

Winton, P. (2006). The evidence-based practice movement and its effect on knowledge utilization. In V. Buysse \& P. Wesley (Eds.), Evidence-based practices and the early childhood profession. Washington, DC: Zero to Three Press.

Winton, P., McCollum, J., \& Catlett, C. (in press). Preparing effective professionals: Evidence and applications in early childhood and early intervention. Washington, DC: Zero to Three.

Winton, P., \& Catlett, C. (n.d.). Walking the walk: Promoting diversity in early childhood intervention through campus-community partnerships. Retrieved 9 December, 2006 from http://www.fpg.unc.edu// $\sim$ walkingthewalk.

Wise, A.E., Leibbrand, J.A., \& Williams, B.C. (1997). NCATE's response to critical issues in teacher preparation today. Action in Teacher Education, 19(1), 1-6.

Wise, A.E., \& Leibbrand, J.A. (2000). Standards and teacher quality: Entering the new millennium. Phi Delta Kappan, 81(8), 612-621.

Wishard, A.E., Shivers, E.V., Howes, C., \& Ritchie, S. (2003). Child care program and teacher practices: Associations with quality and children's experiences. Early Childhood Research Quarterly, 18, 65-103.

Wong-Fillmore, L. (1991). Language and cultural issues in the early education of language minority children. In S. Kagan (Ed.), The care and education of America's young children: Obstacles and opportunities. Ninetieth yearbook of the National Society for the Study of Education, Part I (pp.20-49). Chicago: University of Chicago Press.

Zill, N., Collins, M., \& West, J. (1995). Approaching kindergarten: a look at preschoolers in the United States. Young Children, 51, 35-8. 